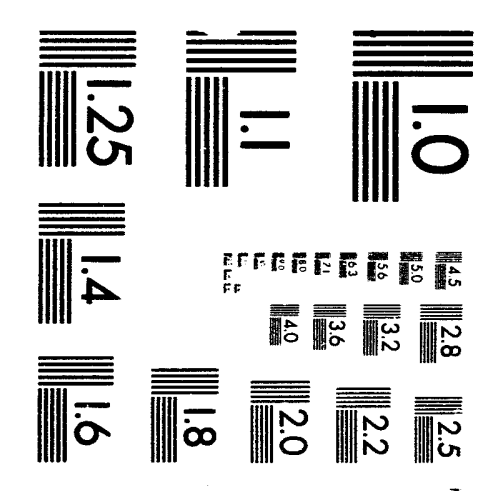



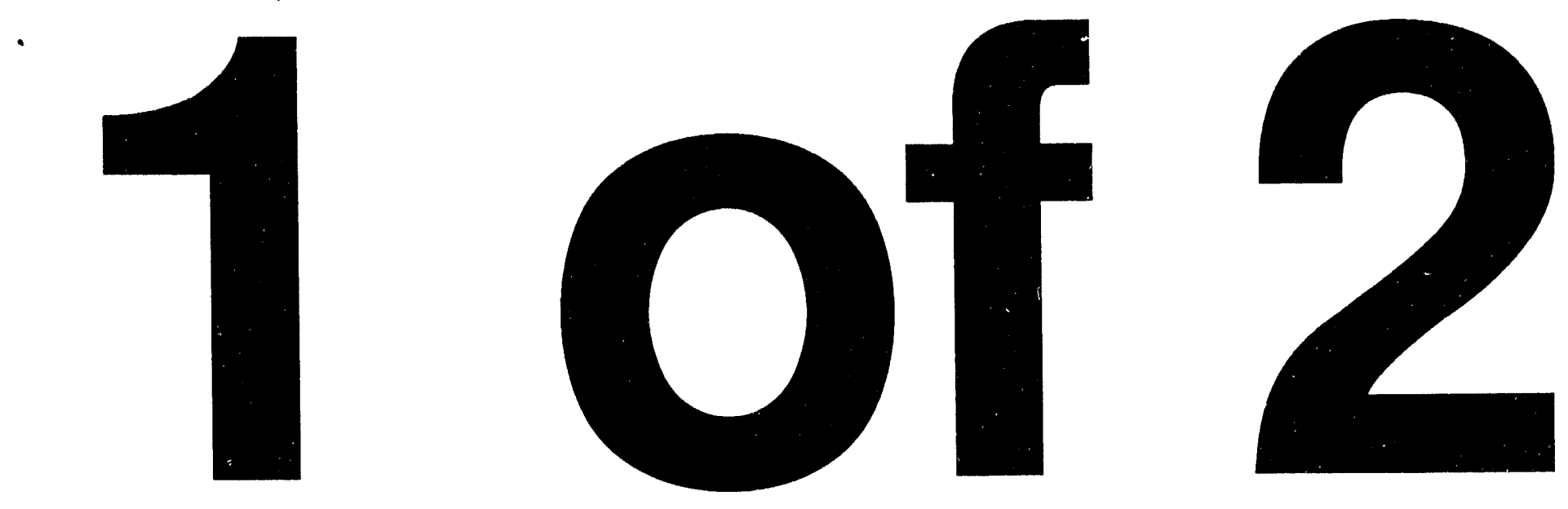


\title{
Synthesis, Rheology and Forming of Y-Ba-Cu-O ceramics
}

\author{
by Tim Green
}

thesis submitted to Iowa State University

Ames Iaboratory, U. S. DOE

Iowa State University

Ames, Iowa 50011

Date Transmitted: July 1993

\author{
Prepared for the U. S. Department of Energy \\ Under contract no. W-7405-eng-82.
}

\section{DISCLAIMER}

This report was prepared as an account of work sponsored by an agency of the United States Government. Neither the United States Government nor any agency thereof, nor any of their employees, makes any warranty, express or implied, or assumes any legal liability or responsibility for the accuracy, completeness, or usefulness of any information, apparatus, product, or process disclosed, or represents that its use would not infringe privately owned rights. Reference herein to any specific commercial product, process, or service by trade name, trademark, manufacturer, or otherwise does not necessarily constitute or imply its endorsement, recommendation, or favoring by the United States Government or any agency thereof. The views and opinions of authors expressed herein do not necessarily state or reflect those of the United States Government or any agency thereof. 
Synthesis, rheology and forming of $\mathrm{Y}-\mathrm{Ba}-\mathrm{Cu}-\mathrm{O}$ ceramics

Timothy M. Green

Under the supervision of Mufit Akinc

From the Department of Materials Science and Engineering Iowa State University

Since the discovery of the high-Tc ceramic superconductors there has been a vast amount of work performed with regard to synthetic methods, and toward improving materials properties. Only in the last two to three years has there been significant amounts of work directed toward use of forming technologies to produce conductor shapes.

A chemical synthesis route is discussed which results in a low-temperature precursor to $\mathrm{Y}-\mathrm{Ba}-\mathrm{Cu}-\mathrm{O}$ ceramics. The synthesis is based on use of molten $\mathrm{Ba}(\mathrm{OH})_{2} \cdot 8 \mathrm{H}_{2} \mathrm{O}$ as a molten salt flux. Two different chemical systems have been examined. The first, based on nitrate salts, has been demonstrated to be a viable precursor material for tape casting and extrusion. The second, made from acetate salts, has been used for powder synthesis and extrusion. The rheological properties of the precursor pastes obtained from either system may be controlled by removal of the liquid fraction during processing.

Examination of the rheology of the pastes shows that flow characteristics of the pastes may be fit to either Bingham Plastic or Hershel-Bulkley models. Yield stress is controlled in both pastes by the volume fraction solids. Viscosity also follows solids loading in the paste. Shear thinning tendencies are controlled by the colloidal nature of the precursor. Rheological measurements indicate the existence of colloidal microstructure in the paste. Comparison of concentric cylinder rheometry and piston extrusion rheometry shows order of magnitude 
differences in yield stress. These differences result from the inherent nature of the test methods, where the degree to which paste dilation is constrained has a major influence on the rheology. 
Synthesis, rheology and forming of $\mathrm{Y}-\mathrm{Ba}-\mathrm{Cu}-\mathrm{O}$ ceramics

by

Timothy Myron Green

A Dissertation Submitted to the

Graduate Faculty in Partial Fulfillment of the

Requirements for the Degree of

DOCTOR OF PHILOSOPHY

Department: Materials Science and Engineering

Major: Ceramic Engineering

Approved:

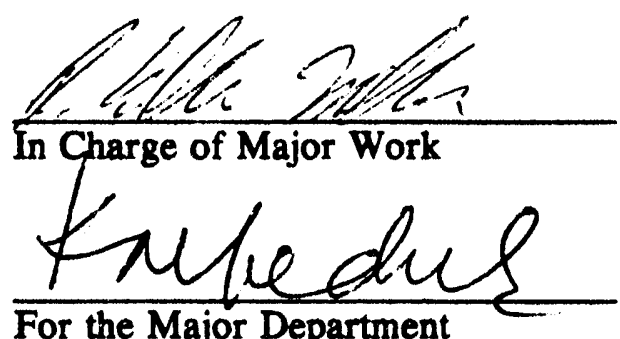

For the Major Department

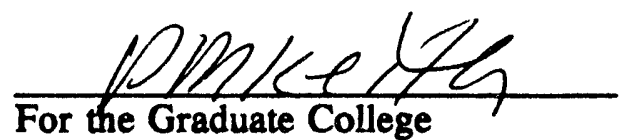

Iowa State University

Ames, lowa

1993 


\section{TABLE OF CONTENTS}

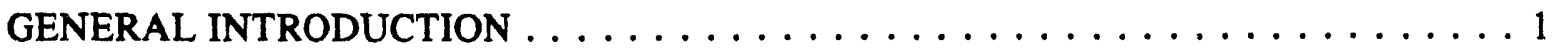

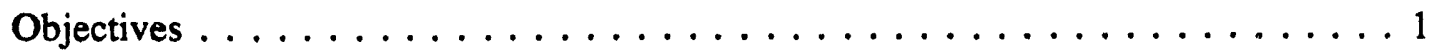

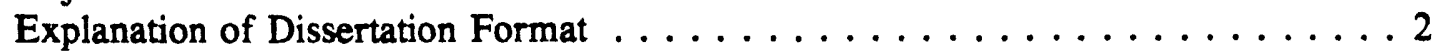

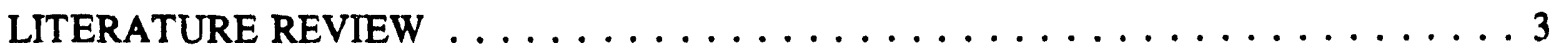

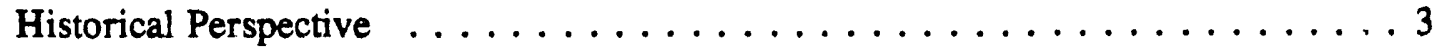

Crystal Structure . . . . . . . . . . . . . . . . . . . . 5

Phase Relations in the $\mathrm{Ba}-\mathrm{Y}-\mathrm{Cu}-\mathrm{O}$ System $\ldots \ldots \ldots \ldots \ldots$

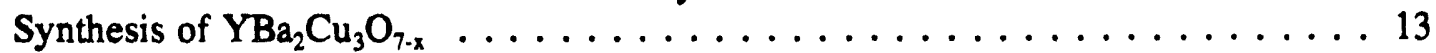

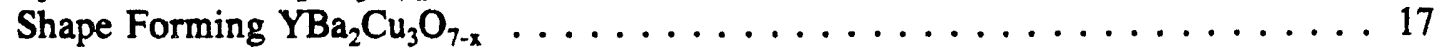

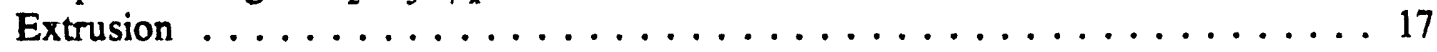

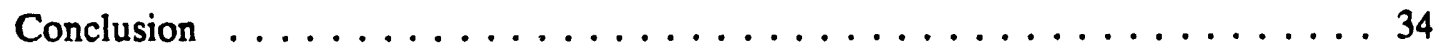

PAPER I. A NITRATE PRECURSOR TO $\mathrm{YBa}_{2} \mathrm{Cu}_{3} \mathrm{O}_{7-\mathrm{x}}$ FIBERS $\ldots \ldots \ldots 36$

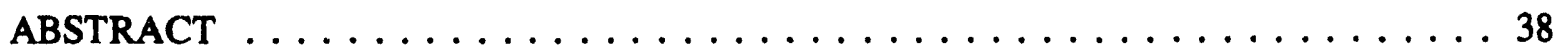

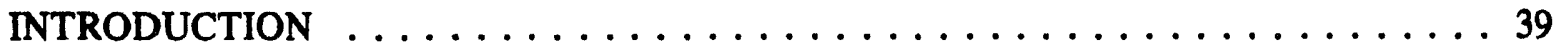

EXPERIMENTAL PROCEDURE $\ldots \ldots \ldots \ldots \ldots \ldots \ldots \ldots \ldots \ldots \ldots \ldots$

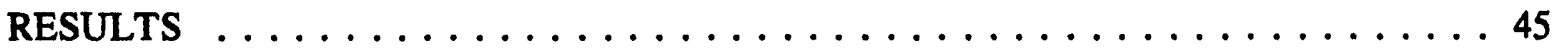

Paste Chemistry ............................ 45

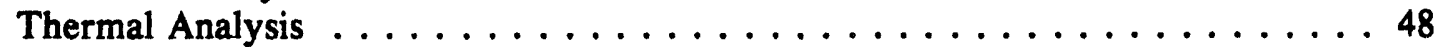

Microstructure of the Dry Paste ..................... 50

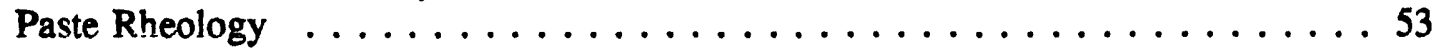

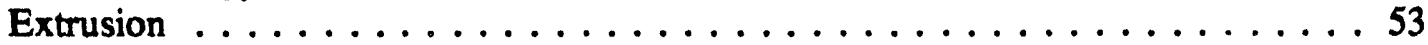

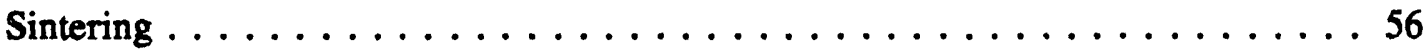

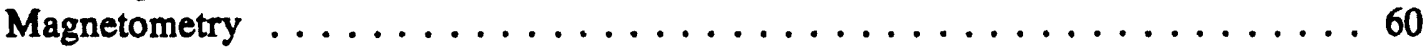

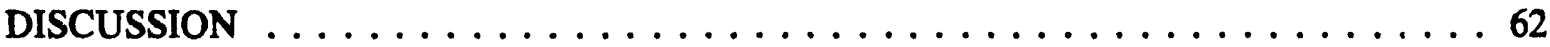

Chemistry of the Paste ....................... 62

Rheology .......................... 65

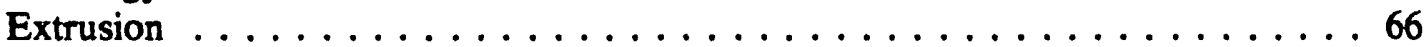

Pyrolysis and Sintering . . . . . . . . . . . . . . . . 67

Superconducting Properties ..................... 68

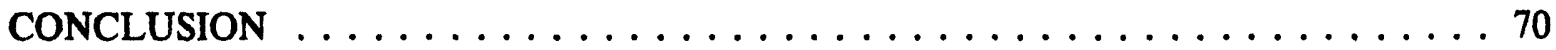

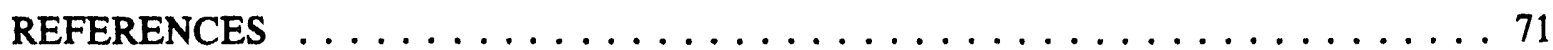


PAPER II. SYNTHESIS AND RHEOLOGY OF A LOW-TEMPERATURE ACETATE PRECURSOR FOR $\mathrm{YBa}_{2} \mathrm{Cu}_{3} \mathrm{O}_{7-\mathrm{x}}$ FIBERS $\ldots \ldots \ldots 74$

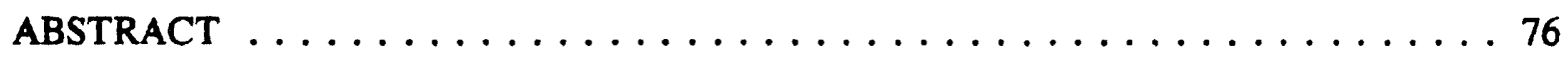

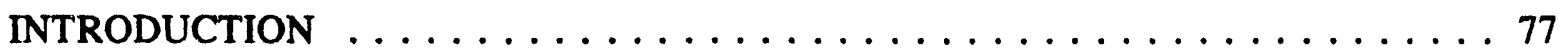

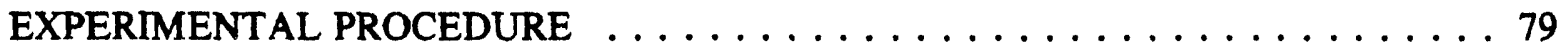

Paste and Fiber Synthesis $\ldots \ldots \ldots \ldots \ldots \ldots \ldots$

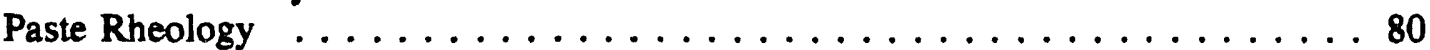

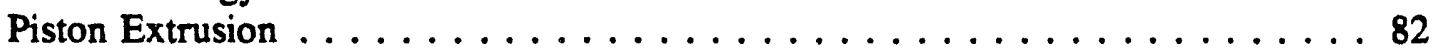

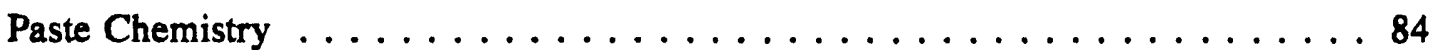

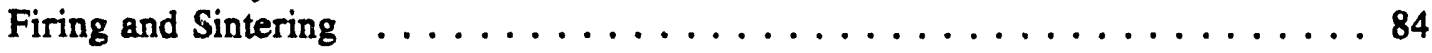

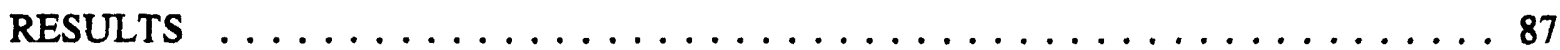

Concentric Cylinder Rheology . . . . . . . . . . . . . . . . 87

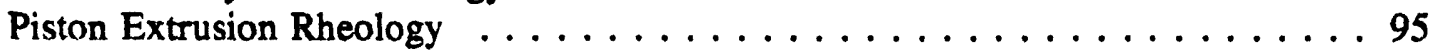

Volume Fraction Solids $\ldots \ldots \ldots \ldots \ldots \ldots \ldots$

Particle Size Analysis . . . . . . . . . . . . . . . . . . . . 103

Paste Chemistry ......................... 105

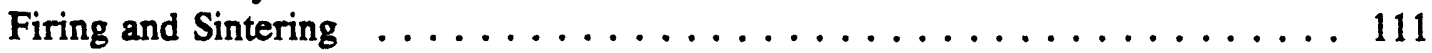

Fiber Yroduction . . . . . . . . . . . . . . . . . . 111

Superconducting Properties ...................... 113

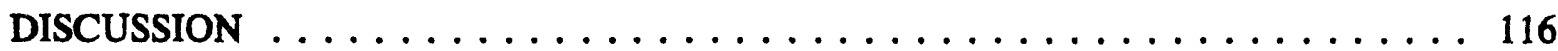

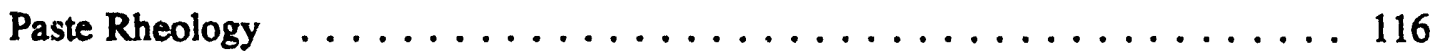

Concentric Cylinder Rheology . . . . . . . . . . . . . . . 116

Piston Extrusion . . . . . . . . . . . . . . . . . . . 120

Paste Cnemistry . . . . . . . . . . . . . . . . . . . 125

Densification and Fiber Forming .................. 125

Superconducting Properties ....................... 126

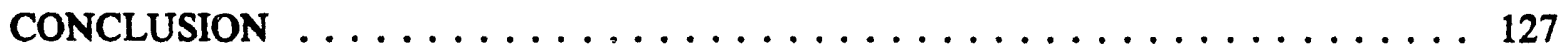

REFERENCES $\ldots \ldots \ldots \ldots \ldots \ldots \ldots \ldots \ldots \ldots \ldots \ldots \ldots \ldots \ldots \ldots \ldots$

GENERAL CONCLUSION $\ldots \ldots \ldots \ldots \ldots \ldots \ldots \ldots \ldots \ldots \ldots$

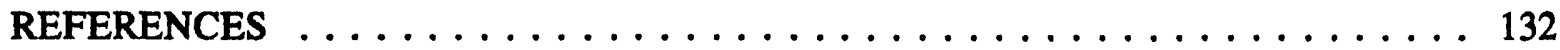

ACKNOWLEDGEMENTS . . . . . . . . . . . . . . . . . . . . . 139 


\section{GENERAL INTRODUCTION}

The discovery of several families of superconducting cuprate ceramics [1-6] generated an unprecedented amount of research toward understanding the chemistry and physics, and optimization of processing methods to improve the superconducting characteristics of these materials. The $\mathrm{Y}-\mathrm{Ba}-\mathrm{Cu}$ oxide system which shows superconducting transition temperatures $\left(\mathrm{T}_{\mathrm{c}}\right.$ ) around $90 \mathrm{~K}$ for the composition $\mathrm{YBa}_{2} \mathrm{Cu}_{3} \mathrm{O}_{7-\mathrm{x}}$, where $0.0<\mathrm{x}<0.5$, is perhaps the most widely studied.

Examination of the literature relating to 123 superconductor research shows that a vast body of work has been compiled on the physical and chemical properties of this ceramic. This research includes examination of phase relationships [7-9], crystal structures $[10,11]$, the effects of chemical substitutions on properties [12], chemical reactions with substrates and ambient environments [13-15], and thermal and mechanical properties [16, 17]. A lesser amount of work has been performed in attempts to develop shaped bodies for practical applications. A summary of some shape-forming techniques which have been used to make superconductor bodies is given in Green and Akinc [18]. The forming techniques used are generally those used for traditional clay-based ceramics, although some powder-free methods such as plasma deposition and vapor deposition $[19,20]$, or metal forming methods such as swaging [21], are also used.

\section{Objectives}

This research was performed in an attempt to develop improved synthetic routes to $\mathrm{YBa}_{2} \mathrm{Cu}_{3} \mathrm{O}_{7-x}$, and to try to produce viable conductor shapes of this material. The chemical 
synthesis was designed to try to produce directly formable precursor systems, with no additional binders or plasticizers, thus reducing the number of processing steps as well as the impurities in the superconducting body. Understanding the processing parameters of the precursor systems from initial synthesis through final production of the $\mathrm{YBa}_{2} \mathrm{Cu}_{3} \mathrm{O}_{7-\mathrm{x}}$ material was a project goal. Examination of the rheology of the system received particular attention due to its importance in common ceramic forming processes. Another objective of the project was to understand the mechanics of the shape forming process for the systems under study.

\section{Explanation of Dissertation Format}

The dissertation consists of a literature review, followed by two separate manuscripts prepared for publication. Both papers have been prepared for submission to the Journal of the American Ceramic Society. References cited in the general introduction and literature review follow the second paper. Note that although both manuscripts are largely the work of this author, Dr. R. W. McCallum appears as second author, for his contributions to the overall direction of the project. Dr. Mufit Akinc (major professor) has made significant contributions throughout the study and appears as third author on these papers. 


\section{LITERATURE REVIEW}

\section{Historical Perspective}

H. K. Onnes first observed the phenomenon of superconductivity in 1911 in mercury. He observed that at cryogenic temperatures, the electrical resistance of materials effectively reaches zero. Sensitive measurements show that the conductivity of materials in a superconducting state may be $10^{16}$ times as high as in the non-superconducting state [22]. In 1933, Meissner and Ochsenfeld observed perfect diamagnetism in superconductors. They found that not only are magnetic fields excluded from a superconductor, which would be expected for perfect conductivity, but that the field is expelled from a normal state sample as the material is cooled below its superconducting transition temperature (the Meissner effect). Perfect conductivity alone would be expected to trap flux within the material. The existence of the Meissner effect implies that the superconducting properties of a material will be destroyed at some critical field strength [23]. Both perfect conductivity and the Meissner effect must be present in a material for it to be considered a superconductor.

The superconducting phenomenon has been explained with varying degrees of success by several phenomenological theories, such as the London or Landau-Ginzburg equations [24]. Bardeen, Cooper and Schrieffer proposed a microscopic theory in 1957 (BCS theory) which explains superconductivity relatively well [23]. The theory may be summarized as follows.

BCS theory states that at a sufficiently low temperature, an attractive interaction exists between electrons. This interaction results in a pairing of the conduction electrons. These pairs of electrons act as single particles as they flow through the crystal structure. As a result 
of the pair formation an energy gap forms about the Fermi level in the electron density of states. The gap separates the superconducting ground state from excited states [24]. The pairing of electrons, with the resulting energy gap, results in the disappearance of resistance exhibited by superconducting materials [24]. The loss of resistance in superconductors is due to the fact that the low-energy inelastic collisions between electrons and the lattice which cause resistance in normal state metals become quantum mechanically disallowed for $T<T_{c}$. Only collisions with energy transfer greater than the width of the band gap $E_{g}$ ( $=$ the pair forming energy, $\Delta$ ) will result in promotion of electrons to an excited state, causing electron depairing and increased resisitivity [23].

The paired electrons (Cooper pairs) mentioned above result from interactions between electrons and the lattice. A very simplistic explanation of the formation of Cooper pairs is as follows. As one electron moves through the crystal, it interacts via Coulomb interaction with the lattice and causes it to distort [22]. A second electron of opposite momentum and spin is 'attracted' by the deformed lattice, and is coupled to the first by this attraction. The existence of the paired electron system as the fundamental superconducting particle is supported by measurements of magnetic flux quantization through superconducting rings, in which the effective unit of charge is $2 \mathrm{e}$ rather than $\mathrm{e}$ [24].

Bednorz and Mueller [1] discovered that the oxide composition $\mathrm{Ba}_{x} \mathrm{La}_{5-x} \mathrm{Cu}_{5} \mathrm{O}_{5(3-y)}$ showed a superconducting transition temperature of $-30 \mathrm{~K}$. This was significantly higher than the previous high transition temperature for $\mathrm{Nb}_{3} \mathrm{Ge}$ of $23.3 \mathrm{~K}$. Shortly after this, Wu et al. [2] reported superconductivity in the $\mathrm{Y}-\mathrm{Ba}-\mathrm{Cu}-\mathrm{O}$ system at a temperature of $93 \mathrm{~K}$. This was important in that it was the first superconductor with a superconducting transition temperature 
above the boiling point of liquid nitrogen $(77 \mathrm{~K})$. Since then, numerous compositions based on yttrium barium cuprates $[9,11]$, bismuth strontium calcium cuprates $[4,28]$, thallium barium calcium cuprates $[5,6,26]$, other oxide superconductors such as $\mathrm{Ba}_{1-\mathrm{x}} \mathrm{K}_{\mathrm{x}} \mathrm{BiO}_{3}$ have been discovered. These materials are ceramics. As a result, they are brittle, and thus present numerous manufacturing problems for superconducting applications. The multicomponent nature of the ceramic superconductors causes problems in synthesis of single phase materials in some systems. There currently exist simultaneous research efforts to increase the transition temperature of the oxide superconductors by discovery of new superconducting phases, improve their mechanical properties and thus enhance their useability, and also to understand why they are superconducting.

This review will concentrate on the $\mathrm{YBa}_{2} \mathrm{Cu}_{3} \mathrm{O}_{7-\mathrm{x}}$ superconductor; its crystal chemistry, synthesis, and manufacturing. This does not mean that the principles discussed below are limited to the 123 phase, in general, they will be applicable to most ceramic superconductors.

\section{Crystal Structure}

The crystal structure of the 123 phase has been termed a defect perovskite [11]. Perovskites, in their ideal form, have a general formula $\mathrm{ABX}_{3}$, where $\mathrm{A}$ and $\mathrm{B}$ are metallic cations. The $\mathrm{A}$ cation is typically a large divalent cation (e.g. $\mathrm{Ca}, \mathrm{Sr}, \mathrm{Ba}$ ), and the $\mathrm{B}$ cation is often a tetravalent transition metal ( $\mathrm{Ti}, \mathrm{V}, \mathrm{Mn})$, although pairs of trivalent cations are also seen. In the ideal perovskite structure the atoms are arranged on a cubic lattice with the large A cation occupying the center of the cube. The smaller B cations are located at the corners of the cube. The anions lie at the midpoints of the cube edges as shown in Figure 1 [25]. This 
ideal perovskite structure is the exception: perovskites are usually non-cubic due to lattice strains induced by variations in the sizes of the atoms in the structure, and are nonstoichumetric due to deviations in valency from the perfect perovskite.

The 123 structure was originally described as a tripled perovskute unit cell along the caxis with a central cation repeat sequence of $(-\mathrm{Ba}-\mathrm{Y}-\mathrm{Ba}-)$ (Figure 2) [11]. Using this model, a 'pure' perovskite would have the formula $\mathrm{YBa}_{2} \mathrm{Cu}_{3} \mathrm{O}_{9}$ and a tetragonal structure. An alternative approach to description of superconductor structures is developed by Smythe [26] after the work of Ruddlesden and Popper [27]. In this work, a series of crystal

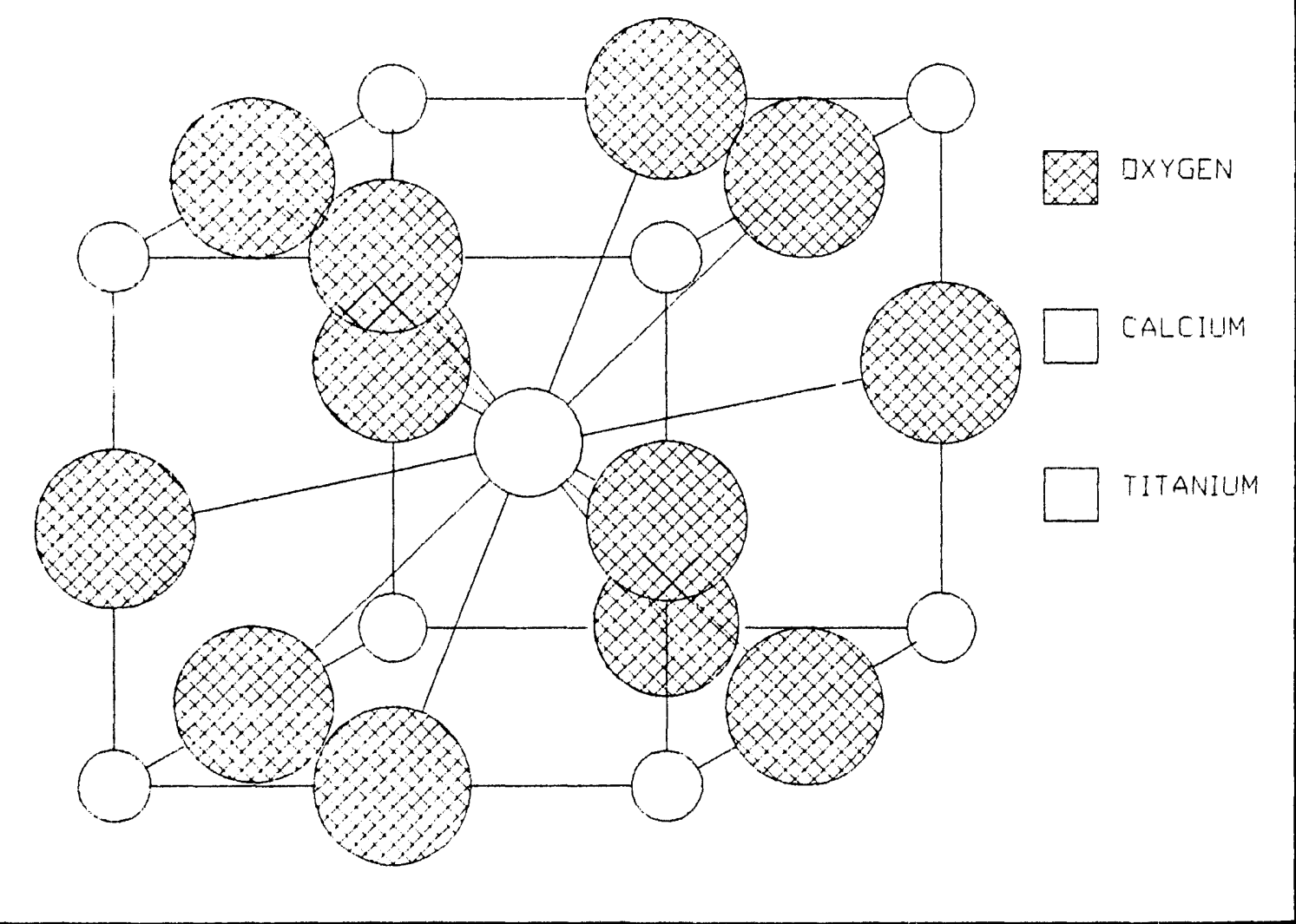

Figure 1. Ideal perovskite structure. The origin is centered on the titanium atoms. 


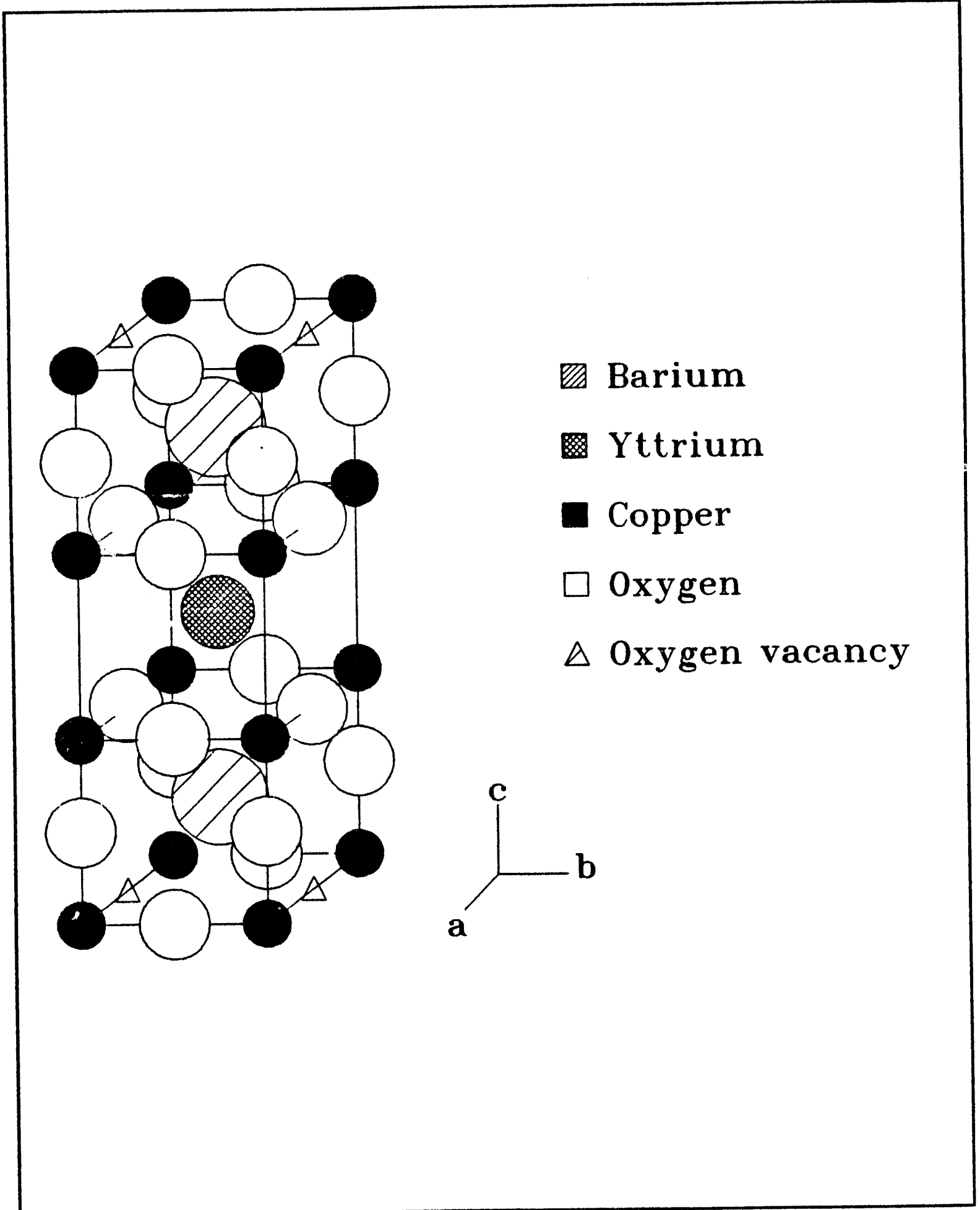

Figure 2. Crystal structure of the $\mathrm{YBa}_{2} \mathrm{Cu}_{3} \mathrm{O}_{7-\mathrm{x}}$ superconductor 
structure in the $\mathrm{Sr}-\mathrm{Ti}$ - $\mathrm{O}$ system were described. These structures are intermediates between $\mathrm{SrTiO}_{3}$ and $\mathrm{SrO}-\mathrm{nSrTiO}_{3}\left(\mathrm{Sr}_{\mathrm{n}+1} \mathrm{Ti}_{\mathrm{n}} \mathrm{O}_{3 \mathrm{n}+1}\right)$. Two members of this structural series are $\mathrm{Sr}_{2} \mathrm{TiO}_{4}$ and $\mathrm{SrTiO}_{3}$, where the former has the $\mathrm{K}_{2} \mathrm{NiF}_{4}$ structure, and the latter has the perovskite structure. Members intermediate in the series may be described as twodimensional layers of perovskite, $\mathrm{n}$ unit cells thick, separated by a single $\mathrm{SrO}(\mathrm{NaCl}$ structure) layer.

The yttrium cuprate analog of the strontium titanates is $\mathrm{YCuO}_{3}$, where all of the copper exists as $\mathrm{Cu}^{3+}$. This may be considered the building block for the yttrium barium cuprate superconductors. We start with a tripled unit of yttrium cuprate, yielding $\mathrm{Y}_{3} \mathrm{Cu}_{3} \mathrm{O}_{9}$. When acceptor doped, with $2 / 3$ of the yttrium atoms replaced by $\mathrm{Ba}^{2+}$, the oxygen content decreases, resulting in $\mathrm{YBa}_{2} \mathrm{Cu}_{3} \mathrm{O}_{8}$. The missing oxygen is removed from around the yttrium atom, which from radius ratio arguments will prefer to be 8-coordinate rather than 12coordinate $\left(r\left(O^{2-}\right)=0.14 \mathrm{~nm}, r\left(B^{2+}\right)=0.156 \mathrm{~nm}, r\left(Y^{3+}\right)=0.116 \mathrm{~nm}\right)$. Copper will not maintain a $3+$ oxidation state at atmospheric pressure, so additional oxygen vacancies are formed. This oxygen comes from the basal plane of the structure [11]. If the oxygen vacancies are disordered, the structure is tetragonal, and the material is not superconducting. If the vacancies are ordered, the material is orthorhombic and the material is superconducting. It has been shown that the transformation between the tetragonal and orthorhombic symmetries is dependent on both temperature and oxygen partial pressure $[29,30]$. At the superconducting composition $\mathrm{YBa}_{2} \mathrm{Cu}_{3} \mathrm{O}_{7-\mathrm{x}}(0<\mathrm{x}<0.5)$, the average formal oxidation state of the copper ions is $2.33\left(2 \mathrm{Cu}^{2+}+1 \mathrm{Cu}^{3+}\right)$. 
The main utility of the Ruddlesden - Popper approach for oxide superconductors is in its application to the structures of the yttrium, bismuth and thallium superconductors. For example, the compound $\mathrm{YBa}_{2} \mathrm{Cu}_{4} \mathrm{O}_{9-\mathrm{x}}$ may be considered to consist of three $\mathrm{Ba}$ doped $\mathrm{YCuO}_{3}$ (perovskite structure) layers and a single $\mathrm{CuO}(\mathrm{NaCl}$ structure) layer. The bismuth 2212 superconductor, $\mathrm{Bi}_{2} \mathrm{Sr}_{2} \mathrm{CaCu}_{2} \mathrm{O}_{8}$, consists of one-half of a double perovskite-like layer, $\left(\mathrm{Ca}_{4} \mathrm{O}\right.$ $\left.\mathrm{CuO}-\mathrm{Sr}_{4} \mathrm{O}\right)$, three $\mathrm{NaCl}$-type layers $\left(\mathrm{Sr}_{4} \mathrm{O}-\mathrm{BiO}_{4}-\mathrm{Bi}_{4} \mathrm{O}-\mathrm{SrO}_{4}\right)$, a doubled perovskite layer $\left(\mathrm{SrO}_{4}-\left[-\mathrm{CuO}_{2}-\right]-\mathrm{Ca}\left(\mathrm{O}_{4}\right)-\left[-\mathrm{CuO}_{2}-\right]-\mathrm{SrO}_{4}\right)$, three $\mathrm{NaCl}$ layers, and another half perovskite layer $[26,28]$. The 2212-thallium superconductor $\mathrm{Tl}_{2} \mathrm{Ba}_{2} \mathrm{CaCu}_{2} \mathrm{C}_{8}\left(\mathrm{~T}_{\mathrm{c}}=110 \mathrm{~K}\right)$, has a similar structure.

Phase Relations in the $\mathrm{Ba}-\mathrm{Y}-\mathrm{Cu}-\mathrm{O}$ System

The $\mathrm{YBa}_{2} \mathrm{Cu}_{3} \mathrm{O}_{7}$ phase exists in the $\mathrm{Ba}-\mathrm{Y}-\mathrm{Cu}$ oxide system (Figure 3)[7, 8, 31]. Because of the phase relations between $\mathrm{YBa}_{2} \mathrm{Cu}_{3} \mathrm{O}_{7}$ and its various reactant phases, synthesis of high purity 123 material is very difficult [7]. It is, however, possible to produce a material with a minimal impurity phase content. The impurity phases coexisting with 123 may include $\left.\mathrm{CuO}, \mathrm{BaCO}_{3}, \mathrm{Y}_{2} \mathrm{BaCuO}_{5}(211)\right)$, and $\mathrm{BaCuO}_{2}$. Reactant phases, which commonly include $\mathrm{Y}_{2} \mathrm{O}_{3}, \mathrm{Ba}(\mathrm{CO})_{3}$, and $\mathrm{CuO}_{x}$, may also appear if the synthetic method is not carefully controlled.

In addition to problems inherent in maintenance of stoichiometry during synthesis, the melting behavior in the 123 system is also a problem. Examination of the pseudobinary joins $\mathrm{Y}_{2} \mathrm{Cu}_{2} \mathrm{O}_{5}-\mathrm{BaCuO}_{2}$ (Figure 4) and $\mathrm{BaO}: 5 \mathrm{YO}_{1.5}-3 \mathrm{BaO}: 5 \mathrm{CuO}$ (Figure 5), shows that the 123 phase melts incongruently. There are several implications of this behavior as it affects the 


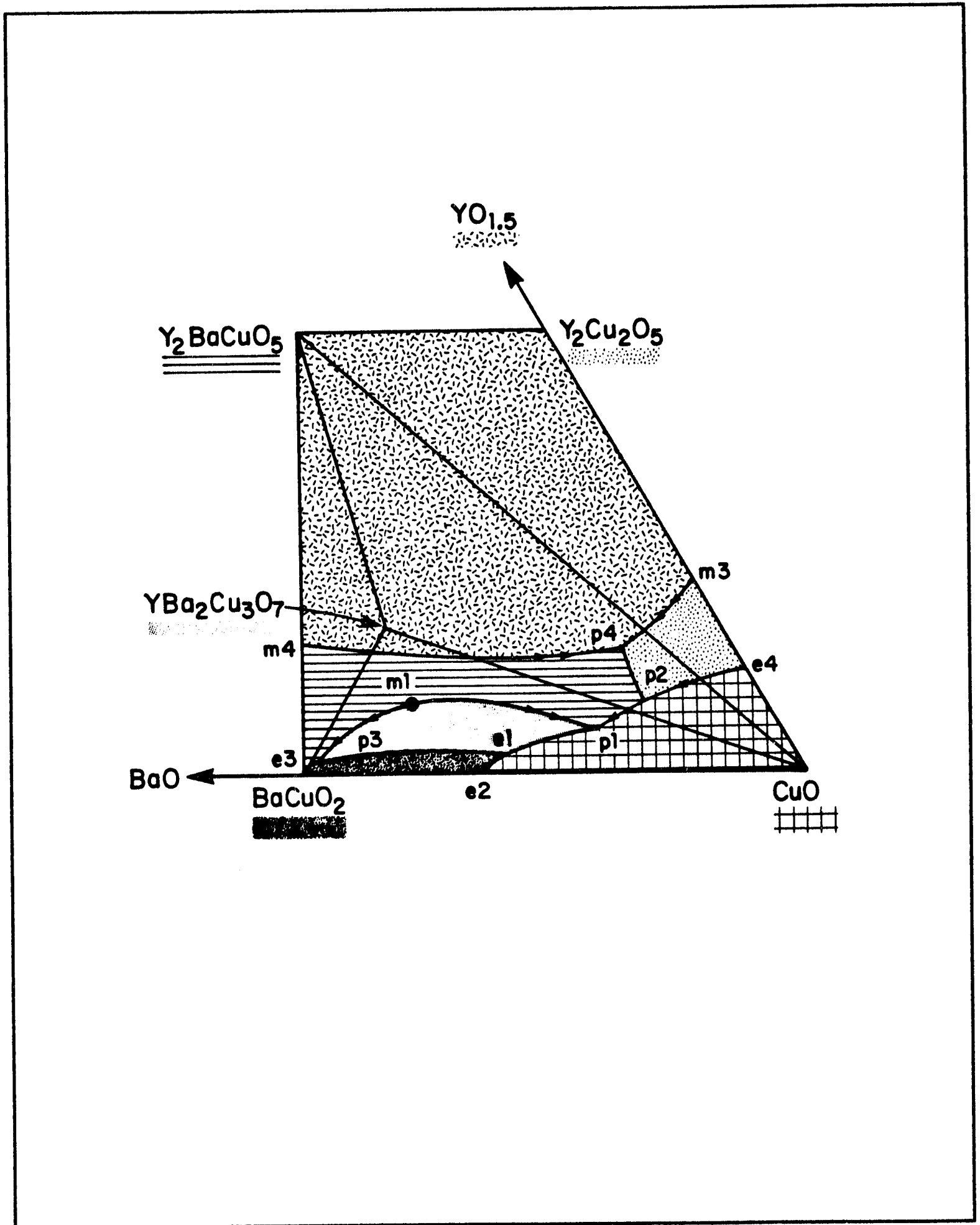

Figure 3. The copper-rich corner of the $\mathrm{Y}-\mathrm{Ba}-\mathrm{Cu}-\mathrm{O}$ phase diagram [36] 


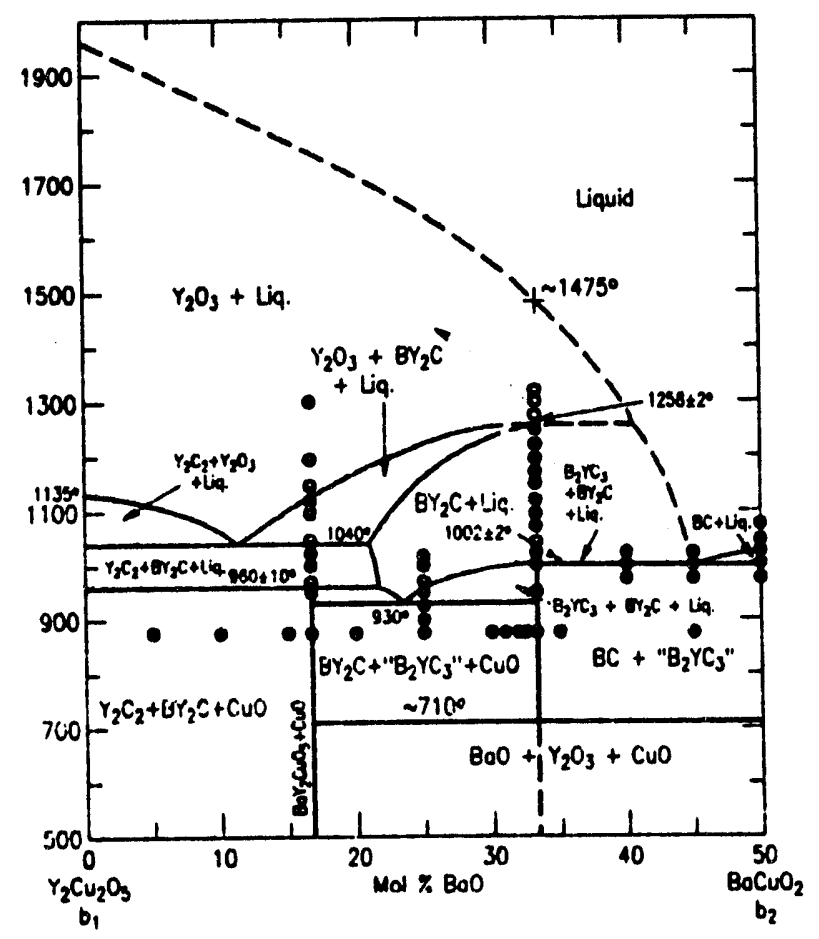

Figure 4. Pseudobinary join $\mathrm{Y}_{2} \mathrm{Ba}_{2} \mathrm{O}_{5}-\mathrm{BaCuO}_{2}$ join [9] 


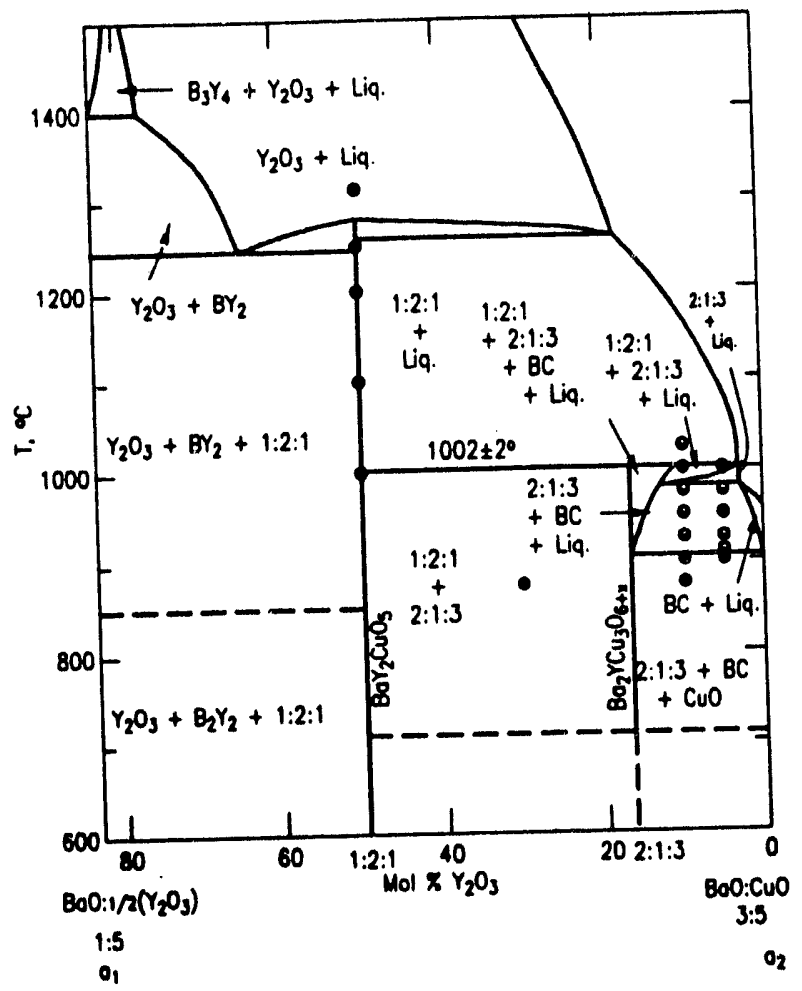

Figure 5. Psuedobinary join $\mathrm{BaO}: 5 \mathrm{YO}_{1.5}-3 \mathrm{BaO}: 5 \mathrm{CuO}$ [9] 
processing of the superconductor. First, crystallization of the 123 phase directly from the mclt will be very difficult, or at least will tend to produce 123 crystals along with one or more impurity phases. Second, bulk compositions which contain $\mathrm{BaO}$ are likely to react with $\mathrm{CO}_{2}$ in the atmosphere to form carbo.ate impurity phases. Third, the $\mathrm{YBa}_{2} \mathrm{Cu}_{3} \mathrm{O}_{7-x}$ phase itself is highly reactive [14].

$$
\text { Synthesis of } \mathrm{YBa}_{2} \mathrm{Cu}_{3} \mathrm{O}_{7-\mathrm{x}}
$$

Solid State Reaction

The first syntheses of 123 involved the solid state reaction of high purity $\mathrm{Y}_{2} \mathrm{O}_{3}$, $\mathrm{BaCO}_{3}$, and $\mathrm{CuO}[2,10,32]$. These reagents are mixed in solid form in a $1: 2: 3$ ratio and ground for several hours, usually under an inert atmosphere. The resulting powder is then pressed into pellets and calcined at temperatures near $900^{\circ} \mathrm{C}$. The homogeneity of the resulting ceramic is generally low, so the grinding and calcination steps must often be repeated several times [33]. The calcined mixture is then pelletized for a final time and sintered at temperatures ranging from $900^{\circ} \mathrm{C}$ to $1020^{\circ} \mathrm{C}$ in flowing air or oxygen. The sintered pellet is then given an oxygen anneal at around $450^{\circ} \mathrm{C}$ to permit uptake of oxygen, forming the superconducting phase.

While the oxide method is capable of producing large quantities of superconducting material, production of theoretically dense 123 polycrystalline materials with high transport critical current densities has not been realized. Many researchers obtain $T_{c}$ values near $90 \mathrm{~K}$, and produce $x$-ray pure materials. Still, several problems persist. 
First, sintering of dry-pressed pellets produced by the oxide method seldom yields a product which exceeds $90 \%$ of theoretical density $[34,35]$. This difficulty in densification of the material is caused by the relatively small temperature range available for sintering the material. Low-temperature sintering is limited by low diffusivities dictated by the Arrhenius relation. As a result, as high a temperature as possible is desirable in sintering operations. The upper temperature limit for sintering 123 is constrained by the melting point, which occurs over a range of $940-1020^{\circ} \mathrm{C}$, with higher melting points occurring at higher partial pressures of oxygen [36]. As noted above, the 123 phase melts incongruently, forming liquid and the solid 211 phase.

A second problem which has been reported in 123 produced by the oxide method is low critical current densities. For most applications current densities, $\mathrm{J}_{\mathrm{c}}$, on the order of $10^{6}$ $\mathrm{A} / \mathrm{cm}^{2}$ will be necessary [37]. Most polycrystalline 123 samples to date show $\mathrm{J}_{c}=10^{2}-10^{4}$ $\mathrm{A} / \mathrm{cm}^{2}$ in zero field conditions $[37,38]$.

Crystallite orientation has been shown to be critical in development of 123 superconductors with enhanced current densities. The majority of current transport in the 123 material is in the a-b crystallographic planes, that is, perpendicular to the c-axis of the unit cell $[37,38]$. Thus, alignment of crystallites in polycrystalline 123 is necessary to optimize current transport. Such alignment may be achieved during the firing step by pressure texturing methods such as sinter-forging, or processing in an oriented magnetic field [39]. The problem is, however, more complicated still. Dimos et al. [40] have shown that grainboundary limited $\mathrm{J}_{\mathrm{c}}$ is also a function of the degree of misorientation of the a- and $\mathrm{b}$ - axes 
between crystallites. So, to obtain a high critical current in polycrystalline samples, a high degree of alignment of the crystallographic axes between grains in the compact must exist.

Grain boundary effects further reduce current transport. Grain boundaries act as weak links in the carrier path through polycrystalline superconductors. In addition, microcracks form during cooling of the ceramic from anisotropic thermal expansion coefficients. The calculated grain size to avoid microcracking in polycrystalline 123 is on the order of $0.5 \mu \mathrm{m}$ [41]. The grain boundaries are also sites for accumulation of contaminant phases, such as 211 , or various carbonate phases created during processing [42].

Finally, ceramic powders produced by solid state processes are often difficult to fabricate by common forming techniques such as pressing, extrusion, or casting without addition of processing aids such as binders or plasticizers [43]. The clay fraction of traditional ceramics acts as a lubricant and moisture buffer during the processing and drying steps of forming operations. The lubrication results in large part from the interlayer water in clay minerals, and from weak Van der Waals bonding between clay particles. Non-traditional ceramics, such as superconductors, do not inherently possess this self-lubricating property. As a result, problems such as poor powder packing, formation of powder agglomerates, low particle shape uniformity, wide particle size distributions, and appearance of drying cracks are common. In order to obtain shaped materials which sinter well, either additives or nonconventional processing techniques must be used. Because of the high degree of reactivity seen in the $\mathrm{Y}-\mathrm{Ba}-\mathrm{Cu}$ superconductors, addition of binders or plasticizers may be detrimental to the purity of the product. Thus, use of improved forming techniques to form shapes of this material is needed. 
Chemical Syntheses of $\mathrm{YBa}_{2} \mathrm{Cu}_{3} \mathrm{O}_{7-\mathrm{x}}$

In an attempt to respond to the processing difficulties resulting from manufacture of 123 superconductors by solid state reaction of oxides, a number of "non-conventional" ceramic processing techniques have been tried. Chemical systems based on nitrates $[44,45]$, oxalates [46], carbonates [47], citrates [48], acetates [49, 50,51], and alkoxides [52] have all been used to produce $\mathrm{YBa}_{2} \mathrm{Cu}_{3} \mathrm{O}_{7-\mathrm{x}}$. These processes range from classical prenipitation techniques to contemporary sol-gel techniques. They either directly yield powders or gels, or for'm viscous, formable precursors. The sol-gel processes are fairly easy to employ and yield chernically homogeneous powders, but forming shapes from gels is not a trivial process. Cracking during drying is often a serious problem in gel-derived shapes.

Precipitation methods generally yield products which are more chemically homogeneous than those obtained by mixing of solid reactants. Coprecipitation $[53,54]$ has been used to produce 123 precursor powders. Problems associated with precipitation methods include particle agglomeration, formation of phases with other than 123 stoichiometry, preferential crystal growth, or broad particle size distributions, all of which reduce sinterability. A further problem with solution techniques is that a $1: 2: 3$ mixture of yttrium, barium, and copper ions in solution will not necessarily yield a 123 bulk composition in the precursor precipitate. The correct stoichiometry needed to yield the desired product must be determined empirically.

Another route for producing superconductors involves use of thin film technology. Films with high current density have been produced by electron beam evaporation, chemical vapor deposition, d.c. magnetron sputtering, and ion beam sputtering [55-57]. A bonus associated with these techniques is the potential for in situ forming of the finished shape. 
Most evaporative methods, however, are limited to formation of thin sheets, and are expensive.

\section{Shape Forming $\mathrm{YBa}_{2} \mathrm{Cu}_{3} \mathrm{O}_{7-\mathrm{x}}$}

Application of forming techniques to superconductors has been summarized by Green and Akinc [18] and Jin and Graebner [58]. As noted above, the forming operations used in superconductors are generally the same as those used on clay-based ceramics, although the differences in system properties often necessitate the use of additives to aid in forming the particulate assemblies.

Superconductors, as implied by the name, are electrical conductors. Applications of ceramic superconductors requires shaping these material into wires, coils or solenoids, conductive substrates, and motor or magnet parts. The need for production of wires is part of the motivation for this project. Because most superconductor synthesis routes produce particulate bodies which are not easily spun or drawn, we will examine extrusion as a means of forming wires of $\mathrm{YBa}_{2} \mathrm{Cu}_{3} \mathrm{O}_{7-\mathrm{x}}$.

\section{Extrusion}

Extrusion is a means of producing bodies which have constant cross-section. Although extrusion is a well developed technology for shaping materials with constant crosssection, parameters such as rheology of the plastic body, extruder configuration, and chemistry of the plastic material all affect the quality of the final product.

The rheology of the plastic body is the prime factor affecting extrudability of the material. In typical ceramic systems, the plastic mass is a dense collection of fine particles in 
a fluid carrier. Rheological parameters which will affect the extrusion process include 1) the yield stress of the material, 2) the viscosity, and 3) the effect of varyied strain rate histories on the material.

The extruder configuration is an easily adjustable parameter in the forming process. The size and shape of the extrudate may be controlled by manufacturing the extruder die to desired specifications. The extruder should also be designed with the rheological properties of the plastic body in mind. For example, a more rugged construction is needed for a plastic material with high yield stress and viscosity.

The chemistry of the plastic material controls its rheological behavior. By altering the chemistry of the plastic body, the yield stress and viscosity may be altered to some extent. For example, in a dense suspension, chemical alteration of the surface charge on the suspended particles may cause flocculation (or conversely, deflocculation) of the system. This will cause a change in the rheological behavior of the system. However, the exact response of the paste to chemical change must be determined empirically.

\section{The Extruder}

The extruder consists of two sections: a feeder and a die. The feeder section provides a means of 1) loading the extruder, 2) transporting the plastic mass to the die, and 3) may include means of modifying the plastic mass by pugging, shearing or deairing. Loading may be via a hopper, or by direct insertion in the barrel. The barrel section is the transport path from the feed zone to the orifice. Generally the barrel is a long straight section of tube, which may be temperature controlled. Transport down the tube is either in batch fashion, with the plastic material forced axially down the tube by a ram or piston, or continuously, 
with the mass driven by one or more screws. Most industrial extruders use a screw feed. Deairing is often performed in the barrel in order to ensure transport of a continuous, voidfree product feed to the die.

The die section (Figure 6) has a major effect on the quality and characteristics of the final extrudate. The degree of reduction from the feed section to the finished diameter, which is variously referred to as the die reduztion ratio, $r=D / D_{0}$, or the turn-down ratio, as well as the degree of taper from the feeder to the die orifice, $\alpha$, are important in defining the flow behavior of the plastic mass $[59,60]$. The taper $(\alpha)$, or die semi-angle, varies from $90^{\circ}$ to $0^{\circ}$ measured from the extruder axis. The former is termed a square entry configuration, the latter is obviously the limiting case of a straight pipe. When $\alpha$ exceeds $60-70^{\circ}$, the flow pattern develops static zones. This modifies the flow, and the moving body behaves as though the die angle was less than $\alpha$. The region from the end to the die taper to the orifice is termed the die land, and may be varied to control the extrudate surface finish.

\section{Extrusion of Pastes}

Extrusion of ceramic bodies has been widely investigated. In a 1987 bibliography, Janney et al. give 672 abstracts published between 1932 and 1984 which relate to extrusion and plasticity [61]. Most of the work prior to the 1970's was with respect to extrusion of clay-based ceramics, and was empirical in nature. This is due to the difficulty in modelling the flow behavior of particulate systems over wide ranges of strain.

In the plastics industry, extrusion of polymeric materials has taken a different route. It has been common to measure the rheological properties and design processes and equipment based on these measurements [62]. In these systems, the flow characteristics are generally 


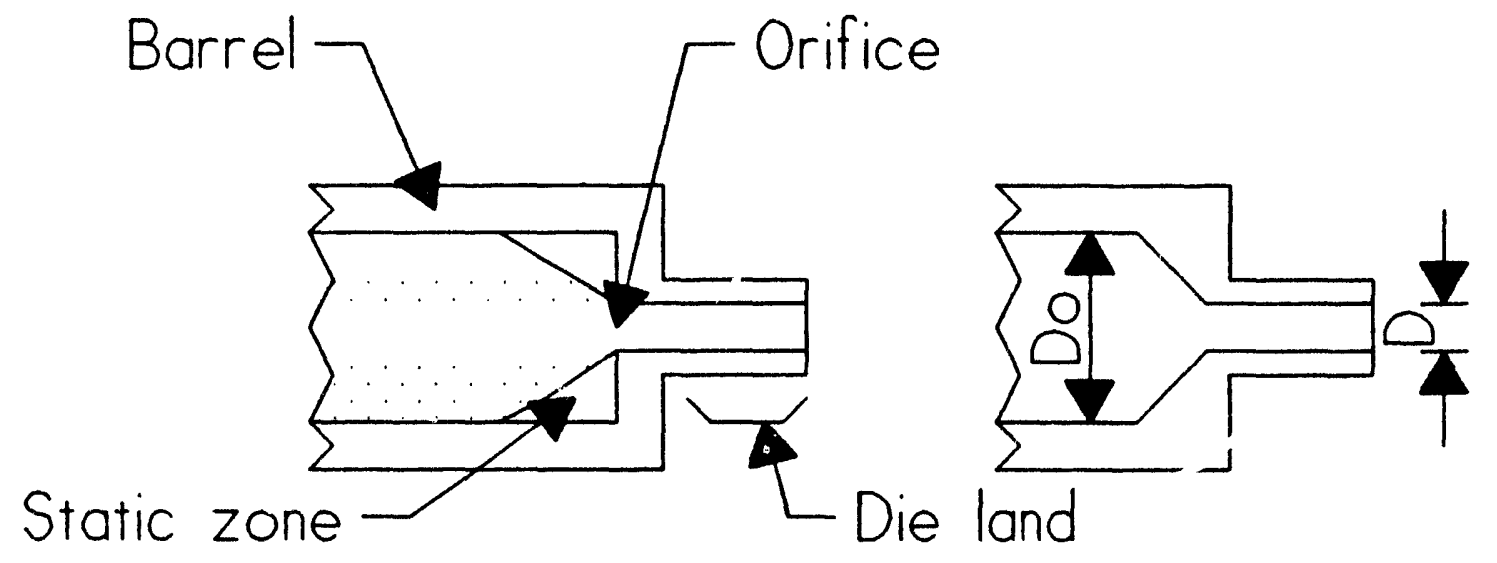

Figure ó. Schematic of extruder die area. (Left) Square entry die. (Right) Tapered entry die

only dependent on strain rate and extension rate [63], and die design based on these parameters is well understood [64].

Most rheological models are based on homogeneous systems, that is, single phase materials [65]. Application of these models to heterogeneous systems has limited applicability. As an example, consider the Hershel-Bulkley model (Equation 1)

$$
\tau=\tau_{y}+\eta_{p}(\dot{\gamma})^{n}
$$

where $\tau$ is the shear stress, $\tau_{y}$ is the yield stress, $\eta_{p}$ is the plastic viscosity, $\dot{\gamma}$ is the strain rate, and $\mathrm{n}$ is the flow exponent $(\mathrm{n}<1$ : shear thinning; $\mathrm{n}=1$ : Newtonian; $\mathrm{n}>1$ : shear thickening) . This model is often employed in characterization of ceramic pastes [66]. When a paste is modelled to this equation, a parameterization of the material properties is produced . It must be noted, however, there is no information in the equation which permits correlation of the material properties as described by the model to the physical or chemical make-up of 
the paste. For example, no information is directly available with regards to effect of the percentage of solids in the paste, or the textures of those solids, on the yield stress.

As a result, ceramic systems are expected to behave differently than polymer systems, even though they may produce similar materials parameters when fitted to a model. Factors such as particle size distribution, quantity of solids in the paste, and viscosity of the carrier medium, as well as processing parameters such as die design and rate of strain, all affect the rheology of the paste $[64,67]$.

Since the 1970's, some theoretical studies have been performed in an attempt to predict paste extrusion pressure, yield stresses, and other extrusion parameters [66 - 70]. One of the first such analyses was Capriz's study of clay behavior during extrusion [68]. Starting with the Bingham Plastic model (Equation 2) which relates yield stress to strain rate and

$$
\tau=\tau_{y}+\eta_{p} \dot{\gamma}
$$

viscosity, various types of flow through extruders were studied. The main constraint applied during the study was that flow was slow enough that viscous stresses were negligible compared to yield stresses. Using the Buckingham-Reiner equation (Equation 3), which relates flow rate $(\mathrm{Q})$ to rheological parameters for Bingham Plastics where $\Delta \mathrm{P}=$ pressure drop through the tube, $R=$ tube radius, $1=$ tube length, $\eta=$ plastic viscosity, and $\tau_{y}=$ yield stress, Capriz shows that extrusion pressure is dependent on $Q^{0.5}$.

$$
\Delta P=\frac{2 \tau_{y} l}{R}+\frac{2 l}{R}\left(\frac{2 Q \eta \tau_{y}}{\pi R^{3}}\right)^{\frac{1}{2}}
$$

This dependence is based on the assumptions that 1) the plastic mass flows as a plug except in regions where shear occurs, and 2) that creeping (i.e. very slow) flow dominates. Creeping 
flow is important in flow regimes where only the wall layer of the paste is sheared; that is, where the shear stress at the wall just exceeds the yield stress of the plastic material. Capriz defines the creeping flow regime based on the extruder characteristic value $(\xi)$

$$
\xi=\frac{\Delta P R}{2 \tau_{y}}
$$

where creeping flow occurs for values of $\xi$ slightly greater than unity [68].

Ovenston and Benbow [70] noted that flow of clays through tubes occurs via a two step process. First, slip at the wall of the tube occurs after a critical wall shear stress is exceeded. Next, as wall shear stress increases, the extrudate velocity increases until the internal yield stress of the plastic body is reached, after which the material deforms. Experimentation showed that the yield stress will seldom be reached in the die orifice. Rather, the paste will flow as a plug, with all motion due to shear at the die orifice wall. The thickness of such a layer, if liquid, would be on the order of $10^{-2} \mu \mathrm{m}$, which is less than typical surface roughness in manufactured tubes. Ovenston and Benbow [70] cite Berghaus [71], stating that Berghaus suggests that the flow is mediated by a layer of extrudate which is of intermediate viscosity. The occurrence of such a layer may arise from radial motion of particles during extrusion. He also notes that the pressure drop could be accounted for by metal drawing theory, following the expression

$$
\Delta P=\tau_{y} \ln \frac{A_{0}}{A}=2 \tau_{y} \ln \frac{D_{0}}{D}
$$

Segre and Silberberg noted that a solids depleted zone occurs during transport of solids through tubes [72]. This depletion zone is due to interactions of particles and the confining surface, and is on the order of 2 particle diameters thick. However, Segre and Silberberg 
performed their work on systems with low volume fractions of solids, so this mechanism is probably not directly applicable to systems where the paste behavior approaches that of a solid.

A significant body of research has been generated by Benbow and his co-workers on extrusion of pastes through square entry dies $[67,69,70]$. Two expressions which account for an observed dependence of flow rate on die pressure in square entry dies with circular orifices have been obtained. Each of the above Benbow equations consists of two terms. The first term relates to flow into the die from the extruder barrel. It implies that flow is plastic, and the pressure drop due to this term is dependent only on the yield stress of the material and the areas reaucuion of the extruder. The second term describes the flow of the plastic material along the die land. The $\mathrm{k}_{\mathrm{f}}$ term accounts for the increase in the die land wall stress with increasing exirudate velocity.

The first Benbow equation

$$
\Delta P=2 \tau_{y} \ln \frac{D_{0}}{D}+4\left(\frac{l}{D}\right)\left(\tau_{f}+k_{f} V\right.
$$

is applicable in cases for pastes composed of fine rigid particles mixed with a low viscosity liquid. The second Benbow equation,

$$
\Delta P=2 \ln \frac{D_{o}}{D}\left(\tau_{y}+k_{b} V^{\prime \prime}\right)+4 \frac{l}{D}\left(\tau_{f}+k_{f} V^{\prime \prime}\right)
$$

applies in cases of fine rigid particles mixed with a non-Newtonian carrier, such as a polymeric solution. In this case, the shear thinning behavior of the typical polymer necessitates some extra terms. Definitions for variables and constants in the above are: $\Delta P$ is the pressure drop through the extruder, $D_{0}$ is the barrel diameter, $\mathrm{D}$ is the die-land diameter, 
$\tau_{y}$ is the yield strength of the body, $k_{b}$ is a constant dependent on the paste velocity at the die entry, $\mathrm{V}$ is the paste velocity in either the extruder body or die orifice, $\mathrm{n}$ is the power law exponent for the body, $L$ is the die land length, $\tau_{f}$ is the yield strength for adhesion of the paste to the walls of the land (as velocity approaches zero/creeping flow), $\mathbf{k}_{\mathrm{f}}$ is a constant dependent on the paste velocity in the die land, and $m$ is the power law exponent for paste at the die land wall [66].

From an experimentally determined relationship between $k_{f}$ and the fluid viscosity, the thickness of the paste/die land interface layer in a Bingham Plastic was estimated to be from 0.5 to $2.0 \mu \mathrm{m}$, depending on the amount of liquid in the paste [70]. The thickness of this layer seems to be independent of the plastic viscosity of the paste. This tends to discredit Berghaus's contention that flow is mediated by a layer of intermediate viscosity material.

Recently, Zheng et al. reevaluated Benbow's work for extrusion pressure through a square entry die [66]. Using the Hershel-Bulkley model, and computer simulations, they found that the Benbow equation should be modified for the size of the die orifice. This modification takes the form

$$
\Delta P=2 \ln \frac{D_{0}}{D}\left(\tau_{y}+k_{b}\left(\frac{V}{D}\right)^{n}\right)+4 \frac{l}{D}\left(\tau_{f}+k_{f} V^{m}\right)
$$

where all variables and constants are as for the Benbow equation. All this modification does is reflect the increase in pressure needed to move extrudate through a small orifice at some velocity. For a given velocity, it takes more pressure to cause flow through a smaller orifice. Similarly, for an orifice of constant diameter, higher extrudate velocity will be reflected by higher extrusion pressures. They also noted that the exponent ' $n$ ' in the Hershel-Bulkley 
model will be the same as ' $n$ ' in the Benbow equation (assuming that the material obeys the Hershel-Bulkley equation). The shear stress in the Hershel-Bulkley equation was stated to be related to $\tau_{y}$ in the Benbow equation, but the dependence was not given.

A different approach to examination of extrusion is computer modelling of the flow patterns of the process. Generally finite element methods are used. Zienkiewicz and Godbole [73] published the results of such a study in 1974. A square entry die was used to define the boundary conditions. Free slip of the paste at the die walls was assumed. Solutions were presented for steady state flow and elasto-plastic solutions. Both analyses obtained similar results for extrusion pressure. No experimental results were given. The result of the calculation show that it is possible to perform finite element modelling on extrusion as long as the slip conditions are properly constrained. However, as seen in the above discussion, wall slip is constrained by the nature of the paste, and usually has a significant impact on the extrusion pressure. This reflects a major current shortcoming with computer modelling approaches. The mathematical description of the flow behavior of pastes is not sufficiently advanced to permit semi-quantitative assessment of extrusion conditions. As noted above, problems exist with modelling of large strains in particulate systems. Recently, similar work has been performed Carlson et al. [74] using somewhat more sophisticated models, but the analyses still fail to fully reflect processes seen in experimental setups.

As noted above, much of the research performed to date on the flow of ceramic materials has been based on the effects of the microscopic factors of the system, such as paste microtexture (size, shape and orientation of grains), colloidal interactions, and carrier rheology and chemistry. As a result, most flow behavior studies have concentrated on the 
effect of the fluid portion of the ceramic paste. However, ceramic pastes have been shown to have behavior similar to that of water saturated soils [75 - 77].

\section{Soil Mechanics}

Soil mechanics principles have been recently utilized to explain behavior of ceramic pastes di ring forming processes. Soil mechanics takes a continuum approach to the stressstrain relations of the ceramic paste, that is, the paste is considered to be a single uniform body, which responds in a consistent fashion to various loading histories.

The key to understanding the soil mechanics approach is the principle of effective stress. Simply stated, when a stress system is applied to a liquid saturated particulate system, the total stress is carried by both the liquid and the particulate skeleton. As an example, consider the application of a isotropic stress to a liquid saturated body enclosed by an impermeable boundary layer. When stress is applied, little volume change will occur. The liquid in the system will be less compressible than the granular skeleton (the granular skeleton contains pores which allow rigid body motion of the grains relative to one another). Because of this 'weakness' of the granular structure, the liquid carries most of the applied stress. As a result, the fluid pressure in the pores increases as the system is loaded. This system is termed 'undrained'. If the water is allowed to leave the system, i.e if there is no impermeable layer, the system is a 'drained' system. The 'undrained' vs 'drained' concept may be extended to ceramic forming processes. Extrusion and ram pressing may be thought of as undrained processes. Slip casting, tape casting, or filtration are drained operations.

The principle of effective stress may be expressed mathematically as 


$$
\sigma_{T}=\sigma^{\prime}+u
$$

where $o_{\top}=$ total normal stress, $o^{\prime}=$ effective normal stress, and $u=$ pore fluid pressure [78]. Fluids cannot support shear stress, so the effective shear stress = total shear stress, and thus the only force resisting applied shear in drained or undrained bodies is due to particle-particle interaction.

In colloidal systems, the effective stress concept is modified to include capillary forces, double layer phenomena, and Van der Waals forces [75]. The modified effective stress equation then becomes

$$
C=0-u+A-R
$$

where $\mathbf{C}=$ the modified effective stress, $0=$ the externally applied pressure, $u=$ pore pressure, $\mathbf{A}=$ attractive forces, and $\mathbf{R}=$ repulsive forces (e.g. electrostatic repulsion). The microscopic factors, $A$ and $R$, can not be measured easily. They can, however, be manipulated to produce a result which may optimize a forming process. For example, changing the charge on the surface of a colloidal particle by altering $\mathrm{pH}$ or by adding surfactants will allow one to engineer the effective stress of a system. This has important implications for shape forming. If alteration of the surface interactions of the particles in a paste cause the paste to be either flocculated or deflocculated, this will be reflected in the force (e.g. extrusion pressure). 
In shape forming a major concern is the amount of force which must be applied to perform a given operation. We need to be able to describe the yield behavior of the ceramic body. For systems which are dependent on interparticle contacts, such as granular ceramics, yield is plastic in nature, and the Mohr-Coulomb relation

$$
\tau=\sigma^{\prime} \tan \phi+C
$$

has been shown to hold [77]. In this relation $\tau=$ the plastic shear strength, $0^{\prime}=$ the effective normal stress acting on a given plane, $\phi=$ the angle of friction, and $C=$ the cohesion intercept, which is dependent on colloidal surface interactions [78]. The parameters in the Mohr-Coulomb relation define the failure envelope obtained by testing the material at progressively higher axial compression values.

Figure 7 shows a hypothetical biaxial Mohr-Coulomb failure system. The failure criterion is described by a series of Mohr circles. Mohr circles are graphical representations of the relationship between normal and shear stresses at various planes in a test material. $\sigma_{1}$ is the maximum normal stress, and $\sigma_{2}$ and $\sigma_{3}$ are the intermediate and minimum normal stresses respectively. By convention, values to the right of the origin are positive. In axisymmetric cases such as extrusion, $o_{2}=\sigma_{3}$. The shear stress asong any plane oriented at an angle $\theta$ to the direction of principle stress is then as given in Equation 12.

$$
\tau=\frac{\sigma_{1}-\sigma_{2}}{2} \sin 2 \theta
$$

The plane having the maximum shear stress occurs at $\theta=45^{\circ}\left(2 \theta=90^{\circ}\right)$. A series of Mohr circles as shown in Figure 7 possess a series of $\tau_{\max }$ values. The shear stress values define a failure line, which is the Mohr failure envelope. 
The stress on a soil body may be divided into two components. First, there is an isotropic stress. In soils, we are concerned with the mean isotropic stress, or hydrostatic pressure (p). In terms of the principle stresses $\sigma_{i}$,

$$
p=\frac{1}{3}\left(\sigma_{1}+\sigma_{2}+\sigma_{3}\right)
$$

For extrusion, which is typically an axisymmetric system, this reduces to

$$
p=\frac{1}{3}\left(\sigma_{1}+2 \sigma_{3}\right)
$$

I ne second component is the shear stress component is termed the deviator stress (q) [80]

$$
q=\frac{1}{\sqrt{2}}\left(\left(\sigma_{1}-\sigma_{2}\right)^{2}+\left(\sigma_{2}-\sigma_{3}\right)^{2}+\left(\sigma_{3}-\sigma_{1}\right)^{2}\right)^{0 s}
$$

where the $o_{i}$ are again principle stresses. The term deviator stress reflects the deviation of the stress system from ideal isotropic conditions. For the axisymmetric case $\left(\sigma_{2}=\sigma_{3}\right)$, this becomes [80]

$$
q=\sigma_{1}-\sigma_{3}
$$

The strain components which are of interest in soil mechanics are the volumetric strain and the deviatoric strain. The volumetric strain is

$$
\varepsilon_{v}=\varepsilon_{1}+\varepsilon_{2}+\varepsilon_{3}
$$

where the $\varepsilon_{\mathrm{i}}$ are the principle strains. 
The deviatoric strain describes the change in shape (deformation) of the body due to the differences in strain along the principle strain axes, and is given by

$$
\varepsilon_{2}=\frac{\sqrt{2}}{3}\left(\left(\varepsilon_{1}-\varepsilon_{2}\right)^{2}+\left(\varepsilon_{2}-\varepsilon_{3}\right)^{2}+\left(\varepsilon_{3}-\varepsilon_{1}\right)^{2}\right)^{0.5}
$$

where the $\varepsilon_{1}$ are again principle strains. For the axisymmetric case, these become

$$
\varepsilon_{v}=\varepsilon_{1}+2 \varepsilon_{3}
$$

and

$$
\varepsilon_{s}=\frac{2}{3}\left(\varepsilon_{1}-\varepsilon_{3}\right)
$$

The relationship between $\mathbf{p}^{\prime}$ and $\mathbf{q}$ for triaxial compression (undrained testing) of materials such as clays or ceramic pastes may be graphically represented as in Figure 8. There are two distinct regions in the diagram. First, at low p', there is a region with an upper bound defined by the Mohr-Coulomb relation. At higher values of p', there is a curved boundary, which defines a strain hardening cap [80]. The boundaries of the diagram define two cases. Inside the boundaries the material behaves elastically. When a stress history path intersects the boundary, the material will behave plastically. So, if a stress history path intersects the Mohr-Coulomb line, the sample will exhibit a shear hardening response. If the path intersects the curved end cap, the material will tend to liquefy. Several loading histories in such a diagram may be considered $[75,76]$. First, consider the limiting case of loading from the origin (unloaded conditions) to I. This loading 
history is the case of simple shear of the material, with no normal stresses applied to the system. Such a path will result only in changes in the shape of the material. The opposite exureme of this path is from the origin to $\mathrm{V}$, which corresponds to application of hydrostatic pressure. Such a loading path will result only in volumetric changes of the material.

There are three other cases to consider. These are 1) compression along a high $q / p^{\prime}$ path, 2) compression along a high p'/q path, and 3)compression along a path where $p^{\prime} / q=1$. In the case of a high $q / p$ ratio, the path will initially run from the origin to II. Along this path elastic deformation and dilation will occur. If the path would continue along the same line past II, failure of the material will occur. However, the system is confined. Thus, failure does not occur. As the material tries to dilate, a negative pore pressure develops, which forces the stress path toward III (decreasing pore pressure $->$ increased effective normal stress). So, as the shear stress is increased, the material will strain harden and follow the Mohr-Coulomb line to point III.

For the second case above, a path from the origin to IV (or V) will initially result in elastic deformation as reflected by initial consolidation of the paste. Increasing the deviator stress at this point will result in induced shear in the material, increasing the pore pressure, and causing liquefaction. The stress path will the shift in the direction of III. So, in this case, the strain hardening end cap controls the upper limit of material behavior and compaction occurs.

The third case is the case where $p^{\prime} / q=1$. In this case, the material is always in a steady state condition. Perfectly plastic behavior occurs at all points along this line, and the volume of the paste remains constant. 


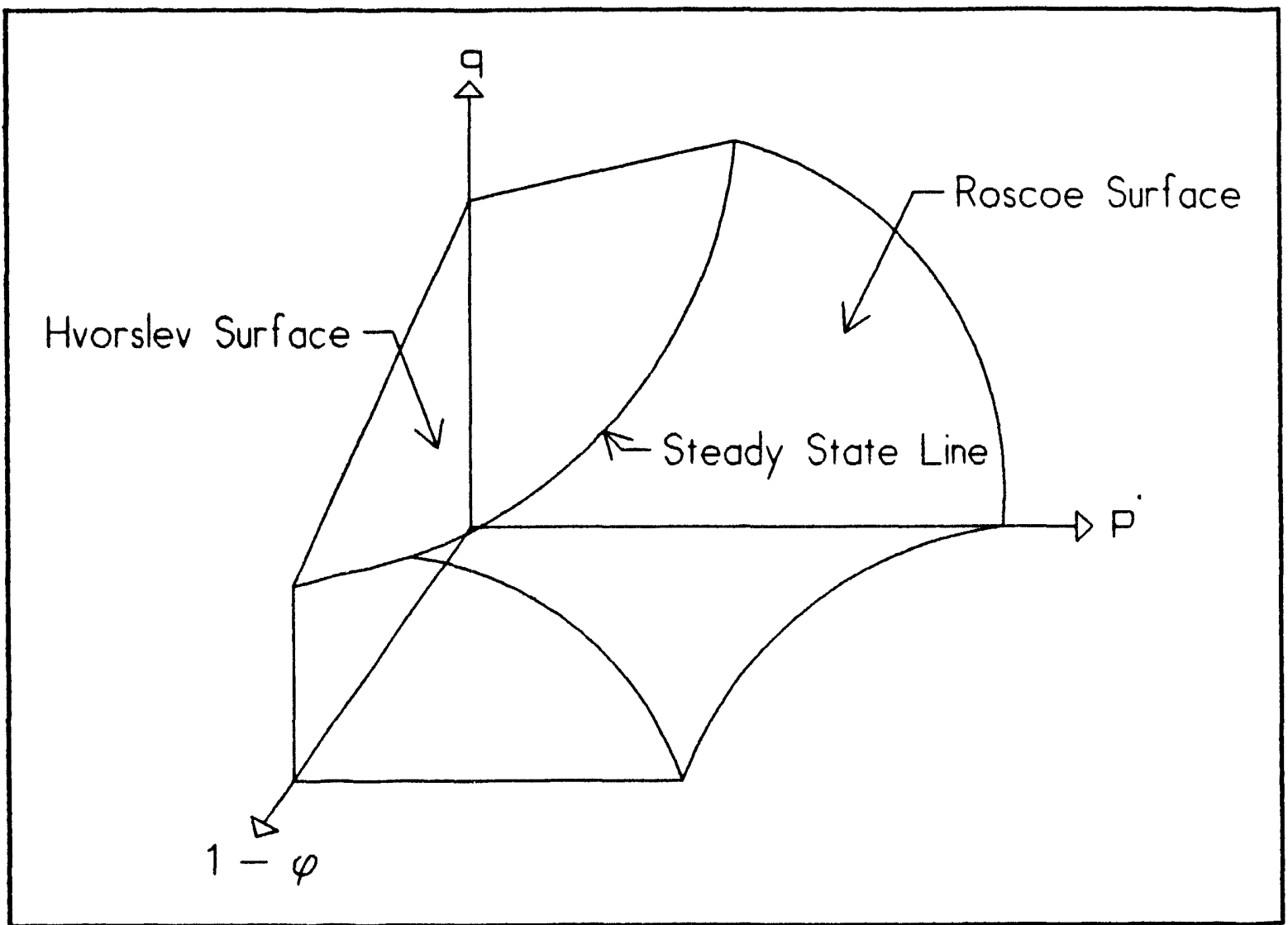

Figure 7. $p^{\prime}-q-(1-\phi)$ diagram for a liquid saturated granular material [76]

It was noted above that the strain exhibited by a material is inversely proportional to the volume fraction of solids in the material. The effect of such behavior on $p^{\prime}-q$ space is shown in Figure 9. As the volume fraction of solids decreases (the p' - q surface moves away from the origin), a lesser relative force is necessary to cause the material to follow a given stress path.

Also seen in Figure 9 are two surfaces: the Roscoe surface and the Hvorslev surface. These surfaces are the traces of the strain hardening end cap and Mohr-Coulomb line, respectively, as the volume fraction solids decreases. Once again, if a stress history path intersects the Hvorslev surface, the material will undergo a dilatant shear hardening behavior 
(brittle shear along a single plane), and it intersects the Roscoe surface, the material will liquefy and flow [76].

Implications for Extrusion

From the above discussion, it is apparent that the level of understanding of the processes which occur during the extrusion of non-clay ceramics is not satisfactory. The number of parameters, including particle size and shape, volume fraction of solids, rheological behavior of the fluid carrier, and stress history of the process all combine to produce a very complex process. At this point in time, the size of the database relating to extrusion of non-clay materials is insufficient to permit accurate prediction of flow behavior of pastes made from such materials. This database will need to be enlarged to permit development of more sophisticated computer models.

Application of soil mechanics principles to extrusion processing have been suggested or implied by several authors $[75,76,79]$. This method seems to have good promise, at least on a continuum mechanics level. Janney suggested that extrusion could be interpreted as liquefaction and steady state flow of an undrained porous particulate body [75]. Schilling showed that it is possible to change the flow behavior of concentrated pastes by altering the stress history path [76]. In general, what is wanted is a stress system in which sufficient liquefaction may be obtained in the extruder to permit flow, but with a system which wiil behave rigidly after leaving the extruder die. 


\section{Conclusion}

The synthesis of ceramic oxide superconductors is, especially in light of their recent discovery, a widely studied field. The level of success of various methods in yielding shaped bodies with optimized superconducting properties, however, is less certain. Most synthetic routes used to produce the $\mathrm{YBa}_{2} \mathrm{Cu}_{3} \mathrm{O}_{7-\mathrm{x}}$ superconductor yield ceramics of less than theoretical density, with critical current capacities 1 - 2 orders of magnitude below the values projected needed for successful application. Many of the problems in these areas may be directly attributed to the chemistry of the $\mathrm{Y}-\mathrm{Ba}-\mathrm{Cu}-\mathrm{O}$ system. The system has peritectic melting behavior, and the common impurity phases are electrically insulating.

The fact that the oxide superconductors are ceramics imposes another set of restrictions on the creation of viable conductor shapes. The brittle nature of ceramics acts to limit the use of the metal forming techniques used to manufacture most of the common conductors in use today. As a result, an unprecedented amount of research has been directed to attempts to produce electrical conductors from the 123 material. Because most of the common synthetic routes used to synthesize the oxide superconductors yield particulaiv systems, ceramic forming techniques such as dry pressing, tape casting, and extrusion have been recently examined.

The main control of the effectiveness of ceramic forming methods in producing conductor shapes is the rheological behavior of the plastic body. Use of conventional rheological models, which were developed for homogeneous fluid systems, has yielded mixed results when applied to particle loaded ceramic pastes. While the basic models provide parameters such as yield stress and viscosity which describe the flow behavior of these pastes, the level of insight which they provide into the inherent nature of ceramic pastes is small. 
For example, little information is accessible from a model such as the Bingham Plastic into the nature of the particulate fraction of a ceramic paste, or into its expected microscopic flow behavior.

The synthesis of superconducting oxides and also the flow behavior of particulate loaded ceramic systems are both new and rapidly developing areas. In order to develop conductor bodies with improved superconducting properties, and to optimize the forming processes needed to make such bodies, much further work will be necessary. 
PAPER I. A NITRATE PRECURSOR TO $\mathrm{YBa}_{2} \mathrm{Cu}_{3} \mathrm{O}_{7-\mathrm{x}}$ FIBERS 


\section{A NITRATE PRECURSOR TO $\mathrm{YBa}_{2} \mathrm{Cu}_{3} \mathrm{O}_{7-\mathrm{x}}$ FIBERS}

Timothy M. Green, R. W. McCallum, and Mufit Akinc Ames Laboratory* and

Department of Materials Science and Engineering

Iowa State University

Ames, Iowa

*Ames Laboratory is operated for the U.S. Department of Energy by lowa State University under Contract No. W-7405-ENG-82. This work was supported in part by the Office of Basic Energy Science. 


\section{ABSTRACT}

Fibers of $\mathrm{YBa}_{2} \mathrm{Cu}_{3} \mathrm{O}_{7-\mathrm{x}}$ have been produced using a low temperature nitrate precursor paste. Molten $\mathrm{Ba}(\mathrm{OH})_{2} \cdot 8 \mathrm{H}_{2} \mathrm{O}$ (m.p. $=78^{\circ} \mathrm{C}$ ), yttrium nitrate solution and crystalline copper nitrate are combined at $90^{\circ} \mathrm{C}$ and mixed to obtain a viscous paste. The rheological properties of the paste are controllable by evaporation of water from the system.

On drying, the paste yields a particulate green body, with an essentially bimodal size distribution. Large $(20.60 \mu \mathrm{m})$ barium nitrate grains are embedded in a finely crystalline matrix of copper hydroxynitrate and yttrium nitrate hydrate. Fibers as long as 1 meter with a $1 \mathrm{~mm}$ diameter were extruded. The presence of the large grains hinders formation of fibers longer than 1 meter.

Magnetometry of the sintered fibers shows a transition temperature of $88 \mathrm{~K}$, with about $50 \%$ flux exclusion. Superconducting properties of the sintered fibers are reduced by the presence of $\mathrm{Y}_{2} \mathrm{BaCuO}_{5}$ impurities and low bulk density. 


\section{INTRODUCTION}

A vast body of research has been devoted to production and characterization of high temperature ceramic superconductors in the past five years [1 -5]. Much of this work has been directed toward enhancement of the physical properties of the superconductors; raising the transition temperature and critical current densities. Optimization of processing parameters to enhance mechanical and electrical properties has also been examined $[5,6]$. Only recently have efforts been directed toward fabrication of shaped bodies. Formation of tapes [7], fibers [8, 9], coils [10], motor parts [11], and electronic devices [12] by various techniques has been examined.

Most research efforts with regard to forming fibers of the $\mathrm{YBa}_{2} \mathrm{Cu}_{3} \mathrm{O}_{7-x}$ (123) superconductor material involve spinning of fibers from sols [13], extrusion of combinations of oxides and various processing additives [14], or encasing oxide powder within metal sheaths [15]. The above processes variously 1) add contaminants which form insulating layers at the grain boundaries, 2) involve several processing steps, or 3) have low yields relative to starting mass.

A technique is presented here which is designed to remedy some of the above problems. Using a low temperature molten salt process [16], a precursor paste of controllable rheological characteristics is produced which can be formed by standard ceramic forming techniques (tape casting, extrusion) to produce rigid, superconducting ceramic shapes. The chemical system is based on nitrates and hydroxides of $\mathrm{Y}, \mathrm{Ba}$, and $\mathrm{Cu}$. No plasticizers or binder additives are needed to form the precursor, though such additives may be beneficial in improving the mechanical behavior of the paste during forming. The paste formed in this process is versatile enough that by adjusting the processing time and conditions, it may lend 
itself to formation of powders (zero dimensional), fibers and rods (one dimensional), sheets (two dimensional) and monoliths (three dimensional). Although no extensive work has been carried out in different chemical systems, the process should be applicable to all cuprate systems containing alkaline earth metals. 


\section{EXPERIMENTAL PROCEDURE}

$\mathrm{Y}(\mathrm{NO})_{3}{ }^{1}$ aqueous solution $\left(2\right.$ mole $\left.\mathrm{L}^{-1}\right), \mathrm{Ba}(\mathrm{OH})_{2} \cdot 8 \mathrm{H}_{2} \mathrm{O}^{2}$ (m.p. $78^{\circ} \mathrm{C}$ ), and $\mathrm{Cu}\left(\mathrm{NO}_{3}\right)_{2} \cdot 2 \frac{1}{2} \mathrm{H}_{2} \mathrm{O}^{3}$ (m.p. $\left.114^{\circ} \mathrm{C}\right)$ are combined in a molar ratio of $1: 2: 3(25 \mathrm{ml}, 31.5$ grams, and 34.9 grams respectively). Molten barium hydroxide is heated to $90^{\circ} \mathrm{C}$ with constant stirring to minimize resolidification at the air-melt interface. An oil bath is used to maintain temperature control. The yttrium nitrate solution is added dropwise to the molten barium salt. Copper nitrate is added to the yttrium-barium solution as either crystalline reagent or in aqueous solution. The order of addition of the yttrium and copper reagents has no effect on the composition of the final product. The resulting mixture was heated with constant stirring. Heating of the paste is continued until the paste reaches the desired consistency for shape forming.

The chemistry of the precursor was examined by several techniques. The phases present in the green body material were determined by powder $x$-ray diffraction (XRD) ${ }^{4}$. Binary mixtures of yttrium nitrate and barium hydroxide, and copper nitrate and barium hydroxide were prepared to aid in elucidating the phases formed during processing. These samples were dried at $110^{\circ} \mathrm{C}$, ground to -200 mesh, and examined by powder XRD.

Simultaneous DTA/TGA ${ }^{5}$ was performed in dynamic oxygen ${ }^{6}$ and argon 7

\footnotetext{
${ }^{1} \mathrm{Y}_{2} \mathrm{O}_{3}, 99.99 \%$ (Molycorp, Inc., Louviers, $\mathrm{CO}$ ), in $\mathrm{HNO}_{3}, \mathrm{AR}$ Grade, (Mallinckrodt Specialty Chemicals Co., Paris, KY)

${ }^{2}$ Assay $100.4 \%$, Reagent Grade (Fisher Scientific, Fair Lawn, NJ)

${ }^{3}$ Assay $98.2 \%$, Reagent Grade (Fisher Scientific, Fair Lawn, NJ)

${ }^{4}$ LC500 Diffractometer (Siemens Analytical X-Ray Instruments, Madison, WI)

${ }^{5}$ TG/DTA 300 (Seiko Instruments USA, Inc., Torrance CA)
} 
atmospheres to determine the temperatures of phase changes in the system, and to act as a guide to firing conditions. Gas flow rates for both gases were $70 \mathrm{cc} / \mathrm{min}$. Temperature ramp rates for all samples were $10^{\circ} \mathrm{C} / \mathrm{min}$. Thermal analyses performed in flowing oxygen permit determination of maximum melting point for the system, which may be correlated with the equilibrium conditions of the bulk composition of the $\mathrm{Y}_{2} \mathrm{O}_{3}, \mathrm{BaO}, \mathrm{CuO}$ system [17].

Scanning electron microscopy ${ }^{8}$ with secondary (SEM) and backscattered (SEM/BS) imaging ${ }^{9}$ and $x$-ray energy dispersive spectroscopy (EDS) ${ }^{10}$ were used to examine the microstructure and chemistry of the paste and paste components. SEM mounts were prepared by two methods. In the first, green fibers were mounted to a graphite stub with a colloidal graphite cement to permit examination of the green fiber surface. The mounts were sputtered with gold to minimize charging effects. For the second method, in order to permit examination of possible radial texture changes in the fiber, green fibers were mounted in a conducting silver epoxy. These mounts were then ground and polished to permit examination of a cross-section of the fiber. Mounts prepared in this fashion had sufficient charge dispersion and needed no sputtered conductive coating.

The paste rheology was examined as a function of processing time using concentric

${ }^{6}$ Zero grade, $99.8 \%$ (Air Products, Allentown, PA)

'Zero grade, 99.998\% (Air Products, Allentown, PA)

${ }^{8}$ Stereoscan 200 (Cambridge Inst., Cambridge, England)

${ }^{9} \mathrm{~K}$ E Developments, Cambridge, England

${ }^{10}$ TN 5500 (Noran, Inc., Middleton, WI) 


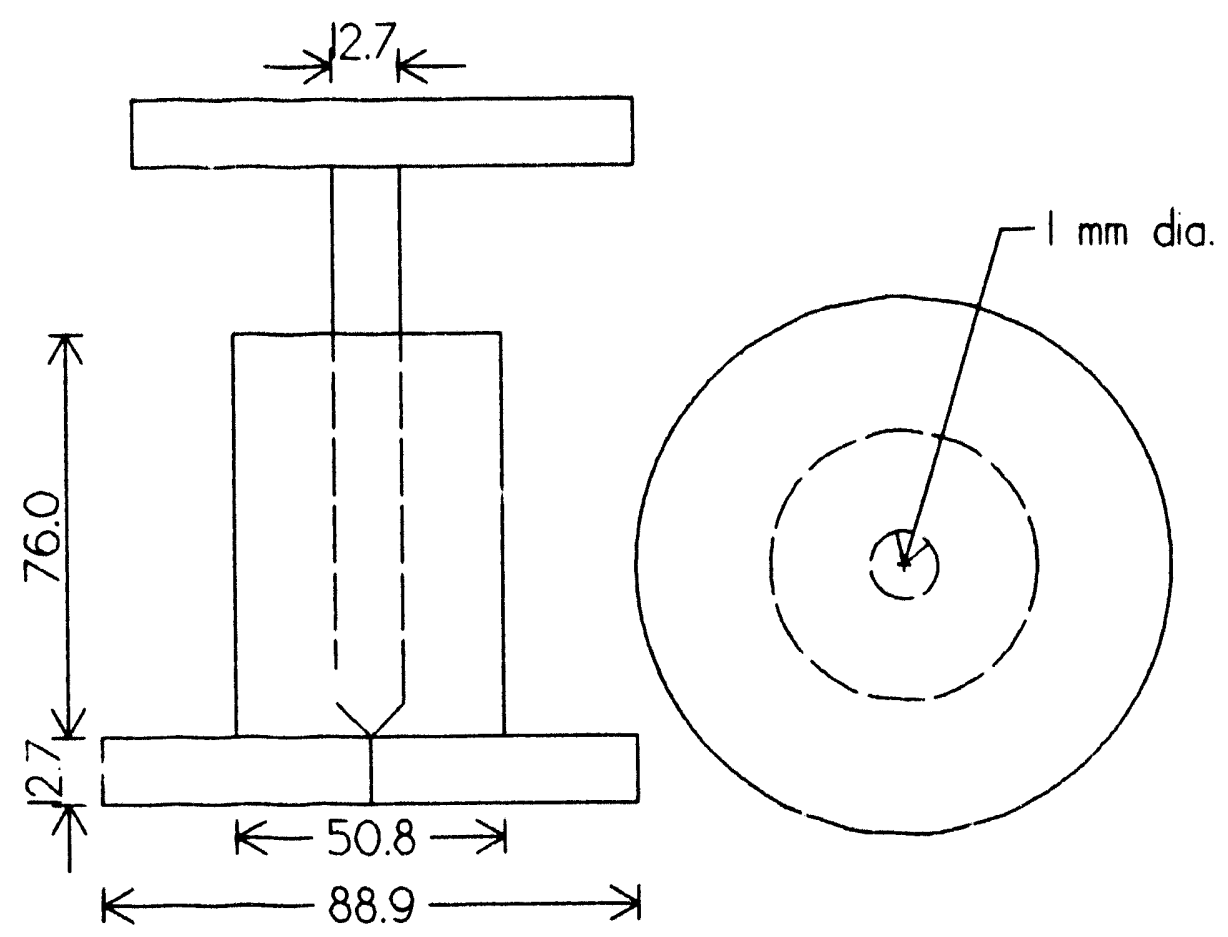

Figure 1. Schematic drawing of ram extruder. All parts constructed from stainless steel. All dimensions in millimeters.

cylinder rheometry " ${ }^{11}$. Flowcurves were messured over a strain rate range of $0-200 \mathrm{sec}^{-1}$, permitting determination of initial yield stress and viscosity as a function of strain rate. All analyses were duplicated to ensure mean values for rheological parameters, and to ensure that batch-to-batch variations were insignificant.

The paste is formed into $1 \mathrm{~mm}$ diameter fibers by ram extrusion. The extruder consists of a $12.5 \mathrm{~mm}$ barrel, with a $45^{\circ}$ die semi-angle, and a $1 \mathrm{~mm}$ orifice with a die land length of $2 \mathrm{~mm}$ (Figure 1). The applied load is typically $10 \mathrm{~kg}$. Ram travel velocities are on the order of $2.5 \mathrm{~cm} / \mathrm{min}$. The fibers are extruded onto a poly(tetrafluoroethylene) (PTFE)

${ }^{11}$ Physica Rheolab MC10 (Physica USA, Spring, TX) 
sheet to eliminate adhesion of the plastic and green fibers onto the substrate. After forming, the fibers are oven dried at $105^{\circ} \mathrm{C}$ for 24 hours. The green fibers are then calcined and sintered in flowing oxygen ${ }^{6}$ in a tube furnace. Oxygen flow rate is $100 \mathrm{cc} /$ minute. The firing schedule was: 1) ramp from room temperature to the desired sintering temperature at $2^{\circ} \mathrm{C} /$ minute, 2) sinter for 4 hours at the peak temperature (typically $940^{\circ} \mathrm{C}$ ), 3) ramp down to $450^{\circ} \mathrm{C}$ at a rate of $5^{\circ} \mathrm{C} /$ minute, 4) hold for 24 hours at $450^{\circ} \mathrm{C}$ to provide an oxygen anneal, and 5) ramp to room temperature at furnace cooling rates.

Phases present in the fired material were examined by powder XRD. Reflected light microscopy was used to examine the microstructure and to identify impurity phases, if any. The fired fibers were prepared as cross-sections for optical light microscopy in the same manner as for SEM samples discussed above. Transition temperature measurements were performed by magnetometry ${ }^{12}$. 


\section{RESULTS}

Processing of the ternary mixture produced by the above procedure results in a multiphase, viscous blue paste. The paste is macroscopically smooth, and shows no inclusions. The inherent hygroscopic nature of the paste acts to hinder drying under normal laboratory conditions, so the paste maintains workability for extended periods.

\section{Paste Chemistry}

Powder XRD of the dried paste shows the presence of two phases: $\mathrm{Ba}(\mathrm{NO})_{3}$ and $\mathrm{Cu}_{2}(\mathrm{OH})_{3} \mathrm{NO}_{3}$. XRD shows no peaks which may be assigned to a yttrium containing phase (Figure 2).

In order to attempt to determine the identity of the yttrium phase, the binary system $\mathrm{Y}\left(\mathrm{NO}_{3}\right)_{3}$ (eq.) $-\mathrm{Ba}(\mathrm{OH})_{2}$ was examined. The barium salt and yttrium solution were mixed in a 1:2 molar ratio, and processed to dryness. XRD shows the resulting material to contain $\mathrm{Ba}\left(\mathrm{NO}_{3}\right)_{2}$ and $\mathrm{Y}(\mathrm{OH})_{3}$ (Figure 3). If present in the ternary mixture, crystalline $\mathrm{Y}(\mathrm{OH})_{3}$ should be detectable by $x$-ray diffraction. To explain the absence of the yttrium hydroxide we examined the pH history of the paste forming process.

Measurement of the $\mathrm{pH}$ of the ternary solution after combination of the barium and yttrium reactants, and after addition of the copper nitrate gave values of $\sim 10$ and $\sim 3$, respectively. The drop in $\mathrm{pH}$ from 10 to 3 takes the solution out of the stability regime $(\mathrm{pH}$ $>$ 6) for $\mathrm{Y}(\mathrm{OH})_{3}$ precipitation [18], and the yttrium hydroxide is resorbed. The yttrium ions in solution may then react with the other anions present in the paste solution. We assume that the final yttrium phase in the ternary is $x$-ray amorphous yttrium nitrate iydrate. If crystalline, based on stoichiometry, the yttrium nitrate hydrate phase should be present in 


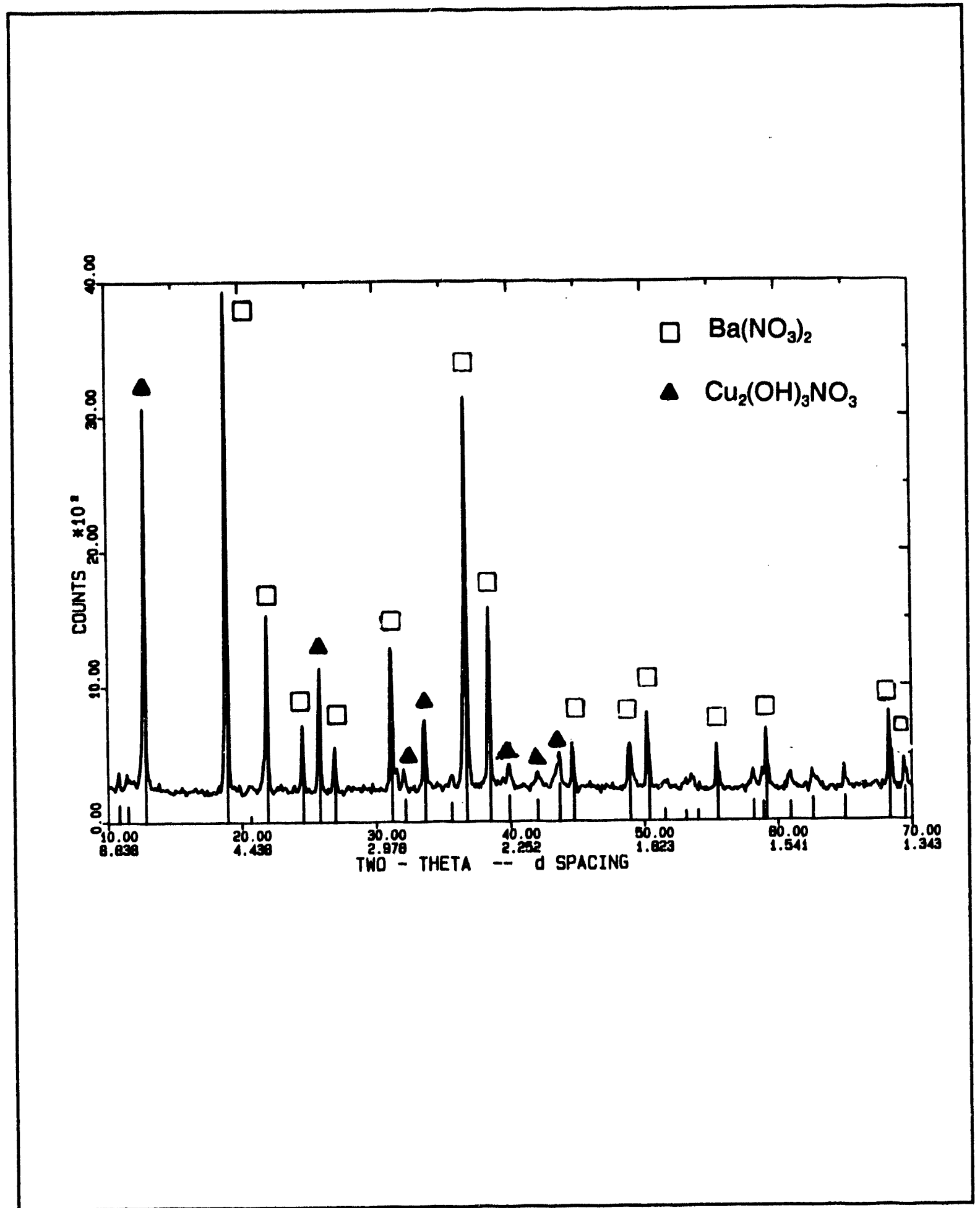

Figure 2. X-ray diffraction pattern of dried nitrate precursor paste. Phase identification as per the graph legend. Radiation $=\mathrm{Cu}-\mathrm{K} \alpha$ 


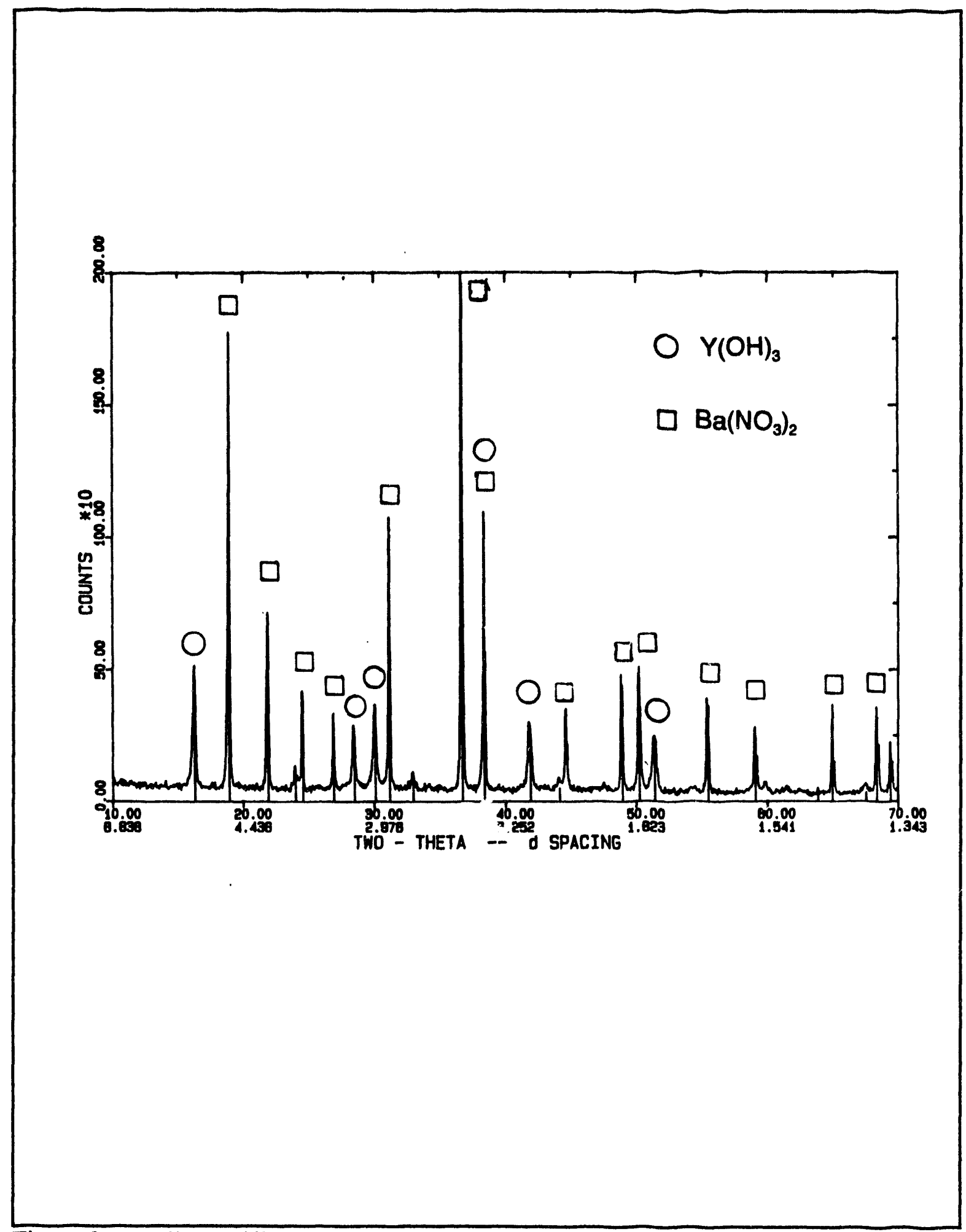

Figure 3. X-ray diffraction pattern of $\mathrm{Y}\left(\mathrm{NO}_{3}\right)_{3}+\mathrm{Ba}(\mathrm{OH})_{2}$ binary mixture product 
sufficient quantities to produce measurable diffraction maxima. However, Holcombe et al. [19] state that yttrium hydroxynitrate salts possess low diffracting power, due to the high percentage of low atomic number species and low crystal densities. This may explain the apparent lack of diffraction peaks for the yttrium phase if it is crystalline. Thermal analysis of the powder, discussed below, adds evidence that the yttrium phase is a yttrium nitrate hydrate.

\section{Thermal Analysis}

Simultaneous DTA/TGA was performed on the precursor in oxygen at a heating rate of $10^{\circ} /$ minute. The thermal analysis shows TGA decomposition events at $108^{\circ}, 154^{\circ}$, $228^{\circ}, 303^{\circ}, 462^{\circ}$ and $594^{\circ} \mathrm{C}$ (Figure 4). Table 1 gives a summary of the thermal history.

Table 1. Thermogravimetric analysis of nitrate precursor material. Heating rate = $10^{\circ} \mathrm{C} /$ minute. Dynamic oxygen atmosphere $-100 \mathrm{cc} /$ minute

\begin{tabular}{|c|c|c|c|}
\hline $\begin{array}{l}\text { Temp. } \\
\left({ }^{\circ} \mathrm{C}\right)\end{array}$ & $\begin{array}{l}\text { Weigh } \\
\text { Actual }\end{array}$ & $\begin{array}{l}\text { Loss } \\
\text { Theor. }\end{array}$ & Probable reaction \\
\hline 108 & 5.3 & 2.9 & $\mathrm{Y}\left(\mathrm{NO}_{3}\right)_{3} \cdot 5 \mathrm{H}_{2} \mathrm{O} \rightarrow \mathrm{Y}\left(\mathrm{NO}_{3}\right)_{3} \cdot 3 \mathrm{H}_{2} \mathrm{O}$ \\
\hline 154 & 2.4 & 2.9 & $\mathrm{Y}\left(\mathrm{NO}_{3}\right)_{3} \cdot 3 \mathrm{H}_{2} \mathrm{O}-\mathrm{Y}\left(\mathrm{NO}_{3}\right)_{3} \cdot \mathrm{H}_{2} \mathrm{O}$ \\
\hline 228 & 9.2 & 9.7 & $3 / 2 \mathrm{Cu}_{2}(\mathrm{OH})_{3}\left(\mathrm{NO}_{3}\right)-3 \mathrm{CuO}$ \\
\hline 303 & 10.1 & 10.1 & $\mathrm{Y}\left(\mathrm{NO}_{3}\right)_{3} \cdot \mathrm{H}_{2} \mathrm{O}-\mathrm{YONO}_{3}$ \\
\hline 462 & 5.8 & 4.3 & $\mathrm{YONO}_{3} \rightarrow 1 / 2\left(\mathrm{Y}_{2} \mathrm{O}_{3}\right)$ \\
\hline 594 & 14.4 & 17.3 & $2 \mathrm{Ba}\left(\mathrm{NO}_{3}\right)_{2}-2 \mathrm{BaO}$ \\
\hline & 49.2 & 47.2 & \\
\hline
\end{tabular}


Assignment of the phases for the listed thermal events is based on comparison of calculated and measured weight losses for each proposed phase change. When possible, the identities of the phases have been verified by XRD (Table II) [24], or in the case of the yttrium phases, after Holcombe [19].

The endothermic event and weight loss $(5.3 \%)$ at $108^{\circ} \mathrm{C}$ are assigned to initial

Table II. Identification of phases detected by XRD for nitrate precursor calcined in air. Temperatures used are transition temperatures from TG/DTA. Air flow rate $=100 \mathrm{cc} / \mathrm{minute}$

\begin{tabular}{|c|l|}
\hline $\begin{array}{c}\text { Temp. } \\
\left({ }^{\circ} \mathrm{C}\right)\end{array}$ & \multicolumn{1}{|c|}{ Phases identified by XRD } \\
\hline \hline 108 & $\mathrm{Cu}_{2}(\mathrm{OH})_{3} \mathrm{NO}_{3}, \mathrm{Ba}\left(\mathrm{NO}_{3}\right)_{2}$ \\
\hline 154 & $\mathrm{Cu}_{2}(\mathrm{OH})_{3} \mathrm{NO}_{3}, \mathrm{Ba}\left(\mathrm{NO}_{3}\right)_{2}$ \\
\hline 228 & $\mathrm{Ba}\left(\mathrm{NO}_{3}\right)_{2}, \mathrm{CuO}$ \\
\hline 303 & $\mathrm{Ba}\left(\mathrm{NO}_{3}\right)_{2}, \mathrm{CuO}, \mathrm{YONO}_{3}$ \\
\hline 462 & $\mathrm{Ba}\left(\mathrm{NO}_{3}\right)_{2}, \mathrm{CuO}, \mathrm{Y}_{2} \mathrm{O}_{3}$ \\
\hline 594 & $\mathrm{YBa}_{2} \mathrm{Cu}_{3} \mathrm{O}_{7}, \mathrm{CuO}, \mathrm{Y}_{2} \mathrm{O}_{3}, \mathrm{Ba}_{2} \mathrm{Y}_{2} \mathrm{O}_{4}$ \\
\hline
\end{tabular}

dehydration of the precursor paste. The excess weight loss over the theoretical value obtained assuming the initial phase is yttrium nitrate pentahydrate is probably due to a mixed hydration state; some of the yttrium nitrate may exist as a hexahydrate. At $154^{\circ} \mathrm{C}$, dehydration from yttrium nitrate trihydrate to yttrium nitrate monohydrate occurs (weight loss $=2.1 \%$ ) [21]. Copper hydroxy nitrate decomposes to cupric oxide at $228^{\circ} \mathrm{C}$ [22]. The next two events are 
changes in the yttrium phase. At $303^{\circ} \mathrm{C}$, yttrium nitrate monohydrate dehydrates and partially denitrogenates to yttrium oxynitrate. This phase then decomposes to yttrium oxide at $462^{\circ} \mathrm{C}$ [21]. Finally, at $594^{\circ} \mathrm{C}$ barium nitrate decomposes to barium oxide with a $16.2 \%$ weight loss [23]. The low actual weight loss suggests that this reaction probably begins prior to $594^{\circ} \mathrm{C}$, but is undetectable by the instrument. The liquid forming reaction of barium oxide, yttrium oxide and copper oxide in oxygen occurs in this system at around $980^{\circ} \mathrm{C}$. Examination of the phase relations for the bulk composition melting at this temperature shows this composition must contain some phases other than $123[17,20]$. This is further reflected by the endothermic events around $900^{\circ} \mathrm{C}$, which are probably due to partial melting of some of the reactant oxides, and the concurrent formation of $\mathrm{Y}-\mathrm{Ba}-\mathrm{Cu}$ phases other than 123 . $\mathrm{X}$-ray analyses of the products at each step listed above are given in Table 2. The $\mathrm{YBa}_{2} \mathrm{Cu}_{3} \mathrm{O}_{7}$ phase appears by $600^{\circ} \mathrm{C}$, but is accompanied by $\mathrm{CuO}, \mathrm{Y}_{2} \mathrm{O}_{3}$, and $\mathrm{BaY}_{2} \mathrm{O}_{4}$.

\section{Microstructure of the Dry Paste}

Electron microscopy of the dried precursor shows the material to have a granular microstructure and to have a generally bimodal size distribution. Figure 5 shows a fracture surface of the dried precursor to contain large, well-formed euhedral crystals, in a fine crystalline matrix [24]. Occasionally the matrix material coats the large crystals, suggesting that precipitation of the large grains is completed while the matrix material is still precipitating. EDS of the large grains shows barium to be the only cation present. The large, barium-containing grains range in size from $20-60 \mu \mathrm{m}$. Examination of the fine matrix material by EDS shows the presence of only copper and yttrium. The matrix consists of particies about $1 \mu \mathrm{m}$ in size. Backscattered imaging (Figure 6) [24] confirms the segregation 


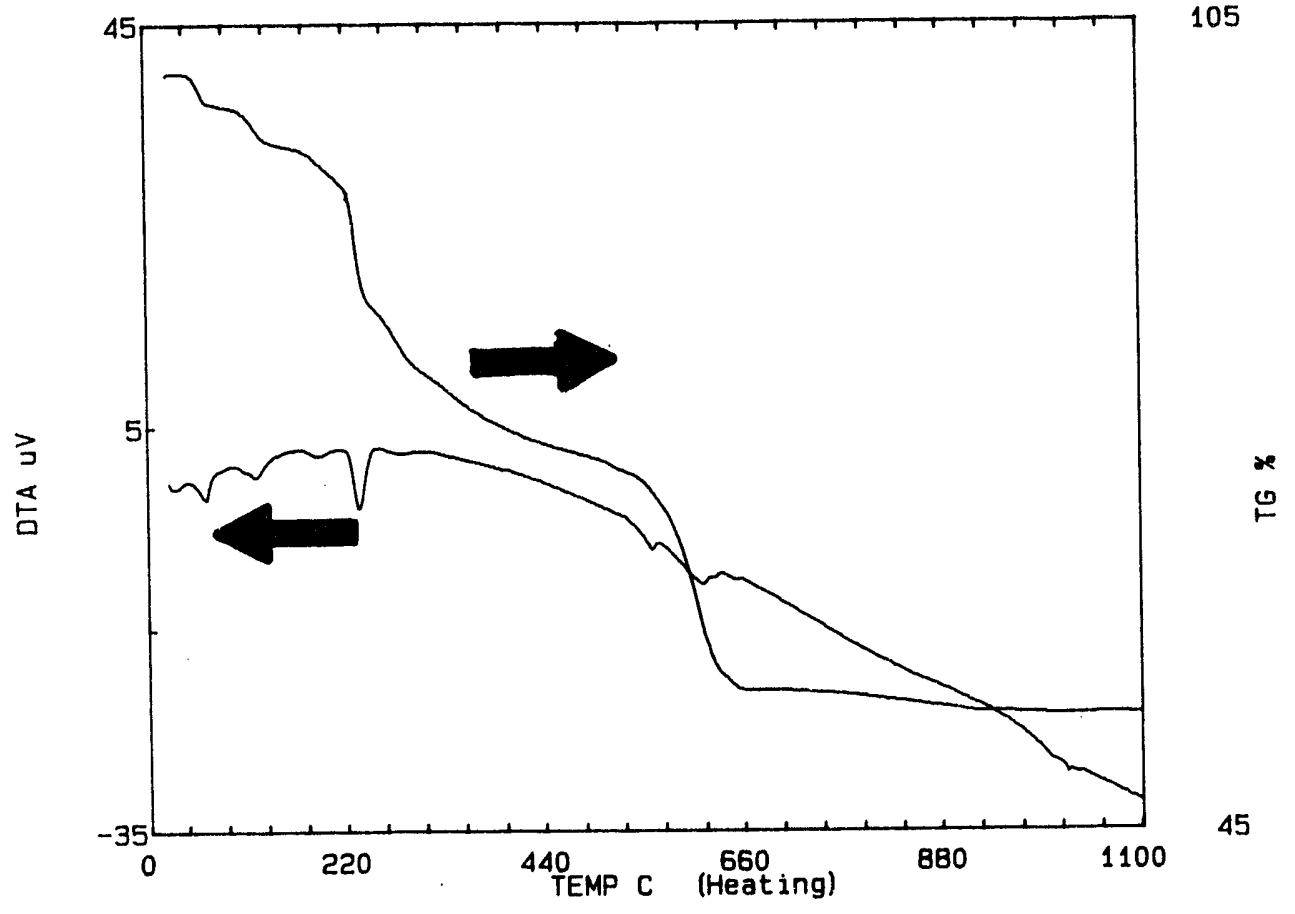

Figure 4. TG/DT analysis of dried nitrate precursor paste in dynamic oxygen. Heating rate $=10^{\circ} \mathrm{C} /$ minute. Oxygen flow rate $=70 \mathrm{cc} /$ minute 


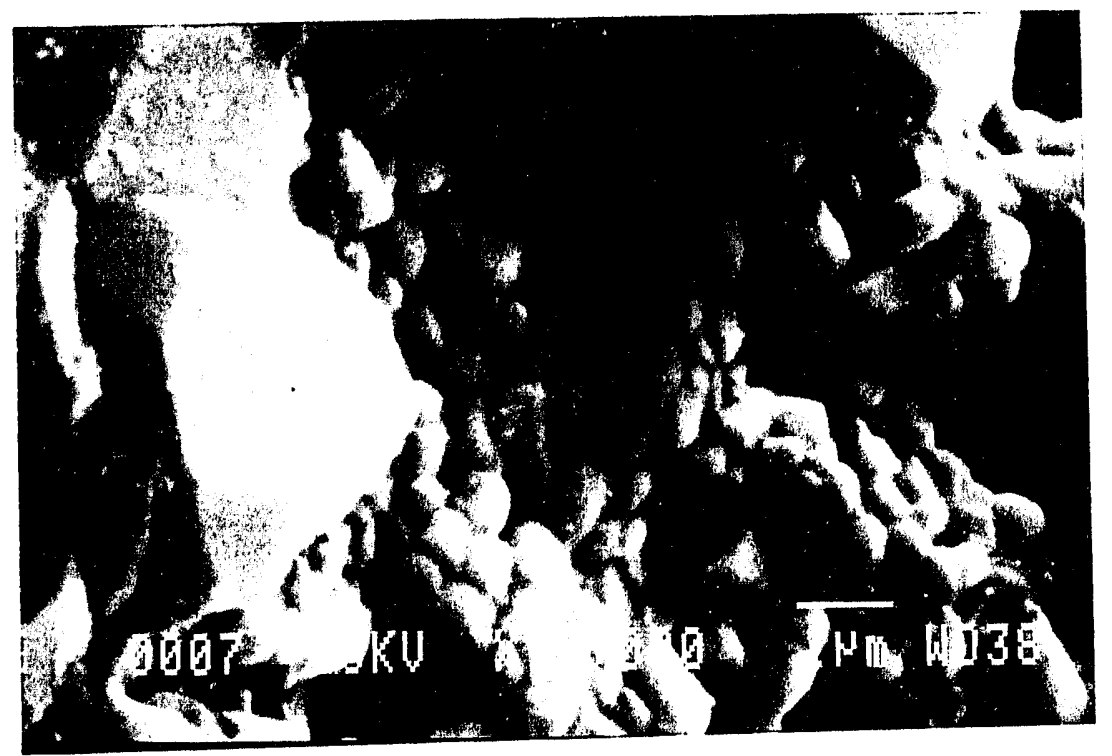

Figure 5. SEM micrograph fracture surface of dried nitrate presursor paste. Note large, euhedral barium nitrate grains in finely crystalline $\mathrm{Y}$ - Ba salt matrix 
of barium from yttrium and copper, as well as showing the highly intimate mixing of the yttrium and copper in the matrix material.

\section{Paste Rheology}

Rheological measurement shows the paste to be non-Newtonian, possessing a yield stress and shear-thinning behavior. Figure 7 shows a typical flowcurve of a sample processed for 120 minutes at $90^{\circ} \mathrm{C}$. The strain rate range for this example is $0-200 \mathrm{sec}^{-1}$. Flowcurves for a single analysis shows large discontinuities at low strain rates. These fluctuations are attributed to frictional effects in the paste, probably arising from interaction of large grains in the paste, and/or breakup of the colloidal matrix with continued shear. Other experiments show the paste thins with time when held at a constant strain rate of 100 or $200 \sec ^{-1}$, i.e., it is thixotropic. For paste processed for 120 minutes, the yield stress is $-1500 \mathrm{~Pa}$. An averaged flowcurve shows a good statistical fit $\left(R^{2}=.98\right)$ to a Hershel-Bulkley model with yield stress $=1472 \mathrm{~Pa}$ and flow exponent $=0.259$.

\section{Extrusion}

Extrusion of the paste is performed by ram extruder. Extrusion of the paste through a $1 \mathrm{~mm}$ orifice was erratic, but continuous fibers as long as 1 meter were produced. The plastic fibers were not perfectly uniform in cross section, local restrictions in diameter down to $0.7 \mathrm{~mm}$ are common. There are often large grains near the points where the plastic fiber failed. Extruder lockup is fairly common. This behavior is attributed to bridging of large grains over the orifice. If the blockage is cleared from the orifice, flow is re-established. Increases in the applied load up to $50 \mathrm{~kg}$ during extruder lockup result in expression of fluid 


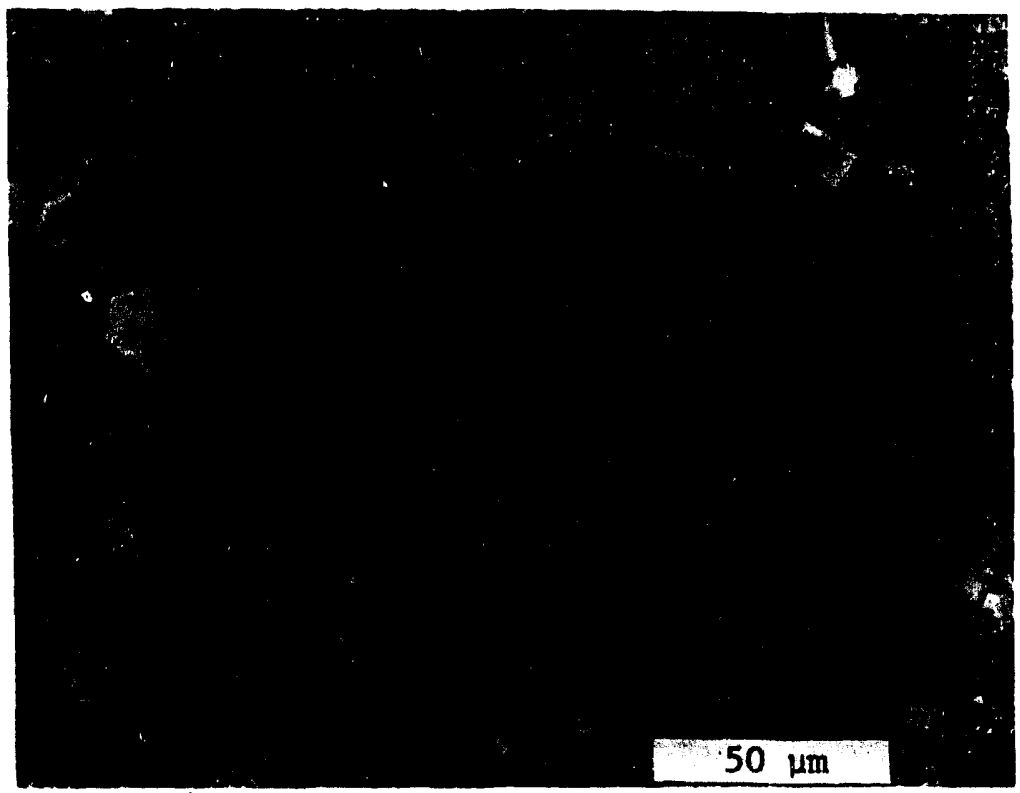

Figure 6. SEM micrograph of dried nitrate precursor material. Backscattered electron image. The matrix has uniform contrast, suggesting homogeneous composition. The large barium-rich grains show significant contrast difference 


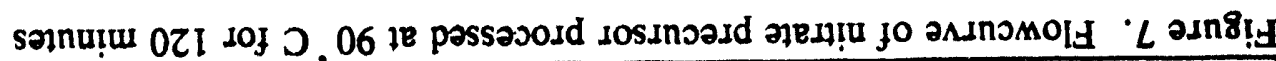

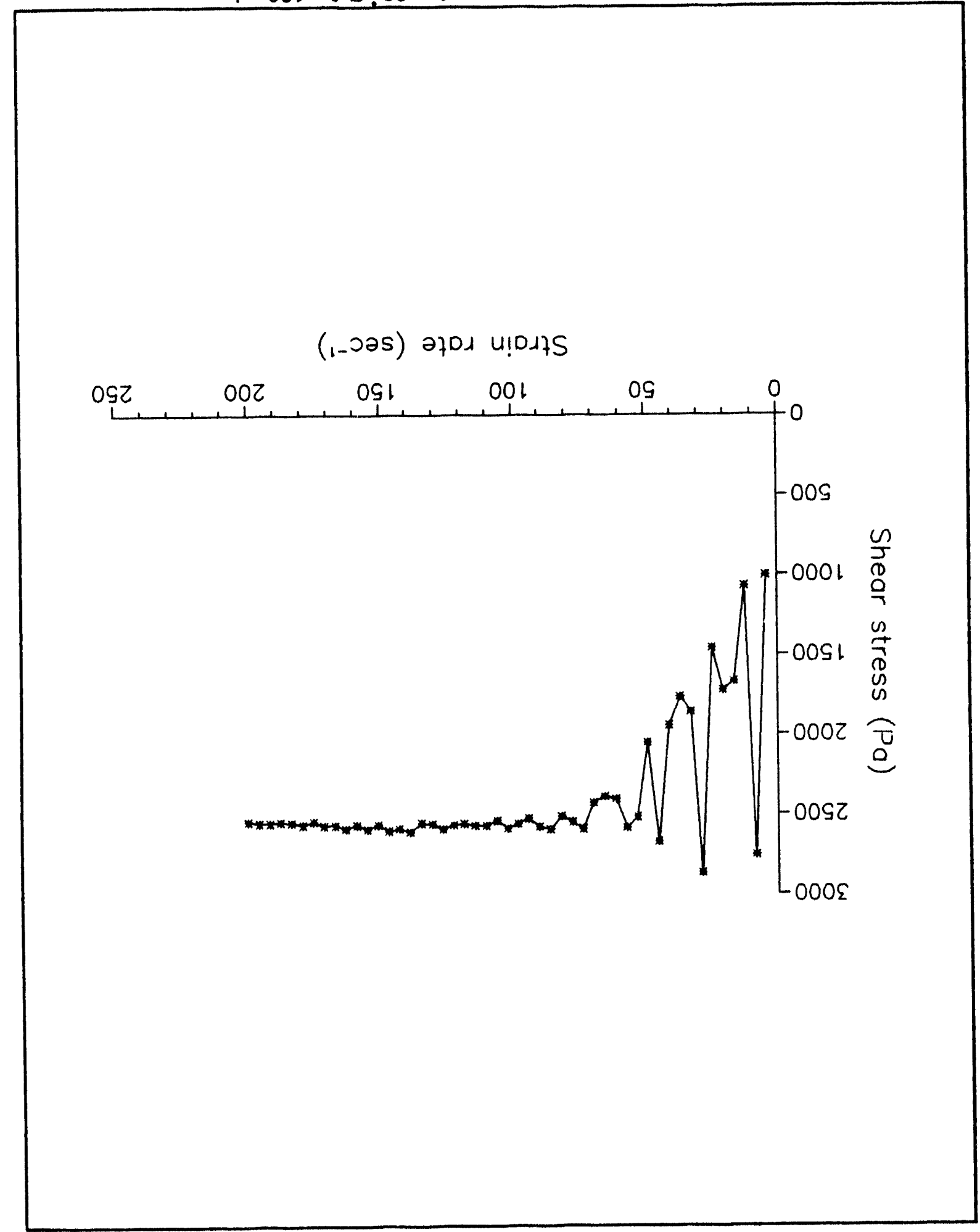


from the paste, but no bulk flow. Grinding of the paste in a mortar and pestle prior to extrusion improves the extrudability of the paste somewhat. This improvement is attributed to reduction of the barium nitrate grain size, and the accompanying increase in homogeneity of the paste.

The optimum processing time was chosen to be the minimum time needed for the fibers to be self-supporting. Processing times from 2 to 2.5 hours gave good results while permitting extrusion to occur at low applied loads. The fibers show only slight slumping after extrusion. Contact with the PTFE substrate usually produces a flat surface with a width less than $25 \%$ of the diameter. Typical strain ratec at the axis of the extruder relative to the wall of the extruder body are around $10 \mathrm{sec}^{-1}$. A typical green fiber is shown in Figure 8. Large barium nitrate grains in the subsurface of the fiber are apparent. The flat section is where the plastic fiber contacted the PTFE substrate. Examination of sectioned freshly extruded fibers shows that there is some annular grain segregation, with the surface consisting of finer material than the more coarsely crystalline center.

\section{Sintering}

Sintered fibers are black and quite brittle. The highest fired bulk density of the fibers observed is $5.10 \mathrm{~g} / \mathrm{cm}^{3}\left(81 \%\right.$ theoretical, based on $\left.\rho_{123}=6.35 \mathrm{~g} / \mathrm{cm}^{3}\right)$. Measured apparent density of the sintered material is $5.78 \mathrm{~g} / \mathrm{cm}^{3}$ (91\% theoretical). The fired material is spongy in appearance (Figure 9), with dense regions separated by regions of high porosity. Linear shrinkage is estimated to be about $20 \%$. The fibers tend to warp on firing.

The composition of the sintered material was examined by XRD and reflected light microscopy. X-ray diffraction shows the material to be 'pure' 123 (Figure 10). This is in 


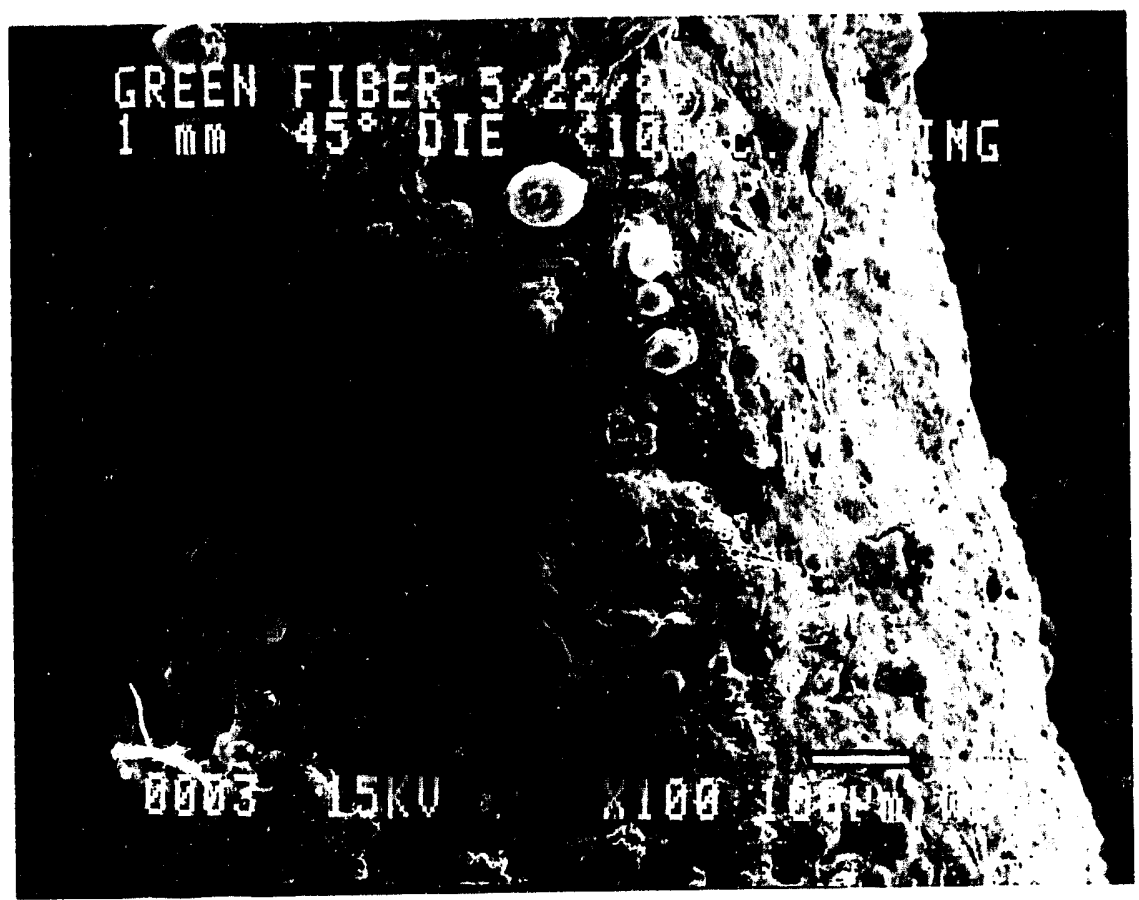

Figure 8. SEM micrograph of $1 \mathrm{~mm}$ fiber extruded using the nitrate precursor paste 


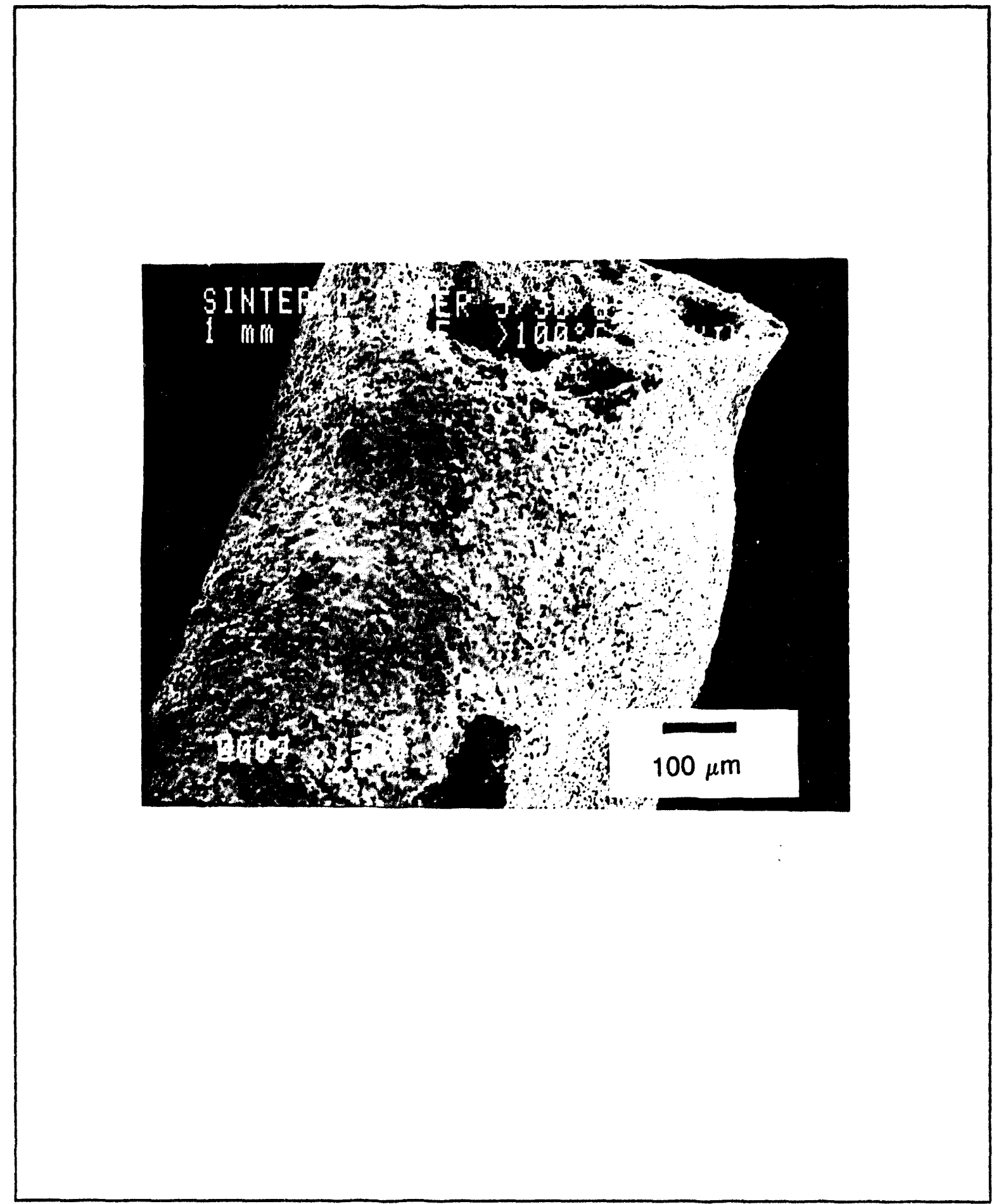

Figure 9. SEM micrograph of sintered $\mathrm{YBa}_{2} \mathrm{Cu}_{3} \mathrm{O}_{7-x}$ fiber produced from nitrate precursor. Fiber fired at $940^{\circ} \mathrm{C}$ for 4 hours. Note the spongy internal texture and surface microcracking 


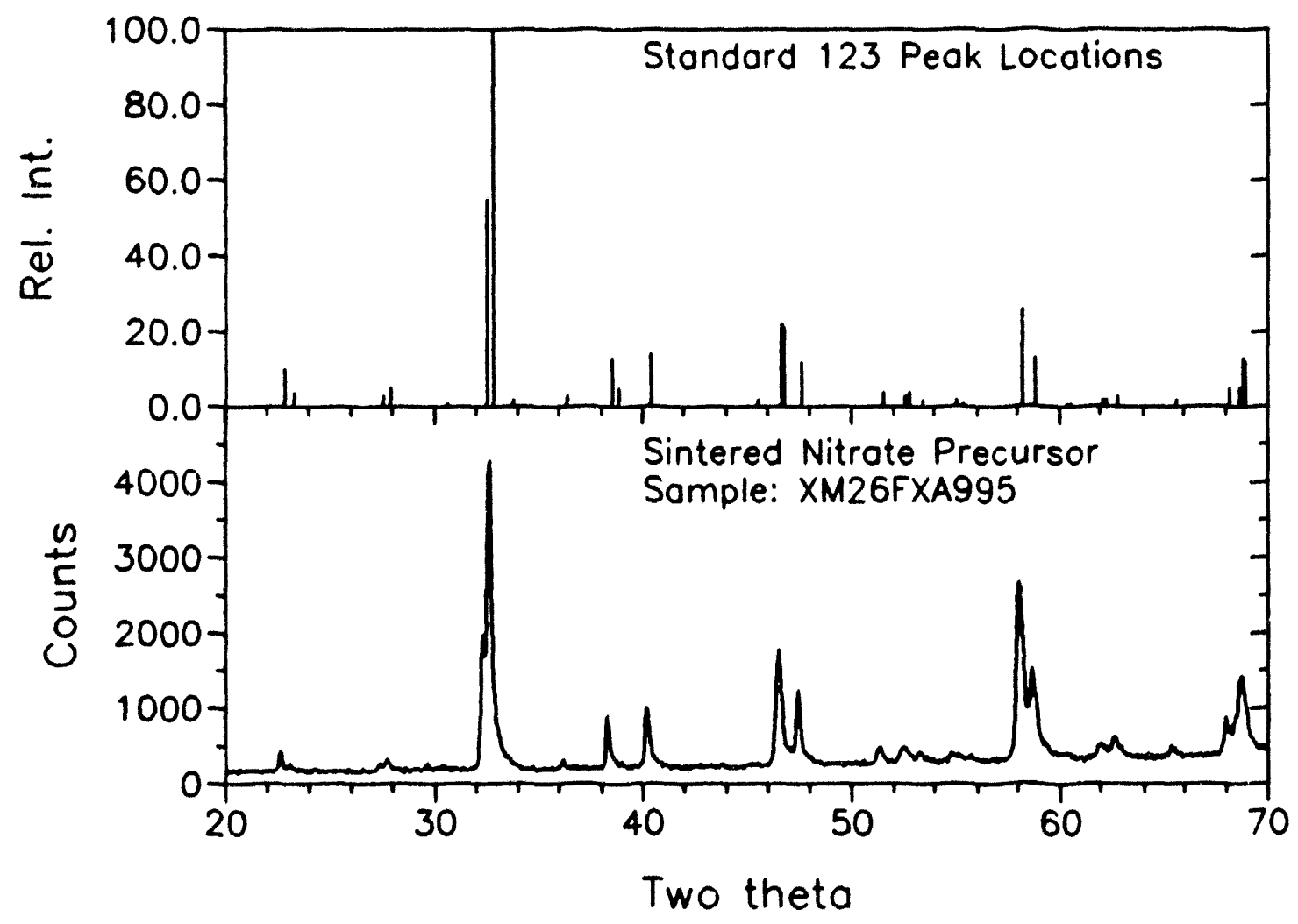

Figure 10. (Upper) Standard $\mathrm{YBa}_{2} \mathrm{Cu}_{3} \mathrm{O}_{7-\mathrm{x}}$ reference pattern and (Lower) X-ray diffraction pattern of sintered nitrate precursor 
contrast to impurities suggested by optical analysis. There is a slight systematic peak shift in the XRD pattern of the sintered nitrate material, consistent with a minor misalignment of the instrument. Optical microscopy was used to check the phase purity of the fibers. Reflected light microscopy reveals the presence of the green, insulating $\mathrm{Y}_{2} \mathrm{BaCuO}_{5}(211)$ phase. Based on areal extent of the 211 phase, the 211 content is estimated at $2 \%$ by volume.

\section{Magnetometry}

SQUID magnetometry was performed to ensure that the fibers were superconducting and to determine the transition temperature (Figure 11). Field cooled and zero field cooled magnetization experiments were performed. A critical transition temperature of $88 \mathrm{~K}$ was determined at $10 \%$ of the saturation value for cooling in a 50 Oe field. The width of the transition is $10.6 \mathrm{~K}$ between $10 \%$ and $90 \%$ of the field cooled saturation value. The sample also shows the Meissner effect, with about $50 \%$ flux exclusion. 


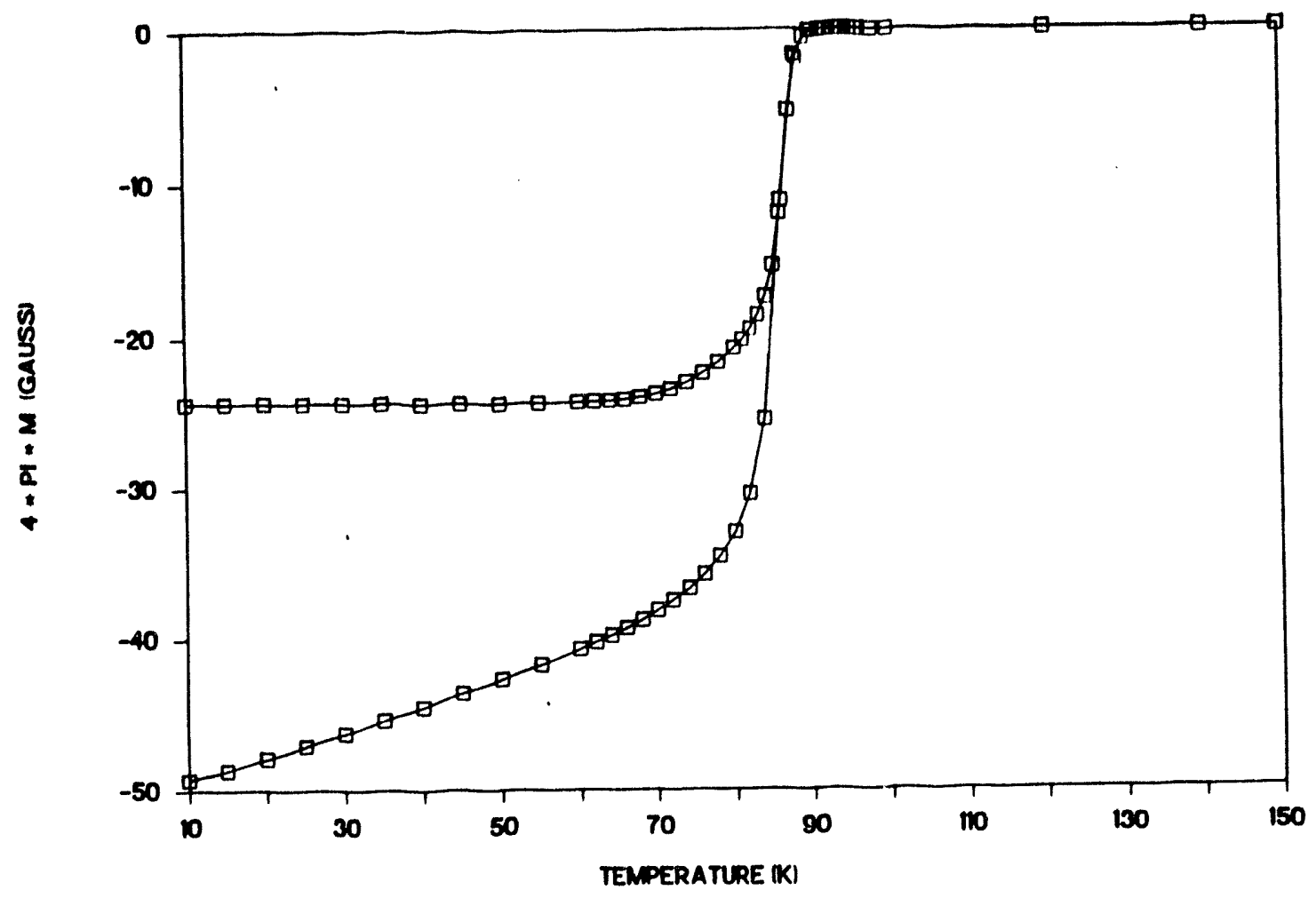

Figure 11. Magnetometer scan of 123 material produced from nitrate precursor. Upper curve is 0 Oe field cooled, lower curve is $\mathbf{5 0}$ Oe field cooled. 


\section{DISCUSSION}

The molten salt approach described above is preferable to classical solution precipitation techniques used in production of superconductors because of the virtual 100 percent yield, and to the standard solid state reaction from oxides due to simplification of the processing sequence. The process as designed uses no additives, but could be altered to permit addition of plasticizers if deemed necessary.

Formation of fibers from the nitrate precursor involves an intimate interrelationship between chemistry, system rheology and forming process. The chemistry of the system is quite flexible; while nitrate has been used as the supporting anion in this project, acetate has also been shown to work as well $[25,26]$.

\section{Chemistry of the Paste}

The chemistry of the paste forming process reflects the varying degrees of solubility of the reactants. In all of the following reactions, it should be remembered that water is released into the system from the hydrated reactant salts. The barium hydroxide acts as a molten salt flux for dispersion and reaction of the subsequent reactants (Equation 1). While Equation 1 implies complete dissociation of the barium hydroxide, Baes and Messmer [18] give evidence for partial dissociation of $\mathrm{OH}^{-}$from the salt.

Addition of yttrium nitrate to the barium hydroxide places the yttrium ion in a stability regime with high drive to precipitate as hydroxide. As a result, an anion exchange reaction occurs in the second step of the paste forming process (Equation 2). As noted above, if the $Y$ - Ba system produced at this point is allowed to fully precipitate, XRD shows the presence of $\mathrm{Y}(\mathrm{OH})_{3}$ and $\mathrm{Ba}\left(\mathrm{NO}_{3}\right)_{3}$. 


$$
2 \mathrm{Ba}(\mathrm{OH})_{2} \cdot 8 \mathrm{H}_{2} \mathrm{O}_{(\text {moleca })}-2 \mathrm{Ba}^{2+}+4(\mathrm{OH})^{-}+16 \mathrm{H}_{2} \mathrm{O}
$$

$$
\mathrm{Y}^{3+}+3 \mathrm{OH}^{-}-\mathrm{Y}(\mathrm{OH})_{3_{\mathrm{m}}}
$$

Addition of the copper nitrate, either as a solid or a solution, lowers the $\mathrm{pH}$ of the system below $\mathrm{pH}=6$, which is the solubility boundary for $\mathrm{Y}(\mathrm{OH})_{3}$ in aqueous systems, and yttrium hydroxide is expected to dissolve. The copper ions give up nitrate ligands for the free hydroxides, which raises the $\mathrm{pH}$ of the solution slightly. This results in precipitation of $\mathrm{Cu}_{2}(\mathrm{OH})_{3} \mathrm{NO}_{3}$, (Equations 3, 4). Formation of $\mathrm{Cu}_{2}(\mathrm{OH})_{3} \mathrm{NO}_{3}$ is again supported by $\mathrm{XRD}$ of the binary system $\mathrm{Ba}(\mathrm{OH})_{2} 8 \mathrm{H}_{2} \mathrm{O}$ and $\mathrm{Cu}\left(\mathrm{NO}_{3}\right)_{2}$.

$$
\begin{gathered}
\mathrm{Y}(\mathrm{OH})_{3}+3 \mathrm{H}_{3} \mathrm{O}^{+} \rightarrow \mathrm{Y}^{3+}+6 \mathrm{H}_{2} \mathrm{O} \\
2 \mathrm{Cu}^{2+}+6 \mathrm{H}_{2} \mathrm{O}+\mathrm{NO}_{3}^{-} \rightarrow \mathrm{Cu}_{2}(\mathrm{OH})_{3} \mathrm{NO}_{3}+3 \mathrm{H}_{3} \mathrm{O}^{+}
\end{gathered}
$$

Finally, with evaporation of the water from the system, the barium and yttrium ions form the final products (Equation 5).

$$
2 \mathrm{Ba}^{2+}+7 \mathrm{NO}_{3}^{-}+\mathrm{Y}^{3+}+\mathrm{H}_{2} \mathrm{O}-\mathrm{Y}\left(\mathrm{NO}_{3}\right)_{3} \cdot \mathrm{XH}_{2} \mathrm{O}+2 \mathrm{Ba}\left(\mathrm{NO}_{3}\right)_{2}
$$


This produces the composite equation for the entire system given in Equation 6.

$$
\begin{aligned}
& 2 \mathrm{Y}^{3+}+4 \mathrm{Ba}^{2+}+6 \mathrm{Cu}^{2+}+17 \mathrm{NO}_{3}^{-}+(9+x) \mathrm{H}_{2} \mathrm{O} \\
& 2 \mathrm{Y}\left(\mathrm{NO}_{3}\right)_{3} x \mathrm{H}_{2} \mathrm{O}+4 \mathrm{Ba}\left(\mathrm{NO}_{3}\right)_{2}+3 \mathrm{Cu} u_{2}(\mathrm{OH})_{3} \mathrm{NO}_{3}+9 \mathrm{H}_{(\text {aq. })}^{+}
\end{aligned}
$$

The final products shown in Equation 6 are known to occur in this process. The species shown in Equations 1 - 5 are only postulated.

The crystallization of the three phases, $\mathrm{Y}\left(\mathrm{NO}_{3}\right)_{3}, \mathrm{Ba}\left(\mathrm{NO}_{3}\right)_{2}$, and $\mathrm{Cu}_{2}(\mathrm{OH})_{3} \mathrm{NO}_{3}$, has a major impact on the flow behavior of the paste during forming processes. The barium nitrate phase precipitates early in the process, and shows a high drive to crystallization, as evidenced by the highly developed crystal forms and large crystal size. The free growth conditions present in the solution are a major factor in development of these crystals. The yttrium and copper phases however, form particles 1 - 2 orders of magnitude smaller than the barium nitrate. Atomic absorption analysis of the supernatant fluid over the paste after 90 minutes processing at $90^{\circ} \mathrm{C}$ shows $1.0 \mathrm{M}$ of $\mathrm{Y}, 0.04 \mathrm{M} \mathrm{Ba}$ and $0.5 \mathrm{M} \mathrm{Cu}$ (relative error $=+/-5 \%$ ), which correspond to a cation ratio of $1.0: 0.04: 0.50$ cation ratio, compared with a initial cation ratio of $1: 2: 3$ indicating that practically all of the yttrium and only $17 \%$ of the copper and $2.5 \%$ of the barium remained in solution. After 180 minutes heating at $90^{\circ} \mathrm{C}$, the analyses showed $0.68 \mathrm{M}, 0.02 \mathrm{M}$, and $0.3 \mathrm{M}$ for $\mathrm{Y}, \mathrm{Ba}$, and $\mathrm{Cu}$, corresponding to a cation ratio of $1.0: 0.03: 0.44$. The change in concentration of the ions suggests first that the barium precipitates first, copper phases precipitate either second or together with the barium salt in the evaporation process, and yttrium precipitates out last. The low barium content of the supernatant at 90 minutes suggests that barium has already precipitated almost quantitatively. There is no change at 180 minutes, so we assume no resorption occurs. The copper salt 
probably precipitates by a simple supersaturation mechanism, as supported by the decrease in concentration in the supernatant solution. The non-linear change in concentration seen in the yttrium concentration as a function of time suggests that precipitation is not due simply to supersaturation mechanisms. Precipitation of the yttrium phase is very likely mediated by heterogeneous nucleation on the earlier precipitated copper phase. The remaining yttrium probably forms a colloidal gel on dehydration [19], which ultimately forms part of the fine matrix material. The high concentration of yttrium in the solution even late in the process adds credence to the hypothesis that any $\mathrm{Y}(\mathrm{OH})_{3}$ which precipitates on initial addition to the barium hydroxide is resorbed into the solution.

\section{Rheology}

Rheological examination of the precursor paste as a function of time and shear rate supports the ideas proposed above. The flowcurves may be fit to a shear-thinning Hershel-

$$
\tau=\tau_{y}+\eta_{p}(\dot{\gamma})^{n}
$$

Bulkley model (Equation 7). The Hershel-Bulkley model is a composite model, combining the yield stress $\left(\tau=f\left(\tau_{y}\right)\right)$ of the Bingham Plastic model (Equation 8), with the shear rate induced changes $\left(\tau=f(\dot{\gamma})^{\mathrm{p}}\right)$ seen in the power law models (Equation 9). Materials with such rheological characteristic are desirable for shape forming operations because high strain rates (for $\mathrm{n}<1$ ) result in reduced viscosity relative to Newtonian materials, which permits easier forming. The existence of a yield stress aids in maintenance of shape after forming. Even at short processing times, the nitrate precursor paste displays a yield stress and shear thinning behavior, both of which are characteristic of particulate loaded slurries [27]. The initial yield 
stress is attributed to the presence of granular material in this case, because the solvent is water, which behaves as a Newtonian fluid. The shear thinning behavior shows two regimes,

$$
\begin{aligned}
& \tau=\tau_{y}+\eta_{p} \dot{\gamma} \\
& \tau=\eta_{p}(\dot{\gamma})^{n}
\end{aligned}
$$

one at strain rates below $50 \mathrm{sec}^{-1}$, one above $50 \mathrm{sec}^{-1}$. In the lower strain rate regime, flow is governed by interaction of the granular material, and by breakup of flocs [28]. At higher strain rates, the flocs are mechanically disrupted. Because the flocs act to occlude fluid from the system, reduction of the floc content in the paste increases the solvent content of the system, which reduces the paste viscosity. Most of the interactions in the paste at high rates of strain are probably due to separation of the material into laminar regimes, with interlaminar effects the main contribution to flow resistance. This behavior is common to slurries with high volume loads of solid particles [27 - 29]. If the paste is retested immediately, the flowcurve exhibits a lower yield stress and decreased viscosity at each strain rate. This behavior is presumed to be due to formation of the laminar structure discussed above. When the paste is allowed to restructure at zero shear for 2 hours, the laminar structure relaxes, and the initial flow behavior is again observed.

\section{Extrusion}

The main parameter in forming of fibers by ram extrusion in this system is the degree of dehydration of the system. From the above discussions it is seen that removal of water from the system increases the percentage of solids in the paste. As the solids fraction 
increases, the yield stress and viscosity increase, i.e., the paste becomes thick and stiff. Because of the high level of solids loading in the paste, it was not possible to predict the time - rheology behavior of the paste system. Trial and error proved to be the best method to determine the optimum processing time. As noted above, the extrusion process was hindered by the non-uniformity of the paste. Variations in diameter and disruption of the fiber were cornmon. These flaws are attributed to the bimodal nature of the solids fraction in the paste, and especially to the effect of the large barium nitrate grains. As noted above, grinding of the paste improved extrusion. This improvement is most likely due to reduction of bridging phenomena in the paste due to barium nitrate grains.

\section{Pyrolysis and Sintering}

Dehydration of the paste at $\mathrm{T}>100^{\circ} \mathrm{C}$ produces brittle blue fibers. The loss on ignition as determined by TGA is around $45 \%$ for the nitrate system. While this is high with respect to synthesis from oxides, it is comparable to oxides produced from other precursor systems. An important advantage of this system is that $100 \%$ of the metal cations used as reagents are recovered as condensed product. This is in contrast to methods involving precipitation and filtration, where a finite quantity of reagent remains in the supernatant reaction liquid. Firing efficiency relative to the solid state synthesis from oxides is good, in that only a single heating/annealing cycle is necessary to convert the precursor to the superconducting phase.

The thermal analysis and XRD of the system shows initial formation of the $\mathrm{YBa}_{2} \mathrm{Cu}_{3} \mathrm{O}_{7}$ phase at $\mathrm{T}=600^{\circ} \mathrm{C}$. XRD at this temperature also shows the existence of several impurity phases. Phase equilibrium of the yttria, baria, copper oxide system shows that for bulk 
compositions which melt at $980^{\circ} \mathrm{C}$ in oxygen, the system must contain some level of impurities [17]. This is supported by reflected light microscopy, where the green 211 phase is readily visible in polished sections.

The fired fibers show fairly good bulk and apparent density values. The sponge like texture observed is most likely an artifact of the initial grain size distribution. The large grains of barium nitrate decompose to barium oxide at $-600^{\circ} \mathrm{C}$, leaving behind large voids. Solid state sintering of this calcined material will not reduce the porosity created in the fiber in a reasonable period of time because of the diffusion controlled nature of the sintering process $[5,6,30]$. Application of liquid assisted sintering techniques is limited in this system, because 1) the system melts incongruently, and 2) extreme grain growth has been observed in samples sintered above the melting point. Further, sintering above the peritectic melting point would likely result in deformation of the fibers. It is likely that a grinding/attrition step could act to reduce the grain size of the barium nitrate, but this would add a step to the process.

Another possible explanation of the porosity is the effect of gas evolution during the firing process. Thermal decomposition of the paste materials releases water and nitrous oxides. This evolution of gases will act to keep pores open until the gas evolution is completed at around $600^{\circ} \mathrm{C}$. If outgassing is the cause of the porosity, it may be reduced by choice of system anions, but not removed completely except by formation of the oxides in the paste synthesis. Regardless of the cause, the porosity will be difficult to eliminate entirely.

\section{Superconducting Properties}

SQUID magnetometry shows the fibers to be superconducting. The transition temperature was determined to be $88 \mathrm{~K}$ at $10 \%$ of the saturation value for 50 Oe field cooled 
samples. Transition temperatures at the $10 \%$ level are more representative of the 'true' transition temperature than the inflection point. This is because the width of the transition may vary widely, with the inflection point marking only the upper limit of the zone. The transition width seen in this system for 10 to $90 \%$ of the field cooled saturation value, $10.6 \mathrm{~K}$, is comparable to that obtained for samples prepared by other solution or solid state methods. Fibers produced by this method show the Meissner effect, with $40-50 \%$ flux exclusion. The incomplete flux exclusion reflects the discontinuous conduction paths. As noted above, the 211 impurity phase is in the sintered fibers obtained from this process. The presence of this insulating phase, in conjunction with the inherent porosity of the sintered fibers, reduces the continuity of the conduction routes in the sintered compact. 


\section{CONCLUSION}

A novel low-temperature nitrate based system has been develuped which permits binderless formation of $\mathrm{YBa}_{2} \mathrm{Cu}_{3} \mathrm{O}_{7-\mathrm{z}}$ fibers. Starting from molten $\mathrm{Ba}(\mathrm{OH})_{2} \cdot 8 \mathrm{H}_{2} \mathrm{O}$, acidic $\mathrm{Y}\left(\mathrm{NO}_{3}\right)_{3}$ solution and crystalline $\mathrm{Cu}\left(\mathrm{NO}_{3}\right)_{2} \cdot 2 \frac{1}{2} \mathrm{H}_{2} \mathrm{O}$, a viscous blue paste is formed by processing at $90^{\circ} \mathrm{C}$. The viscosity and yield stress of the paste are controllable by evaporation of water. The paste may be modelled after the Hershel-Bulkley model, i.e. it has a yield stress and is shear-thinning. Fibers of $1 \mathrm{~mm}$ diameter have been produced from this paste by ram extrusion.

Pyrolysis and sintering of the green nitrate fibers produces $\mathrm{x}$-ray pure $\mathrm{YBa}_{2} \mathrm{Cu}_{3} \mathrm{O}_{7-\mathrm{x}}$. Examination of the sintered bodies by SEM and optical light microscopy shows that the sintered fibers contain about $2 \% \mathrm{Y}_{2} \mathrm{BaCuO5}_{5}$, and have a porous microtexture. Magnetometry of fibers produced by this method show a transition temperature $\left(T_{c}\right)=88 K$, and about $40 \%$ flux exclusion.

The nitrate synthesis is a viable, but not perfect, route to production of 123 fibers. The method has several problems which make fiber forming difficult. The system contains large grains which hinder extrusion. The sintered fibers are brittle and porous. The Y- Ba $\mathrm{Cu}$ - O system has inherent problems, including a low incongruent melting temperature, poor inherent phase purity. Given these factors, it seems likely that a better chemical system exists for this synthetic route to formation of 123 fibers, such as an acetate or hydroxycarbonate based system.. 


\section{REFERENCES}

1. E. R. Vance, "High $T_{c}$ Superconductors--Ceramic Precursor Development Status," Ceramics International, 16 361-368 (1990).

2. M. Brian Maple, "High Tc Oxide Superconductors," Mat. Res, Soc. Bulletin, 15 2024 (1989).

3. Man F. Yan, editor, Ceramic Superconductors II, American Ceramic Society, Westerville, $\mathrm{OH}, 618$ p. (1988).

4. J. H. Sharp, Transactions: "A Review of the Crystal Chemistry of Mixed Oxide Superconductors," Br. Ceram. Trans, Journal, 89 1-7 (1990).

5. D. R. Clarke, T. M. Shaw, and D. Dimos, "Issues in the Processing of Cuprate Ceramic Superconductors," J. Am. Cer. Soc. ,72 1103-1113 (1989).

6. S. Jin and J. E. Graebner, "Processing and Fabrication Techniques for Bulk High-T Superconductors: A Critical Review," Materials Science and Engineering B7 243260 (1991).

7. L. Rao Madhavrao and Raj Rajagopalan, "Thick films of YBaCuO from Precalcined Powders, "International Journal of Modern Physics B, 3, 751-761 (1989).

8. Timothy M. Green and Mufit Akinc, "Shape Forming of Superconducting Ceramics," Am. Cer. Soc. Bull, 70 1162-1166 (1991).

9. Suguru Suzuki, Shinji Asada, Minoru Takahashi, and Yasuo Hikichi, "Effect of Extrusion on $\mathrm{Bi}_{1.4} \mathrm{~Pb}_{0.6} \mathrm{Sr}_{2} \mathrm{Ca}_{2} \mathrm{Cu}_{3} \mathrm{O}_{\mathrm{x}}$ Superconducting Wires, " J. Am. Cer. Soc., 74 714-717 (1991).

10. J. P. Singh, H. J. Leu, S. E. Dorris, and R. B. Poeppel, "Fabrication of Silver-Based Superconducting Coil for Solenoid Application--Paper 152-SIII-90," 1990 Talk Summaries-Electronics Division, American Ceramic Society, Westerville, OH (1990).

11. R. C. Ward, W. B. Carlson, X. Wang, and W. A. Schulze, "Small Ceramic Superconducting Motors--Paper 151-SIII-90," 1990 Talk Summaries-Electronics Division, American Ceramic Society, Westerville, OH (1990).

12. Ronald H. Ono, "Thin Film Processing of Complex Multilayer Structures of HighTemperature Superconductors, " Mat. Res. Soc. Bull, 17 34-38 (1992).

13. Shingo Katayama and Masahiro Sekine, "Fabrication of Superconducting $\mathrm{YBa}_{2} \mathrm{Cu}_{3} \mathrm{O}_{7-\mathrm{x}}$ Fibers by the Sol-Gel Method Using Metal Alkoxides, " J. Mat. Res., 6 1629-1633 (1991). 
14. N. McN. Alford, J. D. Birchall, W. J. Clegg, M. A. Harmer, and K. Kendall, "Process - Microstructure - Property Relations in Ceramic Superconductors, " Ceramic Superconductors II, American Ceramic Society, Westerville, OH (1988).

15. U. Balachandran, K. C. Goretta, R. B. Poeppel, and J. G. Hunt, "Hot Extrusion of High-Temperature Superconducting Oxides--Parer 156-SIII-90," 1990 Talk Summaries-Electronics Division, American Ceramic Society, Westerville, OH (1990).

16. M. Akinc and A. Cellikaya, U.S. Patent 4906 608, March 6, 1990.

17. J. E. Ullman, R. W. McCallum, and J. D. Verhoeven, "Effect of Atmosphere and Rare Earth on Liquidus in RE - Ba - Cu Oxides," L. Mat. Res., 4 752-754 (1989).

18. C. Baes, Jr. and R. Mesmer, The Hydrolysis of Cations, John Wiley and Sons, Inc., New York (1976).

19. C. E. Holcombe, C. C. Edwards, and D. A. Carpenter, "New Yttria Plasters--Report Y-21 10," Union Carbide Corporation-Nuclear Div., Oak Ridge Y-12 Plant, Oak Ridge, TN (1978).

20. R. S. Roth, C. J. Rawn, F. Beech, J. D. Whitler, and J. O. Anderson, "Phase Equilibria in the System Ba - Y - Cu - O in Air," Ceramic Superconductors II, American Ceramic Society, Westerville, OH (1988).

21. Odent, G. and M.-H. Autreusseau-Duperray, "Thermolyse du Pentahydrate du Nitrate d'Yttrium, " Revue de Chimie Minerale 13 196-206 (1976).

22. Mu, Jacob and D. D. Perlmutter, "Thermal Decomposition of Metal Nitrates and their Hydrates," Thermochimica Acta 56 253-260 (1982).

23. CRC Handbook of Chemistry and Physics, R. C. Weast, editor, CRC Press, Boca Raton, Florida (1986).

24. R. P. Millis, Processing of $\mathrm{YBa}_{2} \mathrm{Cu}_{3} \mathrm{O}_{7}$ Tapes From a Molten Salt Precursor, M. S. Thesis, lowa State University, Ames, IA (1990).

25. T. M. Green, R. P. Millis and M. Akinc, "Shape Forming of $\mathrm{YBa}_{2} \mathrm{Cu}_{3} \mathrm{O}_{7-x}$ " (abstract), 1990 Talk Summaries-Electronic Division, American Ceramic Society, Westerville, OH (1990).

26. Timothy M. Green, R. W. McCallum, and M. Akinc, "Synthesis and Rheology of a Low-Temperature Acetate Precursor for $\mathrm{YBa}_{2} \mathrm{Cu}_{3} \mathrm{O}_{7-\mathrm{x}}$ Fibers (To be published).

27. H. A. Barnes, J. F. Walters, and K. Walters, An Introduction to Rheology - Volume 3, Elsevier, Amsterdam (1989). 
28. H. van Olphen, An Introduction to Clay and Colloid Chemistry, 2nd Edition, John Wiley and Sons, Inc., New York (1977).

29. Hunter, Robert J., Foundations of Colloid Science. Volume II, Oxford Science Publications, Oxford (1898).

30. R. Cava, "New Materials Research in High-Tc Superconductivity, " presented at 95th Annual Meeting, American Ceramic Society, Cincinnati, OH, April, 1993. 
PAPER II: SYNTHESIS AND RHEOLOGY OF A LOW-TEMPERATURE ACETATE PRECURSOR FOR $\mathrm{YBa}_{2} \mathrm{Cu}_{3} \mathrm{O}_{7 \cdot \mathrm{x}}$ FIBERS 


\title{
SYNTHESIS AND RHEOLOGY OF A LOW-TEMPERATURE ACETATE PRECURSOR FOR $\mathrm{YBa}_{2} \mathrm{Cu}_{3} \mathrm{O}_{7 \cdot \mathrm{x}}$ FIBERS
}

\author{
Timothy M. Green, R. W. McCallum and Mufit Akinc \\ Ames Laboratory" and \\ Department of Materials Science and Engineering \\ Iowa State University
}

*Ames Laboratory is operated for the U.S. Department of Energy by Iowa State University under Contract No. W-7405-ENG-82. This work was supported in part by the Office of Basic Energy Science. 


\section{ABSTRACT}

A low-temperature process for direct formation of $\mathrm{YBa}_{2} \mathrm{Cu}_{3} \mathrm{O}_{7-\mathrm{x}}$ from acetate precursors is described. Use of low melting point salts permits formation of a precursor paste which has controllable viscosity. The yield stress and viscosity increase with increasing volume fraction of solids in the paste. The paste is physically composed of micrometer size solid particles in an aqueous solution.

Fibers of the precursor paste are produced by constant load piston extrusion. The extruded fibers are of constant $1 \mathrm{~mm}$ diameter, are flexible, and have been produced in lengths of up to 3 meters. The fibers become brittle upon drying. Sintering of the fibers in an oxygen atmosphere yields phase pure $\mathrm{YBa}_{2} \mathrm{Cu}_{3} \mathrm{O}_{7-x}$, as determined by $\mathrm{x}$-ray diffraction. The sintered bodies typically possess bulk densities of 50\%. Reflected light microscopy shows the presence of impurity phases, estimated at $1-2$ percent. The sintered material is superconducting, with a transition temperature of $89 \mathrm{~K}$. 


\section{INTRODUCTION}

Application of ceramic high-temperature superconductors involves manufacturing of a ceramic material into a desired shape by a variety of forming methods such as slip-casting, extrusion, or pressing, in conjunction with state of the art chemical synthetic routes. Due to the chemical and physical characteristics of the $\mathrm{YBa}_{2} \mathrm{Cu}_{3} \mathrm{O}_{7-\mathrm{x}}$ (123) superconductor, extreme care must be taken to minimize grain size, eliminate impurity phases, and optimize firing parameters [1]. $\mathrm{YBa}_{2} \mathrm{Cu}_{3} \mathrm{O}_{7-\mathrm{x}}$ is a difficult material to work with in several respects. First, it melts incongruently [2]. This means that common melt forming techniques can not be used for forming of the ceramic body. Because 123 is a point compound, it is virtually impossible to produce a phase pure material; one or more other phases will be present as contaminants. One of the possible impurity phases is the $\mathrm{Y}_{2} \mathrm{BaCuO}_{5}(211)$ phase which is an insulator. Second, the 123 material has thermal expansion anisotropy, so cracking often occurs on cooling for grains above a critical size. This results in degradation of mechanical and electrical properties. All of the above factors are inherent in the $\mathrm{Y}-\mathrm{Ba}-\mathrm{Cu}-\mathrm{O}$ system, and can not be avoided entirely, only minimized [3].

The common method of producing $\mathrm{YBa}_{2} \mathrm{Cu}_{3} \mathrm{O}_{7-\mathrm{x}}$ involves combination of stoichiometric amounts of yttrium and copper oxide with barium carbonate, followed by repeated grinding and calcining. The resulting powder is then formed to the desired shape and sintered [4]. This process is time consuming, and results in poor homogeneity of the sintered body. Methods using precipitation from solution are also reported [5 - 7]. Some of these methods lend themselves to improved homogeneity of the precursor, and thus to sintered body homogeneity, but may result in uncontrollable crystal growth, as well as low recovery of the reactants in the solution. 
Previous work $[8-11]$ has shown that a low-temperature precursor to $\mathrm{YBa}_{2} \mathrm{Cu}_{3} \mathrm{O}_{7-\mathrm{x}}$ could be produced via a molten salt route using nitrates. In this method, molten barium hydroxide was combined with yttrium nitrate and copper nitrate to produce a binderless, formable precursor paste which could be fired to the $\mathrm{YBa}_{2} \mathrm{Cu}_{3} \mathrm{O}_{7-\mathrm{x}}$ superconductor. $\mathrm{A}$ problem with this method was the tendency for formation of large barium nitrate grains in the melt during processing. The nitrate grains caused 1) the precursor to be difficult to extrude due to particle bridging over the extruder orifice, and 2) resulted in porosity in the sintered fiber.

Iu this paper, we study the use of copper and yttrium acetates as co-reagents to barium hydroxide for production of 123 fibers. The primary goal of this investigation was to develop a synthetic route to 123 which would permit extrusion of fibers with a minimum number of processing steps, and as few processing additives as possible. In the course of this work, we also examined the rheological behavior of the acetate paste as a function of processing parameters. Concentric cylinder and piston extrusion rheometry methods were used to examine the paste rheology. 


\section{EXPERIMENTAL PROCEDURE}

Paste and Fiber Synthesis

31.5 grams $(0.10$ moles $\mathrm{Ba})$ molten barium hydroxide octahydrate $\left(\mathrm{Ba}(\mathrm{OH})_{2} \cdot 8 \mathrm{H}_{2} \mathrm{O}^{1}\right.$, m.p. $=78^{\circ} \mathrm{C}$.) was heated with constant stirring at $90^{\circ} \mathrm{C}$ in a constant temperature oil bath. 16.9 grams $(0.05$ moles $\mathrm{Y})$ yttrium acetate $\left(\mathrm{Y}\left(\mathrm{CH}_{3} \mathrm{COO}\right)_{3} 4 \mathrm{H}_{2} \mathrm{O}^{2}\right)$ was added and stirred until dispersed in the molten salt. 29.95 grams ( 0.15 moles $\mathrm{Cu})$ copper acetate $\left(\mathrm{Cu}\left(\mathrm{CH}_{3} \mathrm{COO}\right)_{2} \cdot \mathrm{H}_{2} \mathrm{O}^{3}\right)$ was then added to the mixture with constant stirring. The resulting paste was a viscous black slurry. In order to improve the homogeneity of the mixture, $10 \mathrm{ml}$ of water was typically added to the slurry after addition of the copper acetate. The initial weight of the paste (processing time $=0$ ) was 88.4 grams. The slurry is processed at $90^{\circ} \mathrm{C}$ with constant stirring, resulting in loss of water from the paste by evaporation, until the desired consistency for forming is reached. The definition of an extrudable consistency was determined by trial and error. Typical processing times needed to obtain a paste which could be shaped by piston extrusion was 75 minutes, corresponding to a paste weight of 70 grams.

The plastic paste material was formed into fibers by constant load piston extrusion. The extruder was stainless steel, with a $12.7 \mathrm{~mm}$ barrel, a $1.0 \mathrm{~mm}$ orifice, and a $45^{\circ}$ semiangle. A schematic of this extruder has been published elsewhere [12]. Constant extrusion load was applied by loading the piston with lead blocks.

\footnotetext{
${ }^{1}$ Assay $100.4 \%$, Reagent grade (Fisher Scientific, Fair Lawn, NJ)

${ }^{2}$ Assay $99.9 \%$ (Aldrich Chemical Co., Milwaukee, WI)

${ }^{3}$ Assay $=100.4 \%$, Reagent grade (Fisher Scientific, Fair Lawn, NJ)
} 
Paste Rheology

Acetate pastes were prepared as described above. A series of experiments was performed, examining the rheological characteristics of the pastes at 15 minute intervals from 0 to 90 minutes. Concentric cylinder rheology ${ }^{4}$ was used to determine the yield stress, and to obtain flowcurves (shear stress as a function of controlled rotational strain rate) for each time period. The rheometer test configuration was Z5-DIN $\left(r_{\text {cup }}=4.3 \mathrm{~mm}, r_{b o b}=4.0 \mathrm{~mm}\right)$. The strain rate history used was $0-200 \sec ^{-1}$ over 200 seconds, hold at $200 \mathrm{sec}^{-1}$ for 50 seconds, $200-0$ sec- $^{-1}$ over 200 seconds. This sequence permitted observation of the strain rate dependence, thixotropic tendencies, and effects of internal paste structure on flow behavior. All measurements were performed at $27 \pm 2^{\circ} \mathrm{C}$.

Yield stress values were obtained by two methods. First, yield stresses for the pastes at each processing time were obtained by direct measurement, using controlled shear stress (controlled torque) methods. The accuracy of this technique is $+/-100 \mathrm{~Pa}$. Second, yield stress values were obtained by fitting the controlled strain rate flowcurve data to either a Bingham Plastic or Flershel-Bulkley model, and using the regression data to infer yield stress. Temperature dependence was examined only in a superficial manner.

In the course of the work, it was noted that there was some variation in the rheological parameters obtained by concentric cylinder rheometry for identically processed samples. As a result, times used in this report are nominal. We found that paste weight is the variable which produces consistent results, so references will be to processing conditions which produce a given weight of wet paste.

\footnotetext{
${ }^{4}$ Physica Rheolab MC-10 (Physica USA, Spring, TX)
} 
The rheology of particulate pastes is strongly dependent on the volume fraction of solids in the paste. In order to obtain values for the volume fraction of solids in the pastes as a function of processing time, two methods were used. In the first method, the volume fraction solids was determined by comparison of paste weight loss as a function of time. In this case, all of the solid material was assumed to precipitate from the reaction solution immediately on mixing. The equation

$$
\text { Vol.frac. sol. }=1-\frac{\frac{w t . \text { paste }}{P_{\text {parte }}}-\frac{w t . \text { solids }}{\rho_{\text {solids }}}}{\frac{w t . \text { paste }}{\rho_{\text {paste }}}}
$$

was used in calculation, with the determined constant $\rho_{\text {solids }}=2.3 \mathrm{~g} / \mathrm{cm}^{3}$ used for the dry paste density. This method yields a value for volume fraction solids which defines the upper bound for solids content at each processing time.

In the second method, paste samples of known weight were obtained at each processing time. The samples were diluted in ethylene glycol, and dispersed by stirring for 30 seconds. The samples were then centrifuged at $5000 \mathrm{rpm}$ for 8 hours. The supernatant fluid was poured off, and its density determined by pycnometry. The remaining material was oven dried at $110^{\circ} \mathrm{C}$ for 48 hours, and weighed. The volume fraction of solids was determined by this method for each processing time. This method defines the lower boundary for the volume fraction solids, due to the finite solubility of the paste in ethylene glycol.

Particle size analysis was performed on the paste as a function of processing time. Wet sieve analysis was performed on samples processed for 15 minutes. The size fraction from -20 to +200 mesh $(850 \mu \mathrm{m}$ to $75 \mu \mathrm{m})$ was examined. The entire paste batch was 
processed for 15 minutes, decanted into a sieve stack, and flushed through with ethylene glycol. The weights of the retained fractions were determined after drying, and weight fractions oversize determined for the system. The retained material was combined, and examined by scanning electron microscopy to examine the microstructures of the retained grains.

To examine the fine fraction of the solid material in the pastes, centrifugal particle size analysis was used. Paste samples were taken at 30 and 75 minutes. These samples were diluted in ethylene glycol, and ultrasonically disrupted for 5 minutes. The dispersed samples were then analyzed by sequential gravitational and centrifugal particle size analysis ${ }^{5}$ over a range of $60-0.3 \mu \mathrm{m}$.

\section{Piston Extrusion}

The fiow behavior of the acetate paste was examined by piston extrusion. The extruder (Figure 1$)$ has a barrel diameter $\left(D_{0}\right)$ of $12.7 \mathrm{~mm}$ ( 0.5 inches). The die entry used in this study is square entry $\left(\alpha=90^{\circ}\right.$ ). A number of dies with different orifice diameters and die land lengths were manufactured. Die orifices (D) used in this study were $1 \mathrm{~mm}$ and 2 $\mathrm{mm}$ diameter. Die land lengths (L) were $10.0 \mathrm{~mm}$ (0.4 inches) and $15.8 \mathrm{~mm}$ (0.6 inches) resulting in L/D combinations of 15.8:1, 10:1, 7.9:1, and 5:1. All extruder parts were stainless steel.

\footnotetext{
${ }^{5}$ SA-CP4 Particle Size Analyzer (Shimadzu Sci. Inst., Columbia, MD)
} 
83

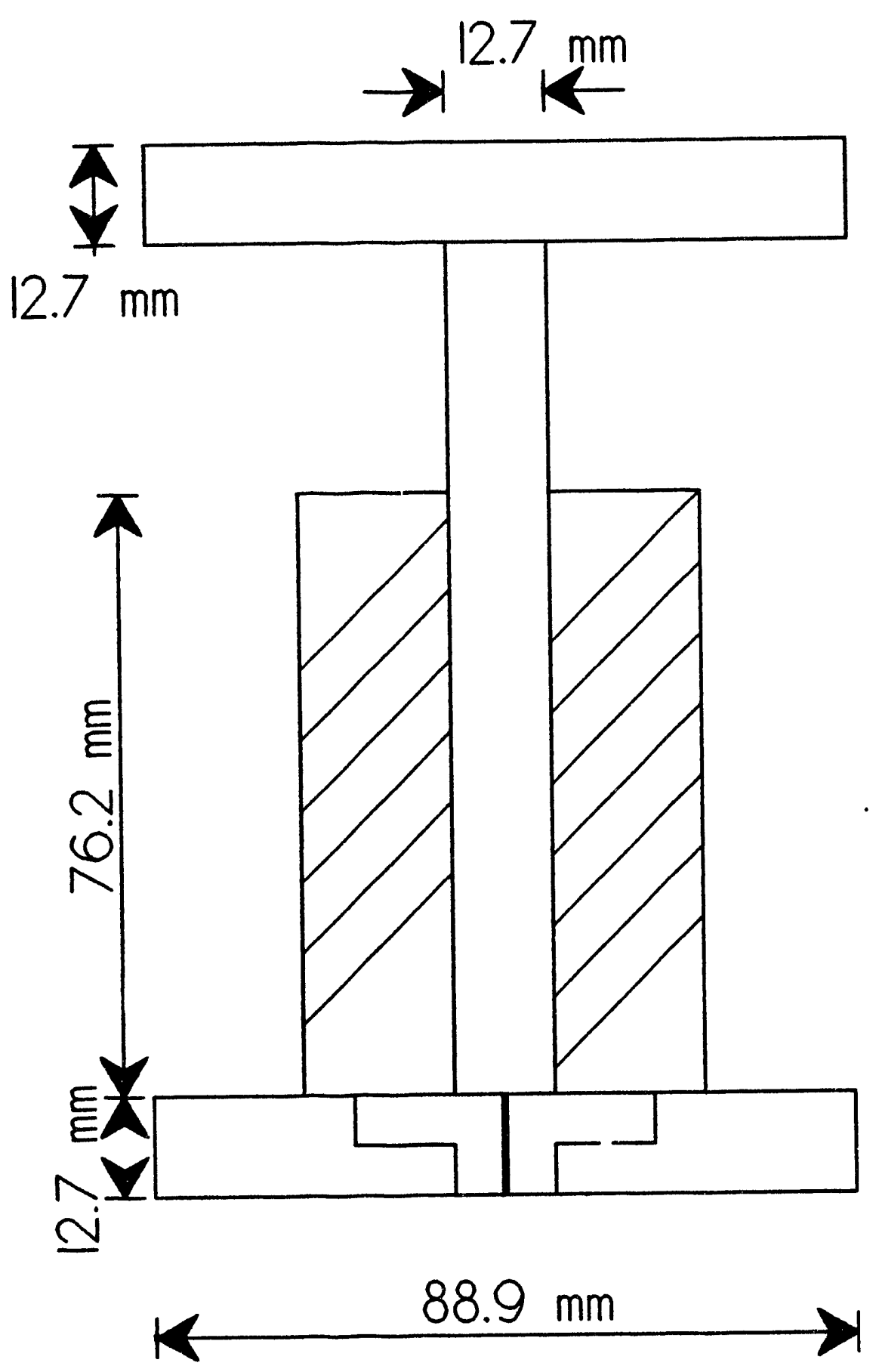

Figure 1. Cross-sectional view of piston extruder used for determination of acetate paste flow parameters 
Piston travel was controlled by use of a mechanical testing machine ${ }^{6}$ operating in compressional mode. Crosshead speeds used for this study were 5, 10, 20, 50, 75, and 100 $\mathrm{mm} / \mathrm{minute}$. Data is stored digitally for further analysis.

\section{Paste Chemistry}

The identification of phases present in the dry paste material was initially examined by powder $x$-ray diffraction (XRD) ${ }^{7}$. Two factors tended to limit the effectiveness of XRD as an analytical tool for this system. First, the dried paste showed poor signal to noise ratios. Second, the published database of $\mathrm{x}$-ray patterns for the yttrium compounds is quite limited. In order to determine the chemistry of the paste, infrared spectroscopy (FTIR) ${ }^{8}$ was used. Infrared spectra were taken between $4000 \mathrm{~cm}^{-1}$ and $440 \mathrm{~cm}^{-1}$ ). Spectra obtained from FTIR were compared to published standard spectra [13]. Spectra which could not be identified were assigned probable identities based on identification of spectral bands.

\section{Firing and Sintering}

The densification behavior of the acetate precursor was examined. Ten separate batches of the precursor were prepared as described above. Samples from three dried paste batches were chemically analyzed by inductively coupled plasma - optical emission

\footnotetext{
${ }^{6}$ Instron 4204 (Instron Corp., Canton, MA)

${ }^{7}$ LC500 Diffractometer, (Siemens Anal. X-ray Irst., Madison, WI)

${ }^{8}$ IR-98, (IBM-Bruker, Bruker Instruments, Billerica, MD)
} 
spectroscopy (ICP-OES) ${ }^{9}$ to ensure that minimum compositional variation existed between batches. All ten batches were then combined and ground in a mortar and pestle to -200 mesh. The powder obtained from this procedure was divided using a riffle splitter to obtain random

\section{5 gram samples.}

The samples were uniaxially pressed into $12.7 \mathrm{~mm}(0.5 \mathrm{inch})$ diameter pellets. No die lubricants were used, in an effort to minimize introduction of spurious phases. The powder was loaded to $34.5 \mathrm{MPa}(5000 \mathrm{psi})$ and held at that pressure for 10 minutes. The pellets were then removed from the die and stored in a dry argon atmosphere.

The densification behavior of the acetate precursor was examined under a variety of atmospheric, temperature, time and applied pressure conditions. The study was divided into four sections. In the first, the pellets were fired in oxygen for varying times and temperatures. A second set of pellets were pre-fired in argon to $650^{\circ} \mathrm{C}$, after which they were sintered in oxygen at several temperature/time combinations. In the third section, the pellets were prefired in air, with a subsequent oxygen sinter. In the final section, pelletizing pressure was examined. In this section the uniaxially pressed pellets were isostatically pressed to $206 \mathrm{MPa}$ (30 ksi), pre-fired in argon, and sintered in oxygen.

After firing, the bulk and apparent densities of the pellets were determined by Archimedean displacement methods. Xylene ${ }^{10}$ was used as the reference fluid. Apparent density values obtained by the Archimedean method were checked by gas pycnometry ${ }^{11}$.

\footnotetext{
${ }^{9}$ ARL 3410 with Minitnrch (Applied Research Labs., Valencia, CA).

${ }^{10}$ Reagent Grade (Fisher Scientific, Fair Lawn, NJ)

${ }^{11}$ Multivolume pycnometer (Micromeritics Inst. Corp., Norcross, GA)
} 
Extruded fibers were fired under controlled atmosphere to obtain $\mathrm{YBa}_{2} \mathrm{Cu}_{3} \mathrm{O}_{7-\mathrm{x}}$. All gas flow rates were kept constant at $100 \mathrm{cc} /$ minute. The sintering schedule was chosen based on the results of the sintering study discussed above and TG/DTA results. Calcination was in flowing argon, ramping from room temperature to $650^{\circ} \mathrm{C}$ at $1^{\circ} \mathrm{C} /$ minute, with a 4 hour hold. The furnace was then ramped under flowing oxygen conditions at $2^{\circ} \mathrm{C} /$ minute to $960^{\circ} \mathrm{C}$ and held at temperature for 4 hours. The samples were then cooled at $10^{\circ} \mathrm{C} /$ minute to $450^{\circ} \mathrm{C}$, and held for 24 hours in flowing oxygen to provide an oxygen anneal.

Fired pellets and fibers were examined by $\mathrm{x}$-ray diffraction, $\mathrm{SEM}^{12}$, reflected light microscopy, and magnetometry ${ }^{13}$. X-ray diffraction and reflected light microscopy give information on phase content and purity of the sintered materials. SEM was used to examine the sintered microstructure. SQUID magnetometry was employed to determine the superconducting transition temperature and level of Meissner effect.

\footnotetext{
${ }^{12}$ Stereoscan 2000, (Cambridge Sci. Inst., Cambridge, England)

${ }^{13}$ Quantum Designs (San Diego, CA)
} 
RESULTS

\section{Concentric Cylinder Rheology}

Flowcurves obtained for the acetate paste as a function of paste weight and nominal processing time are given in Figures $2 \mathrm{a}-\mathrm{h}$. The data shown are only for conditions of increasing strain rate $\left(0-200 \mathrm{sec}^{-1}\right)$. The flowcurve data points for Figure 2 are all the

results of averaging 3 tests on the sample. Both shear stress and viscosity curves are shown. A clear trend of increasing yield stress and viscosity values with increasing processing time is seen.

Increasing paste weight also affects the degree of linearity of the flowcurves. In Figures 2 a-f, large fluctuations are apparent in the shear stress curves at low strain rates. The fluctuations decrease with increasing strain rate for any given flowcurve. In conjunction with this variation in shear stress, there is also a change from in flow behavior from generally Newtonian (Figure $2 \mathrm{a}-\mathrm{c}$ ) to a Bingham or Hershel-Bulkley behavior (Figure 2e, 2f). The flowcurves for all paste weights show a decrease in viscosity as strain rate increases, that is, the pastes are shear thinning.

The fluctuation in shear stress seen at low strain rate for the pastes processed for short times (higher paste weight) was studied by measuring the flowcurve over both increasing and decreasing strain rate paths. Figure 3 shows the results of such a test for a strain rate history $0-100-0 \sec ^{-1}$. The strain rate history was a complete cycle from $0-200-0 \mathrm{sec}^{-1}$ as described above. On increasing strain rate, the flowcurve exhibits shear stress fluctuations at low strain rate, and smooths at high strain rates. When tested at a constant strain rate of 200 $\sec ^{-1}$ for 50 seconds, the material exhibits a very small thixotropy. When the strain rate is reduced, the fluctuations in shear stress are not observed. 

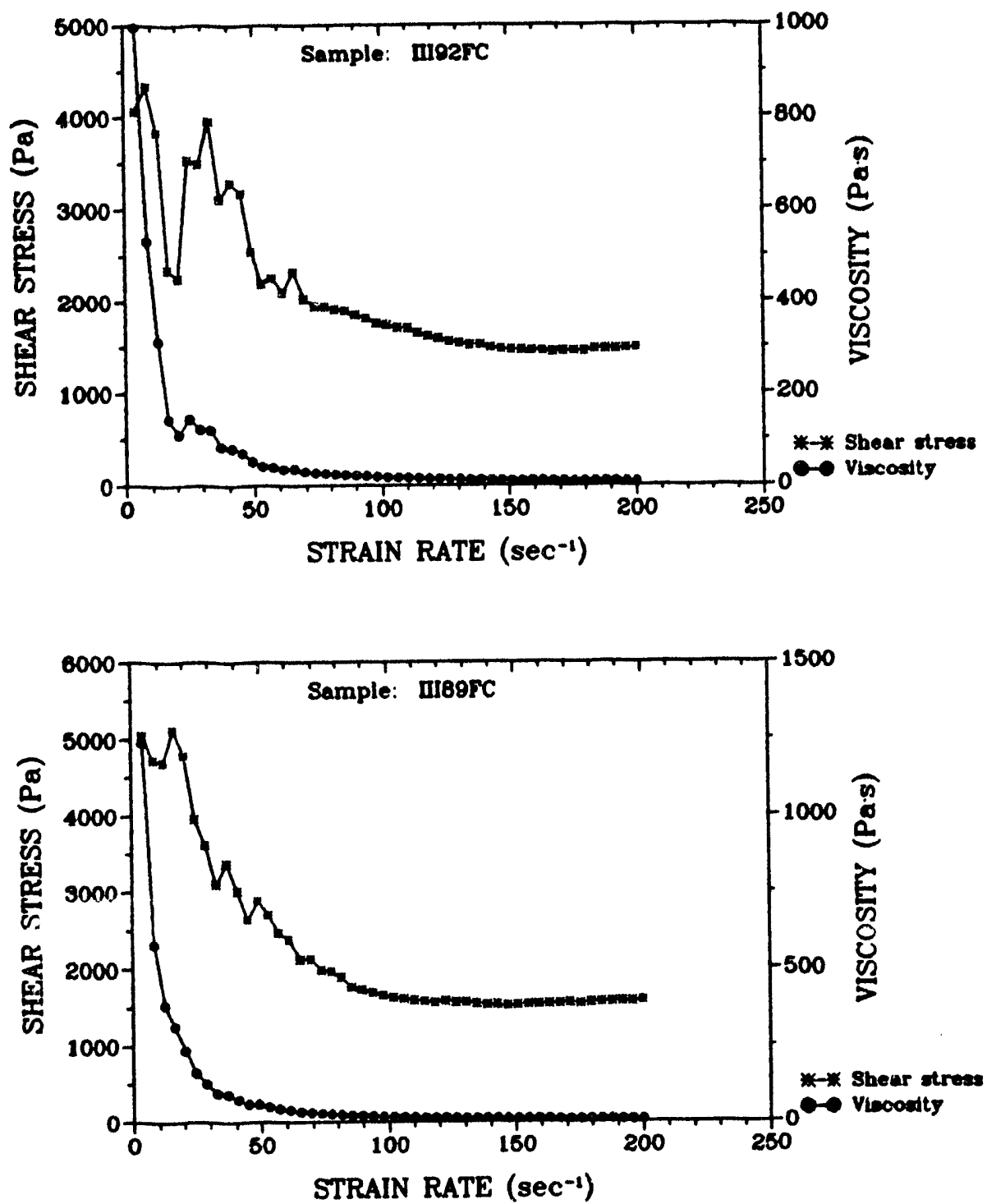

Figure 2. Flowcurves for acetate pastes. (a) Paste weight $=81.15$ grams. (b) Paste weight $=79.02$ grams 

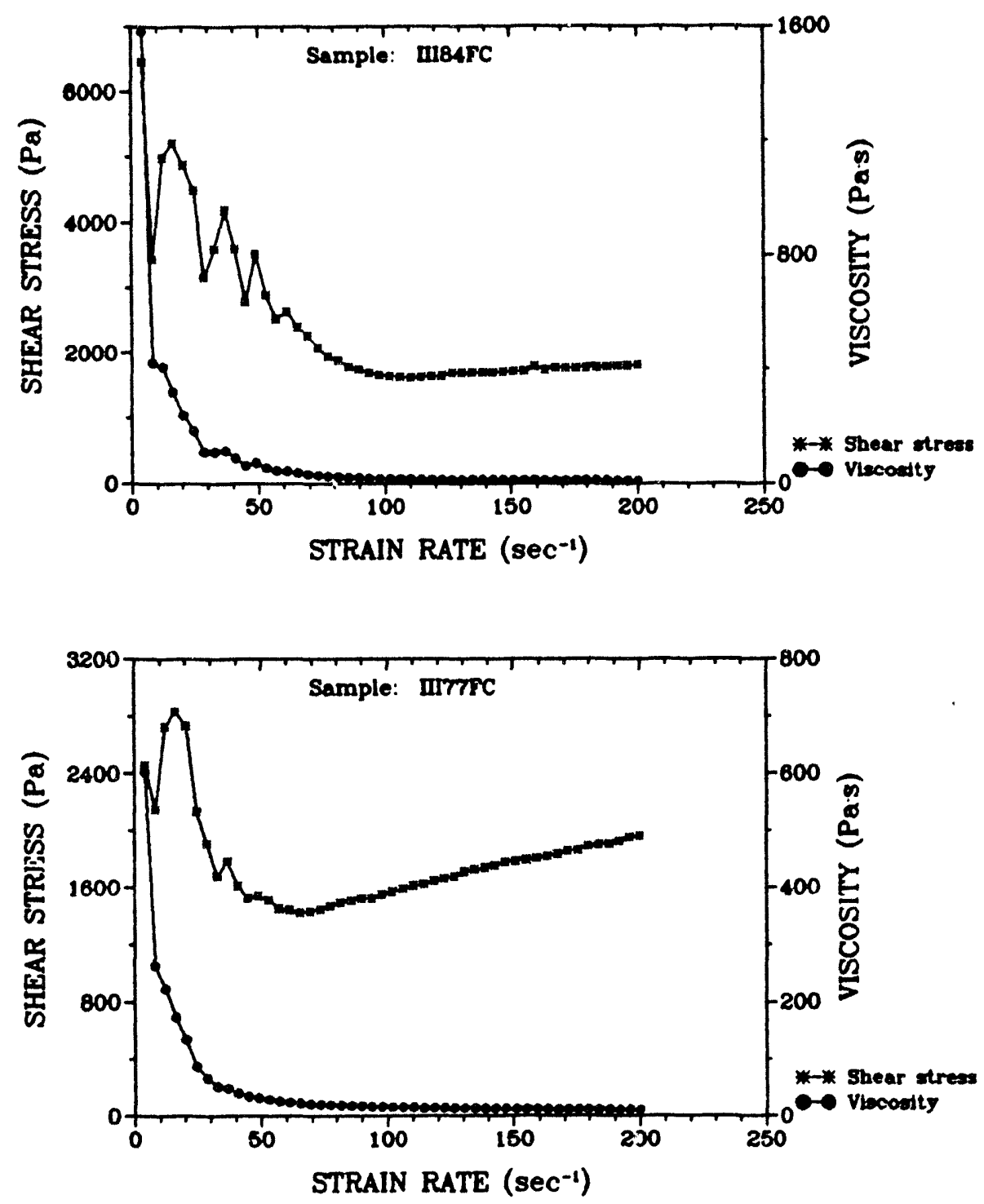

Figure 2. (continued) (c) Paste weight $=78.10$ grams. (d) Paste weight $=77.40$ grams 


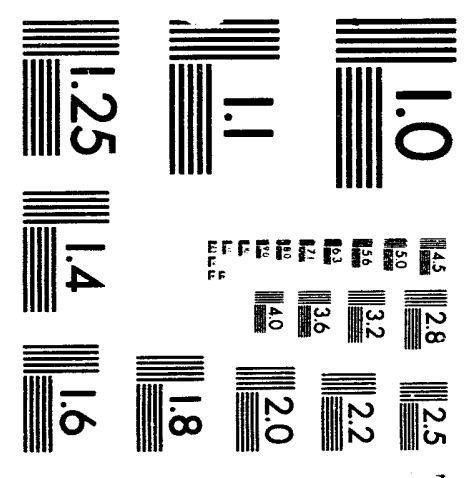



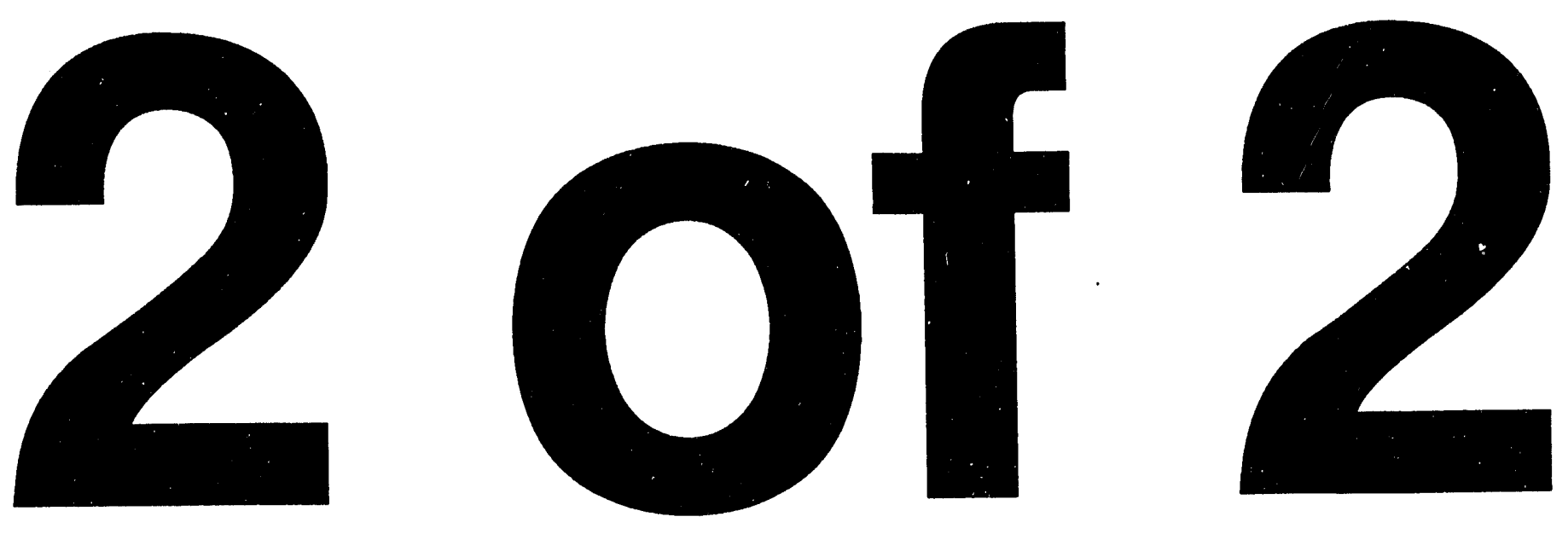

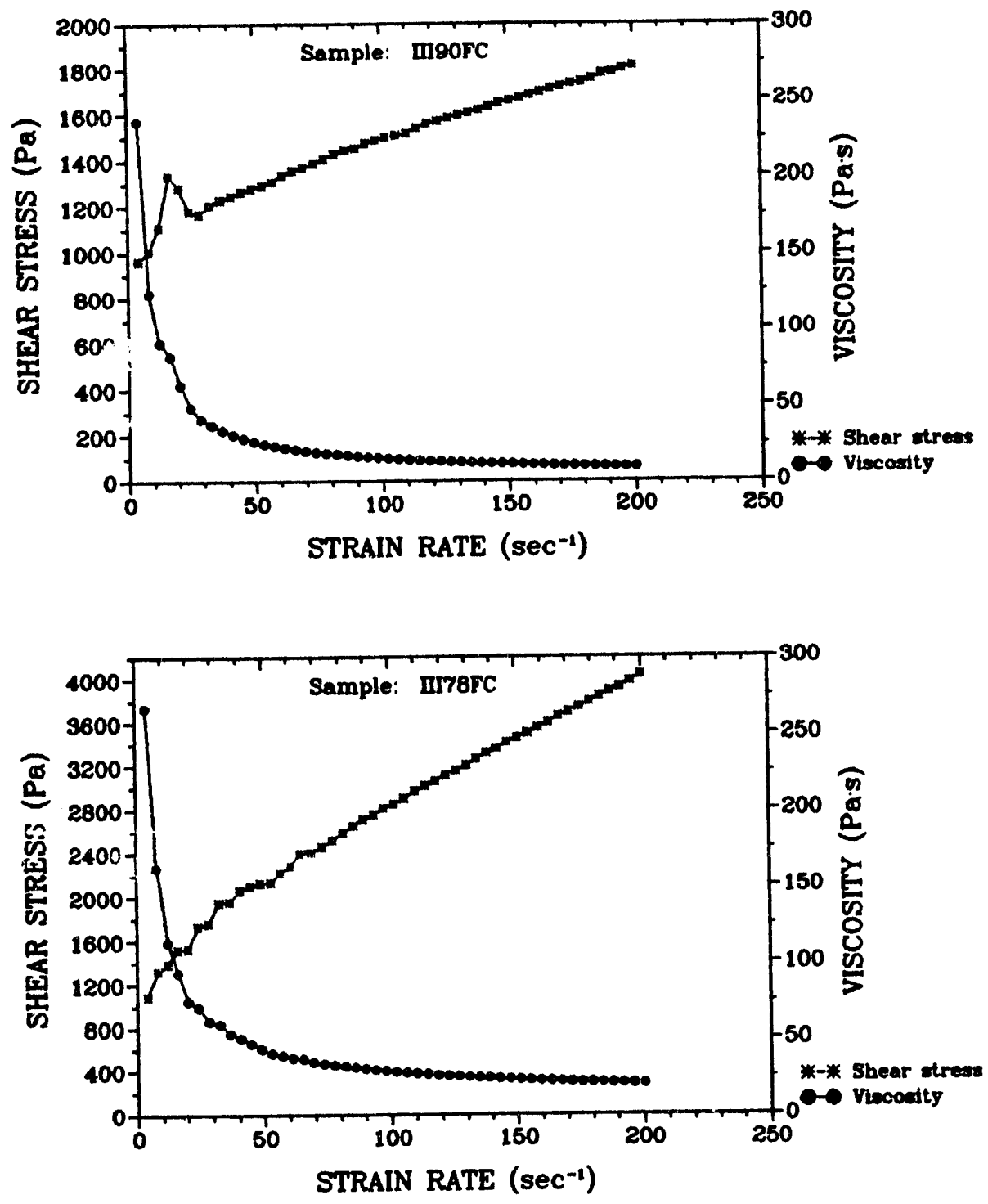

Figure 2. (continued) (e) Paste weight $=76.22$ grams. (f) Paste weight $=71.26$ grams 

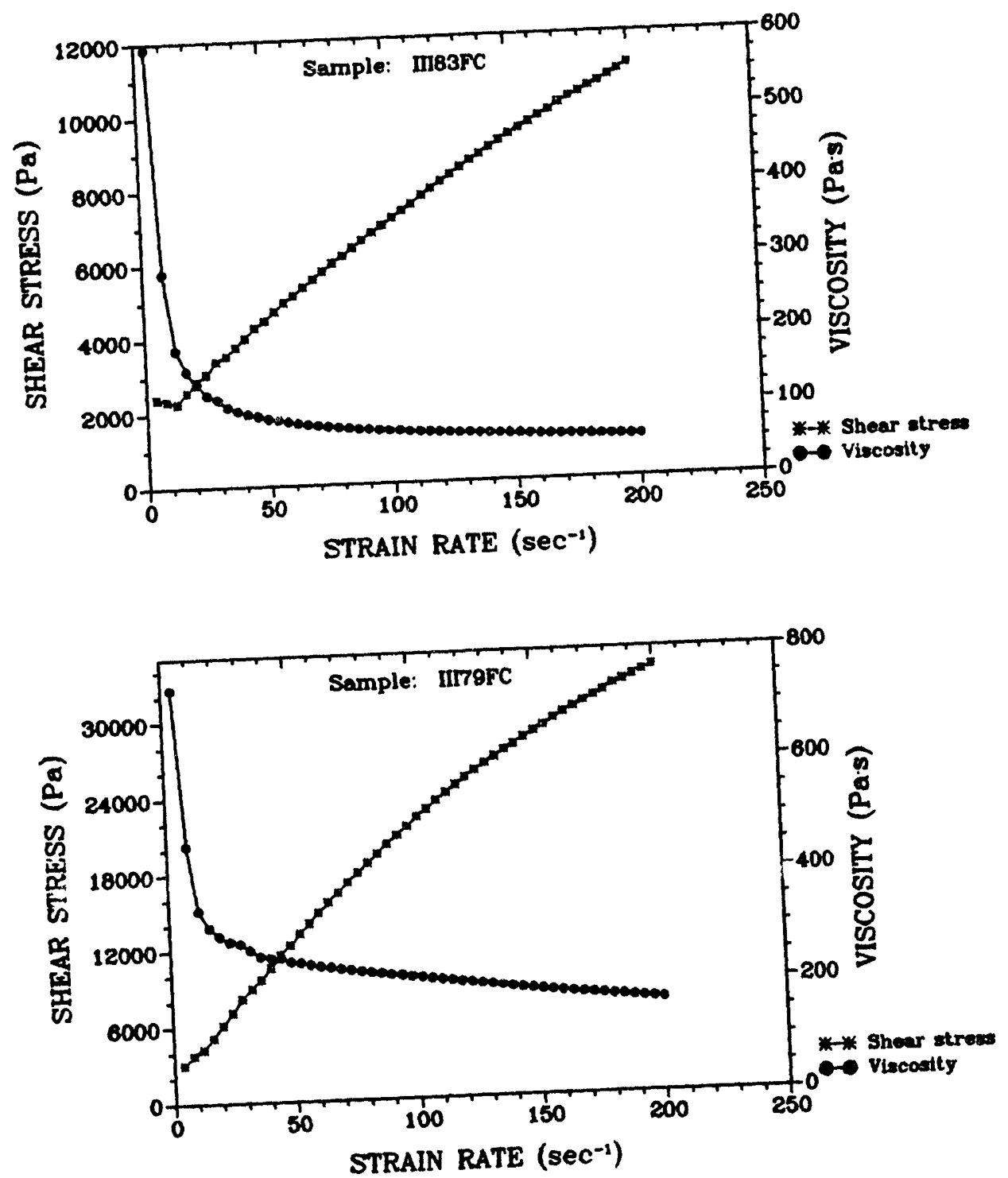

(continued) (g) Paste weight $=70.20$ grams. (h) Paste weight $=66.60$ gram 


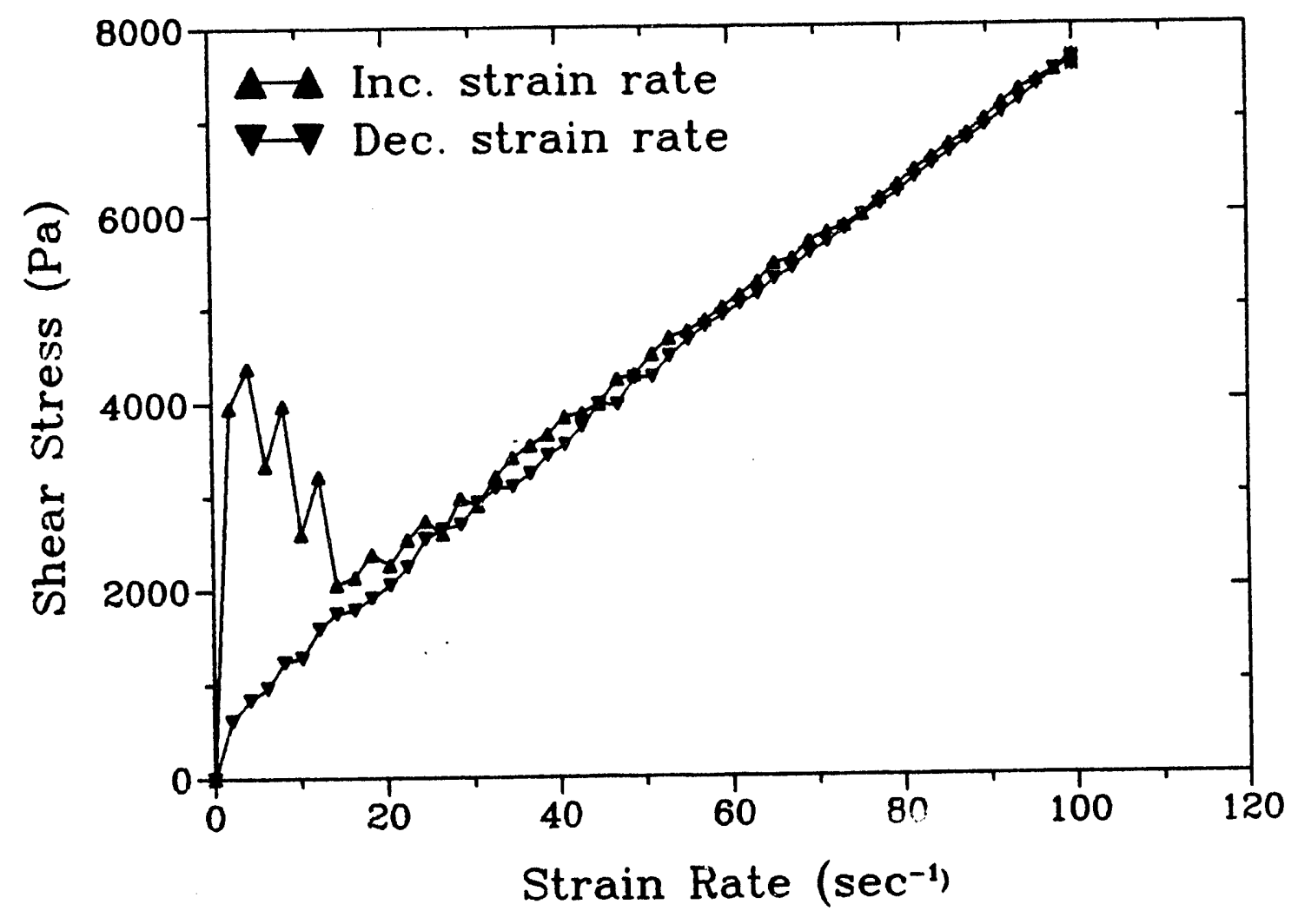

Figure 3. Flowcurve for acetate paste processed for 40 minutes. Paste weight $=76.1$ grams. Note that the fluctuations in shear stress with increasing strain rates do not appear for decreasing strain rate 
Yield stress measurements were obtained by controlled shear stress measurements, as well as by regression from various rheological models. Measured yield stress values as a function of paste weight are shown in Figure 4. There are two regions in the shear stress plot. First, there is a relatively flat (zero slope) region at high paste weight. At paste weights below 76 grams, the yield stress of the paste increases rapidly, and in a relatively linear fashion.

For comparison purposes, regression analysis was used to 1) infer yield stress values for the acetate pastes, and 2) obtain other rheological parameters such as plastic viscosity and power law exponent for the pastes. The rheology data for several pastes were statistically fit to a Hershel-Bulkley model

$$
\tau=\tau_{y}+\eta_{p}(\dot{\gamma})^{n}
$$

over a strain rate range of $0-100 \mathrm{sec}^{-1}$. The parameters in the model are: $\tau=$ shear stress, $\tau_{y}=$ yield stress, $\eta_{p}=$ plastic viscosity, $\dot{\gamma}=$ strain rate, and $n=$ power law exponent. This model is often applied to partic.. slurries and soils [14]. A representative set of analyses is given in Table I. Both measurement and regression show increasing yield stress with decreasing paste weight. The regression analysis also shows increasing plastic viscosity with decreased paste weight. There is an increase to the power law index, indicating that the material becomes more Bingham Plastic in behavior as the solvent is removed. 
Yield stress vs paste weight

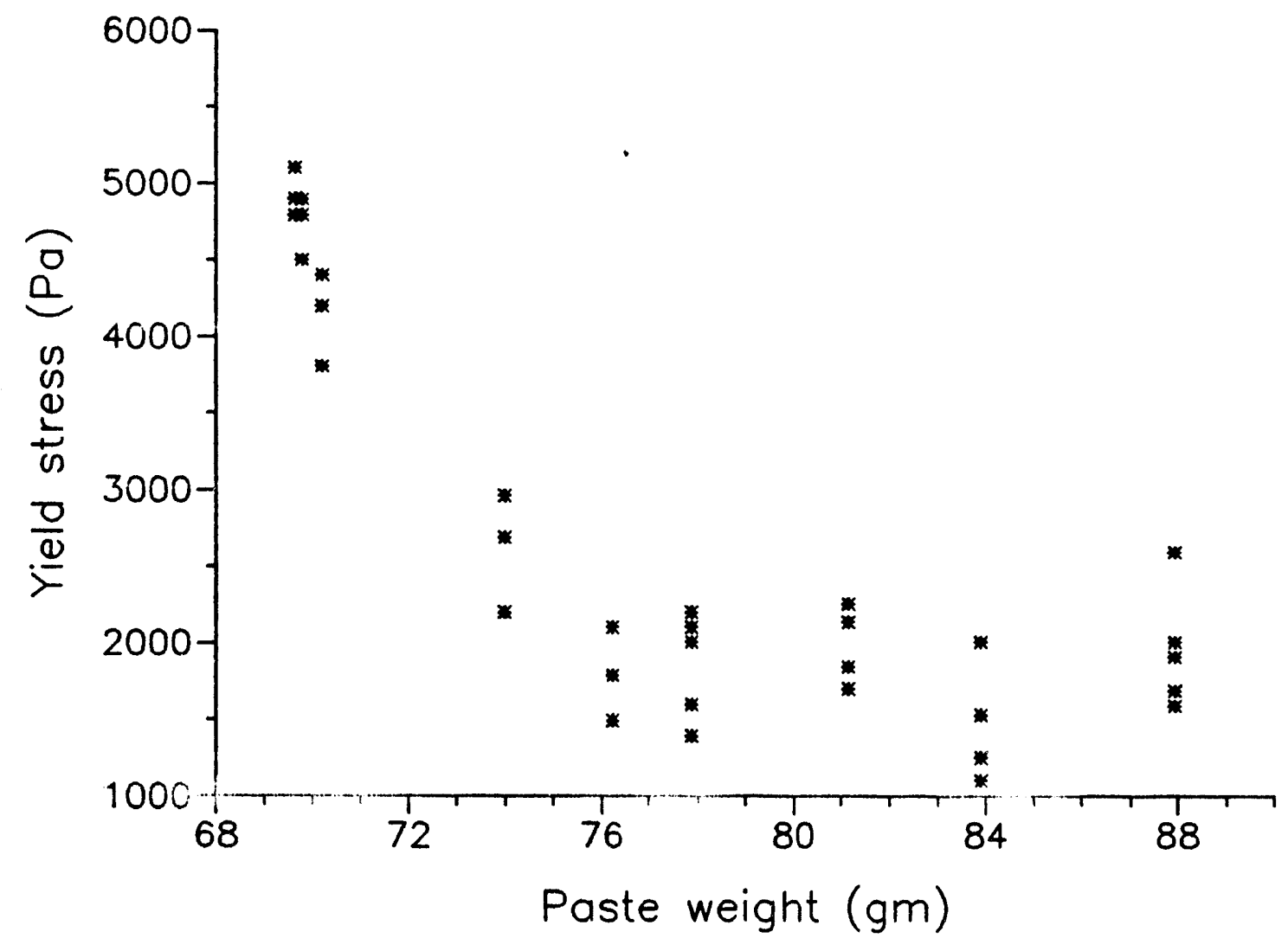

Figure 4. Yield stress as a function of paste weight. Data are measured values obtained by controlled torque methods 
Table I. Regression analyses for selected acetate pastes. Parameters are $\tau=$ shear stress, $\tau_{\mathrm{y}}=$ yield stress, $\eta_{\mathrm{pl}}=$ plastic viscosity, $\dot{\gamma}=$ strain rate, $\mathrm{n}=$ power law exponent

\begin{tabular}{|c|c|c|c|c|c|}
\hline $\begin{array}{c}\text { Paste Wt. } \\
(\mathrm{g})\end{array}$ & $\begin{array}{c}\text { Meas. Yield } \\
\text { Stress } \\
(\mathrm{Pa})\end{array}$ & $\begin{array}{c}\text { Yield Stress } \\
(\text { regressed }) \\
(\mathrm{Pa})\end{array}$ & $\begin{array}{c}\text { Plastic } \\
\text { Visc. } \\
(\mathrm{Pa} \cdot \mathrm{s})\end{array}$ & $\begin{array}{c}\text { Power Law } \\
\text { Exponent }\end{array}$ & $\begin{array}{c}\text { Coeff. of } \\
\text { Deter. } \\
\left(\mathrm{R}^{2}\right)\end{array}$ \\
\hline 77.87 & 1600 & 799 & 17 & 0.23 & 0.89 \\
\hline 76.22 & 1600 & 1065 & 28 & 0.72 & 0.96 \\
\hline 71.26 & 3300 & 1133 & 136 & 0.73 & 0.96 \\
\hline 70.20 & 3700 & 1480 & 196 & 0.80 & 0.98 \\
\hline 66.60 & 5200 & 2948 & 374 & 0.90 & 0.97 \\
\hline
\end{tabular}

\section{Piston Extrusion Rheology}

Extrusion data were collected at crosshead speeds of $5,10,20,50,75$, and 100 $\mathrm{mm} /$ minute for the four die ratios $(5: 1,8: 1,10: 1,16: 1)$. Typical load vs time data for tests on a 10:1 die are shown in Figure 5. From the data obtained in this manner, a representative load for steady state flow may be obtained. For this study, we used the minimum value observed after development of steady state flow. Tests were performed at paste weights of 70 grams ( 0.59 volume fraction solids) and 67 grams ( 0.65 volume fraction solids).

Using the load values obtained by the above method, piston force is plotted as a function of crosshead speed for the various dies (Figure 6). The data produce generally straight lines, with a slight shear-thinning occurring at low crosshead speeds. For the purposes of this study, each data set was treated as a straight line. From the force data, we 


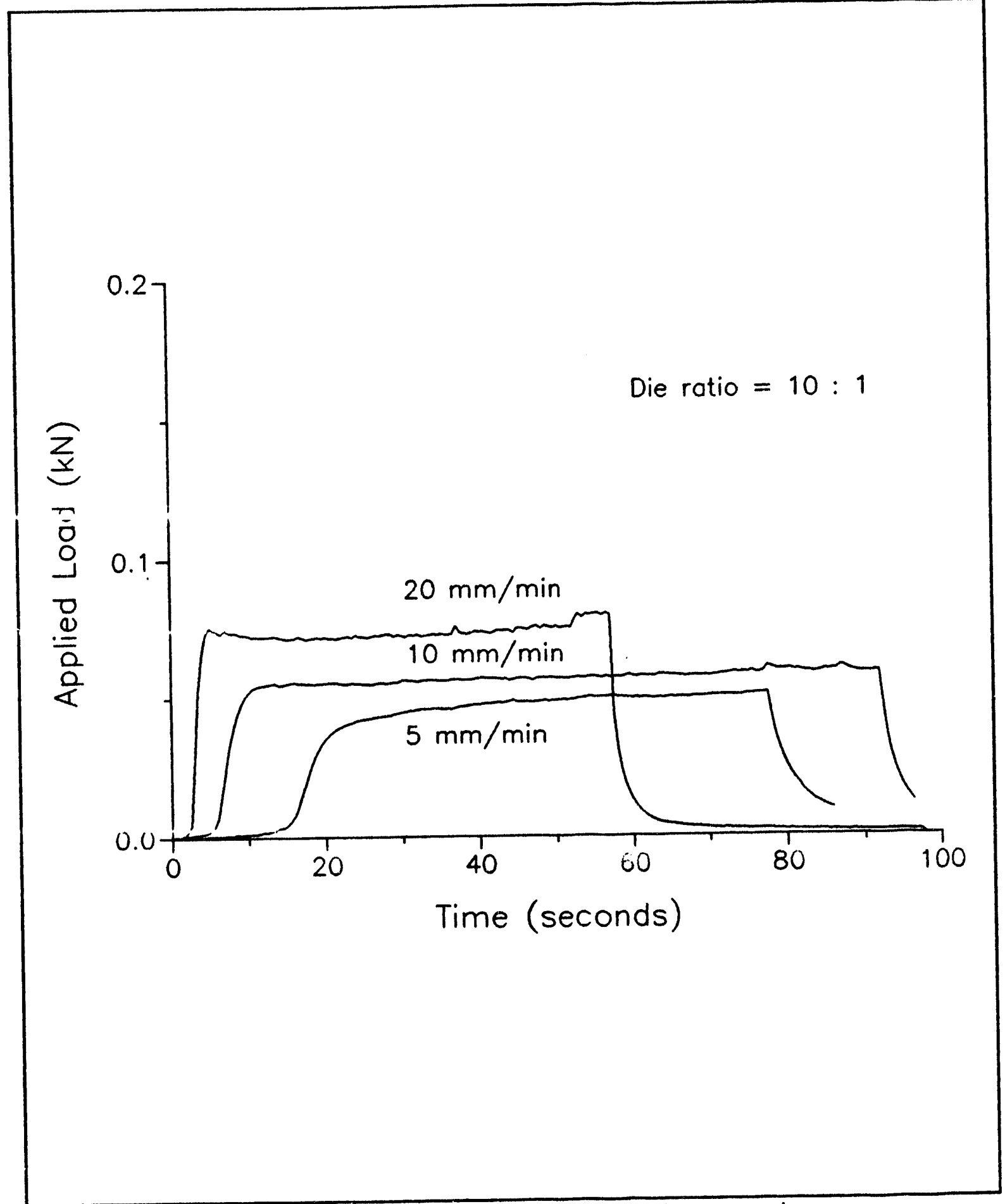

Figure 5. Representative load vs time data obtained by piston extrusion on a compressional testing machine. Paste weight $=70$ grams 


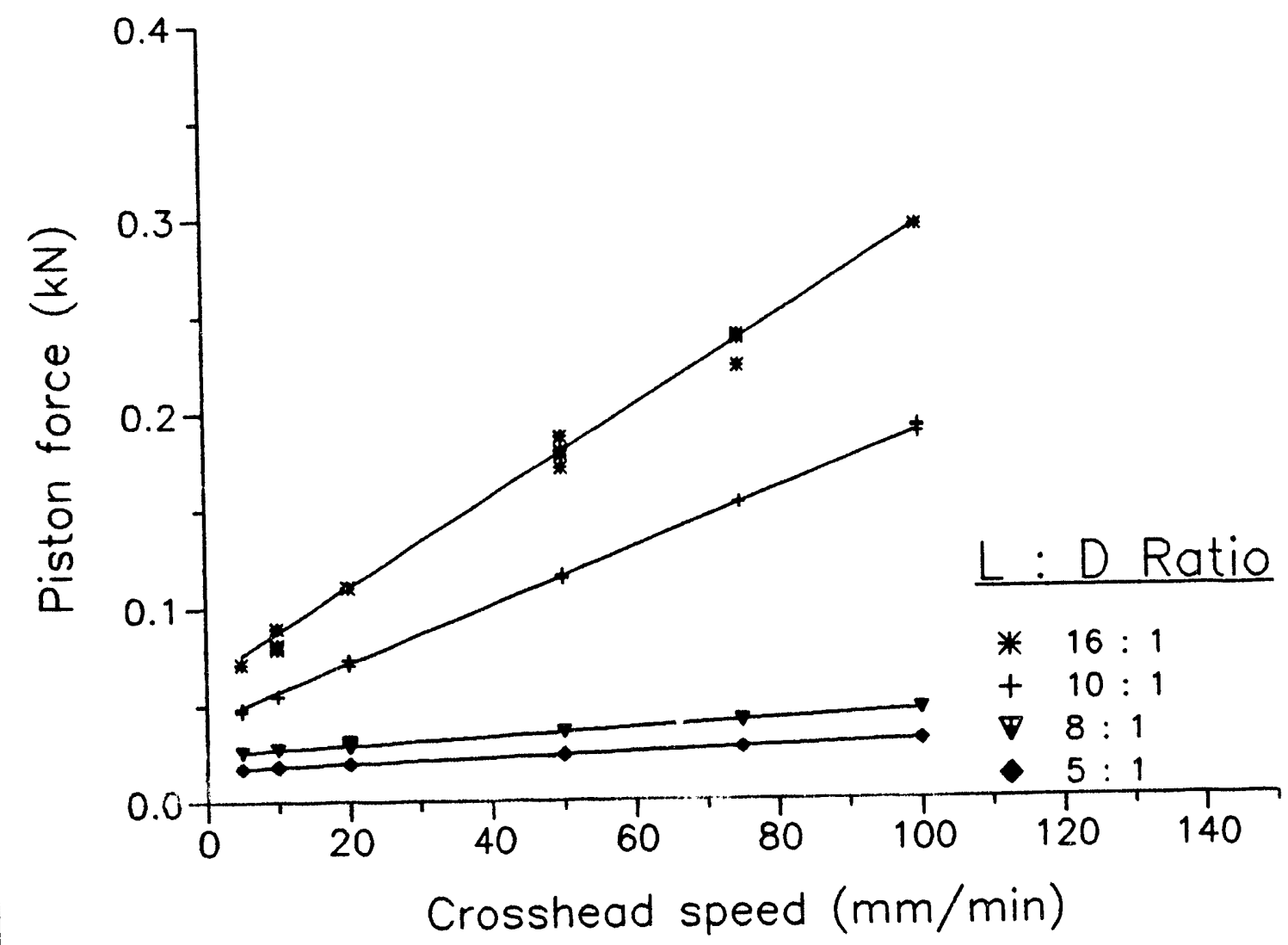

Figure 6. Piston force vs crosshead speed for the four dies used in this study. Paste weight $=70$ grams 
may calculate the total pressure needed to cause paste extrusion using the relationship $P=$ F/A. The pressure data obtained for various dies and crosshead speeds testing a 70 gram paste are given in Table II. The data were analyzed after the method described by Benbow [15 - 17]. Benbow claims that extrusion pressure has two components. The first term describes flow in the die barrel. It suggests that flow in the barrel is plastic and that the pressure component depends only on die reduction and paste yield stress. The second term describes flow through the die land. Flow in this region is controlled by the minimum shear stress needed to cause flow, and the resistance to flow along the die wall as a function of pressure. The relationship is as given in Equation 3

Table II. Extrusion pressures for paste weight $=70$ grams ( 0.6 volume fraction solids)

\begin{tabular}{|c|c|c|c|c|}
\hline \multicolumn{5}{|c|}{ Extrusion Pressure (kPa) } \\
\hline Die ratio & $5: 1$ & $8: 1$ & $10: 1$ & $16: 1$ \\
\hline $5 \mathrm{~mm} / \mathrm{min}$ & 203.3 & 273.5 & 391.0 & 548.2 \\
\hline $10 \mathrm{~mm} / \mathrm{min}$ & 209.8 & 288.2 & 440.2 & 622.3 \\
\hline $20 \mathrm{~mm} / \mathrm{min}$ & 222.8 & 301.4 & 538.5 & 770.5 \\
\hline $50 \mathrm{~mm} / \mathrm{min}$ & 261.7 & 359.0 & 933.4 & 1215.1 \\
\hline $75 \mathrm{~mm} / \mathrm{min}$ & 294.2 & 407.1 & 1079.2 & 1585.7 \\
\hline $100 \mathrm{~mm} / \mathrm{min}$ & 326.7 & 456.2 & 1325.0 & 1956.2 \\
\hline
\end{tabular}




$$
P=2 \ln \frac{D_{0}}{D} \sigma_{y}+4 \frac{L}{D}\left(\tau_{0}+\beta V\right)
$$

The variables are: $P=$ pressure applied to the barrel; $D_{0}=$ the extruder barrel diameter; $D$ $=$ the die orifice diameter; $\sigma_{y}=$ paste yield stress; $L=$ die land length; $\tau_{0}=$ initial die wall shear stress; $\beta=$ the die land velocity factor, and $V=$ paste velocity at the die land wall. Equation 3 is then modified to account for velocity effects in the barrel region (Equation 4)

$$
P=2 \ln \frac{D_{0}}{D}\left(\sigma_{x}+\alpha V\right)+4 \frac{L}{D}\left(\tau_{0}+\beta V\right)
$$

There are two new parameters: $\sigma_{y o}=$ the zero velocity shear stress in the barrel, and $\alpha=$ the barrel velocity factor. The main point is that Equations 3 and 4 are each sums of two linear equations dependent on extrudate velocity.

Given the pressure for each die configuration and crosshead speed, we can calculate the extrudate velocity for each pressure. We assume no extrudate backflow in the extruder barrel, and conservation of volume during flow. Next, a plot of pressure vs. L/D ratio for constant extrudate velocity is produced (Figure 7). Extrapolation of the lines in Figure 7 to $L / D=0$ yields regressed applied pressure values. Differences are due to velocity effects on extrusion pressure. Regression of the applied pressure data to zero velocity provides the value of $\sigma_{y}$, using the relationship $P_{0}=2 \ln \left(D_{0} / D\right) \sigma_{y}$. The die wall resistance $\tau_{0}$ is the slope of the pressure vs (L/D) line at zero velocity. The $\beta$ value is the change in $\tau_{0}$ with extrudate velocity. 


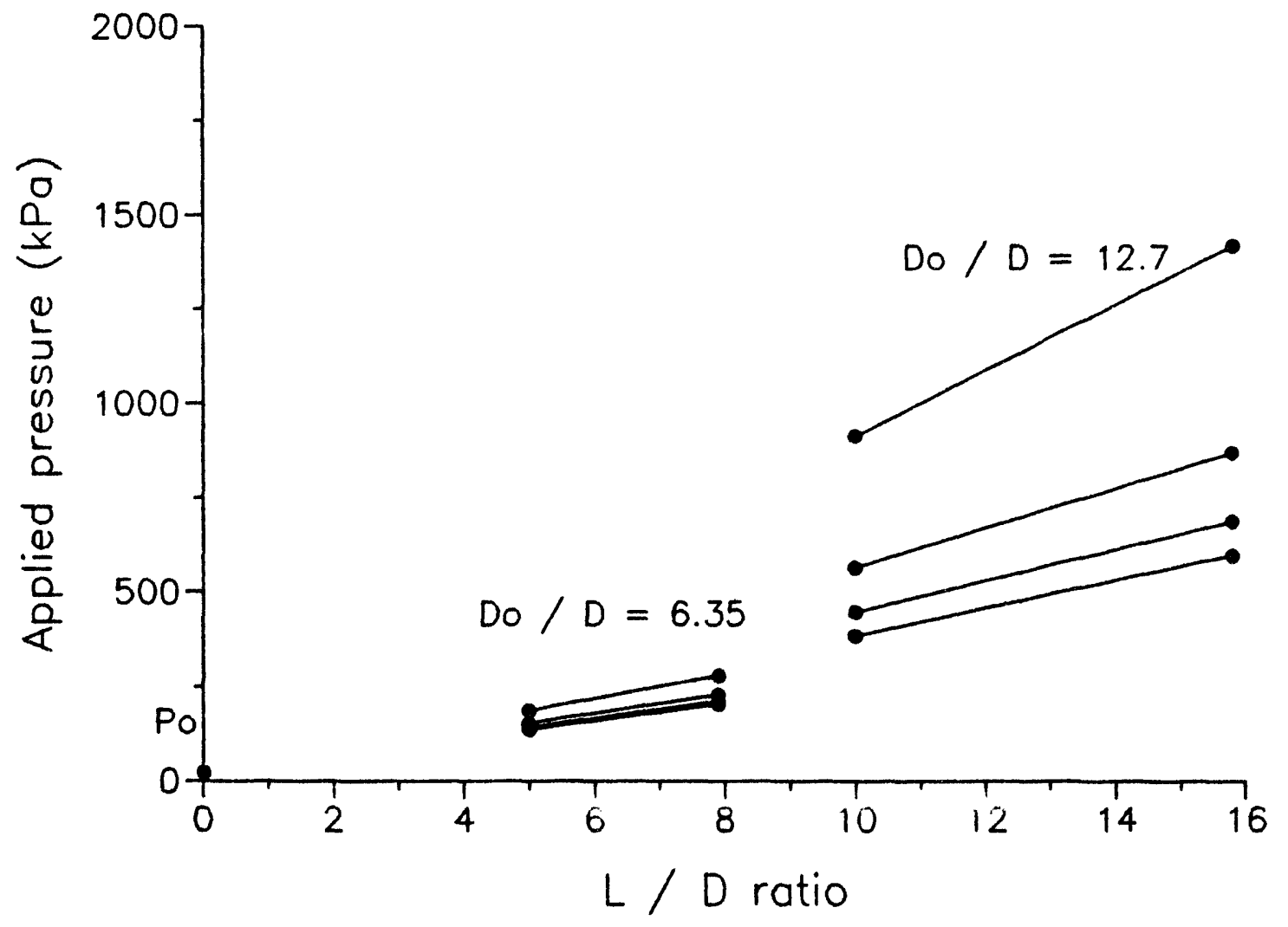

Figure 7. Extrusion pressure vs L/D ratio. Note that the data fall into two groups, for each $D_{0} / D$ ratio. The piston speeds are $5,10,20$, and $50 \mathrm{~mm} / \mathrm{min}$ from bottom to top of each $D_{0} / D$ set 
101

The paraneters obtained in this manner may be further reduced by use of computer assisted numerical analysis ${ }^{14}$. By solving Equation 4 for several L/D ratios and extrudate velocities, we obtain the velocity dependent yield stress $\left(\tau_{y_{0}}\right)$ and the velocity factor for paste flow in the barrel, $\alpha$. Data for 67 gram pastes are shown in Table III. Performing the analysis described above yields the parameter values for Equation 3 or 4 given in Table IV.

\section{Volume Fraction Solids}

Determination of the volume fraction of solids in the pastes as a function of paste weight by the methods described above yielded a range of values (Figure 8). At high paste weights (low volume fraction solids) the data from the two methods vary significantly (calculated - measured $\approx 20 \mathrm{vol} . \%$ ), but the data approach one another at lower paste weights

Table III. Extrusion pressure data for 67 gram acetate paste ( 0.65 volume fraction solids)

\begin{tabular}{||c|c|c|c|c|}
\hline \multicolumn{5}{|c|}{ Extrusion Pressure $(\mathrm{kPa})$} \\
\hline \hline Die ratio & $5: 1$ & $8: 1$ & $10: 1$ & $16: 1$ \\
\hline $5 \mathrm{~mm} / \mathrm{min}$ & 982.5 & 1324.5 & 2052.3 & 2909.44 \\
\hline $10 \mathrm{~mm} / \mathrm{min}$ & 1040.6 & 1411.5 & 2495.9 & 3583.8 \\
\hline $20 \mathrm{~mm} / \mathrm{min}$ & 1156.6 & 1586.3 & 3383.1 & 4932.5 \\
\hline $50 \mathrm{~mm} / \mathrm{min}$ & 1505.0 & 2106.6 & 6044.9 & 8978.9 \\
\hline $75 \mathrm{~mm} / \mathrm{min}$ & 1795.3 & 2541.1 & 8263.0 & 12350.7 \\
\hline $100 \mathrm{~mm} / \mathrm{min}$ & 2085.56 & 2976.6 & 10481.2 & 15722.7 \\
\hline
\end{tabular}

\footnotetext{
${ }^{14}$ Eureka (Borland International, Scotts Valley, CA) or Mathcad (Mathsoft, Cambridge, MA)
} 


\section{Acetate Precursor Paste}

\section{File: VFRACTSO.SPF}

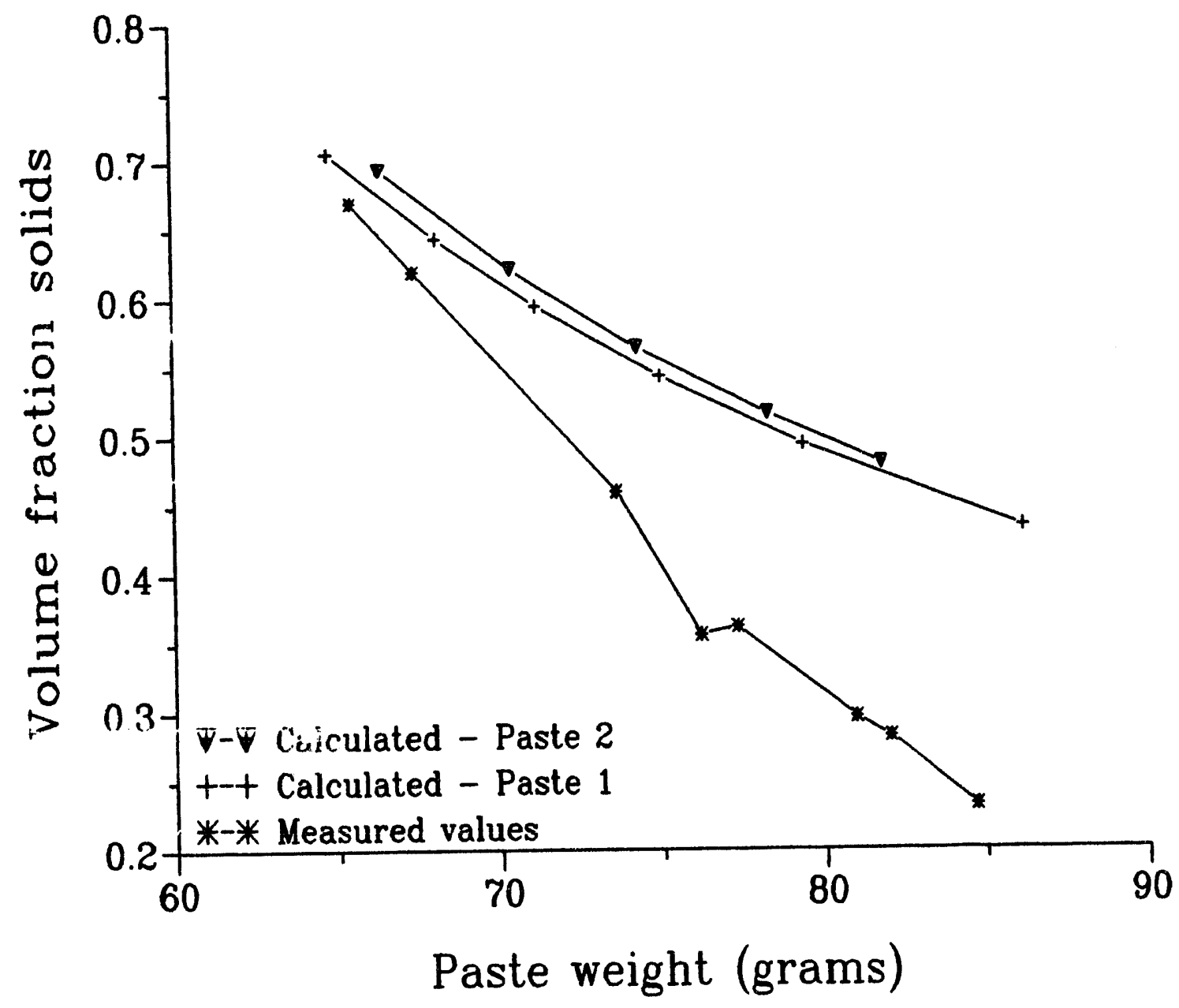

Figure 8. Volume fraction solids as determined by calculation described in text, and by measurement 
(calculated - measured $\approx 5$ vol. $\%$ ). Both methods reflect the increase in volume fraction of solids as paste weight decreases. For this paper we will use the median value between the calculated and measured volume fraction solids as representative of the acetate paste. A representative set of paste weight / volume fraction solids pairs are given in Table V.

\section{Particle Size Analysis}

Sieve analysis of the acetate paste yielded the results shown in Table VI. The total weight of the retained fraction was 0.310 grams; bulk density $=3.0$ grams. Total paste weight was 82 grams ( 0.37 volume fraction solids), thus, the retained fraction made up $0.4 \%$ of the total paste weight. For a paste density of $1.8 \mathrm{~g} / \mathrm{cm}^{3}$, the volume fraction of solids retained in the sieves is roughly $0.2 \%$. SEM imaging (Figure 9) shows that the retained material consists of fine grained masses, possibly dried flocs, and agglomerates of platy and rod-shaped particles.

Table IV. Volume fraction of solids for some representative paste weight values

\begin{tabular}{|c|c|}
\hline Paste Weight (grams) & Volume fraction solids \\
\hline 85.0 & 0.36 \\
\hline 80.0 & 0.42 \\
\hline 75.0 & 0.49 \\
\hline 70.0 & 0.59 \\
\hline 65.0 & 0.70 \\
\hline
\end{tabular}




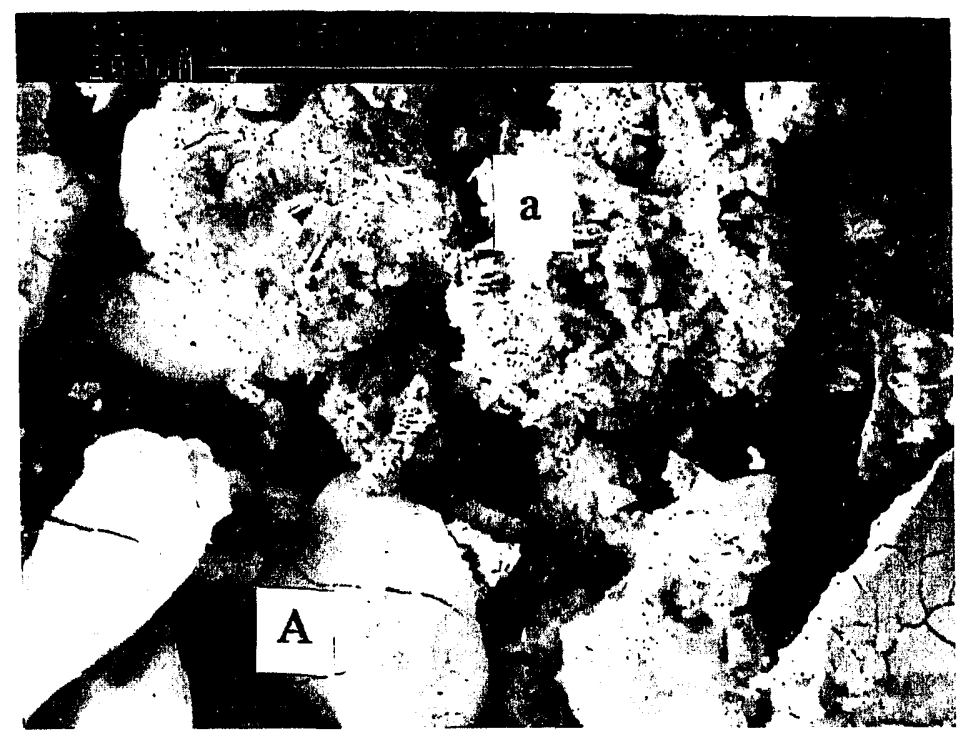

Figure 9. SEM micrograph of retained fraction from sieve analysis. Note that there are agglomerates of fine particles (A), and aggregates (a) of larger material 
Table V. Sieve analysis of acetate paste. Weight fractions are normalized in terms of the weight of the retained fraction [12]

\begin{tabular}{|c|c|c|}
\hline Sieve No. & Size $(\mu \mathrm{m})$ & Fract. Oversize \\
\hline 20 & 850 & 0.08 \\
\hline 40 & 425 & 0.17 \\
\hline 50 & 300 & 0.13 \\
\hline 70 & 212 & 0.20 \\
\hline 100 & 150 & 0.22 \\
\hline 140 & 106 & 0.11 \\
\hline 200 & 75 & 0.09 \\
\hline
\end{tabular}

Analysis of the fine fractions in the paste shows no dependence on processing time/paste weight. Results of sequential sedimentation-centrifugation analysis are given in Table VII. There is only a $0.1 \mu \mathrm{m}$ change in median particle size diameter for a 45 minute processing time change. Both pastes show a size distribution $1.5-2.0 \mu \mathrm{m}$ wide, with 12 and $17 \mathrm{wt}$. \% of the total below $0.15 \mu \mathrm{m}$. No material was observed larger than $1.5 \mu \mathrm{m}$. This suggests the larger fractions seen in the sieve analysis are disrupted by sonication, or there were insufficient large grains present for the particle size analyzer to detect.

\section{Paste Chemistry}

Attempts to determine the phases present in the acetate paste yielded mixed results. Bulk chemical analysis of the acetate paste by ICP-OES showed that batch to batch variation in elemental composition was minimal. Analysis of three paste samples yielded weight 
Table VI. Particle size analysis for acetate pastes by centrifugation [12]

\begin{tabular}{|c|c|c|}
\hline Size Range $(\mu \mathrm{m})$ & $\begin{array}{c}\text { \% in range } \\
(30 \text { minutes })\end{array}$ & $\begin{array}{c}\text { \% in range } \\
(75 \text { minutes })\end{array}$ \\
\hline $60-3.0$ & 0.0 & 0.0 \\
\hline $3.0-1.0$ & 40.4 & 20.2 \\
\hline $1.0-0.8$ & 28.5 & 38.0 \\
\hline $0.8-0.6$ & 10.3 & 18.3 \\
\hline $0.6-0.4$ & 2.2 & 4.7 \\
\hline $0.4-0.3$ & 0.4 & 1.8 \\
\hline $0.3-0.0$ & 18.2 & 17.0 \\
\hline Median size $(\mu \mathrm{m})$ & 0.93 & 0.84 \\
\hline
\end{tabular}

fractions for $\mathrm{Ba}, \mathrm{Y}$, and $\mathrm{Cu}$ of $0.287 \pm 0.007,0.434 \pm 0.004$, and $0.147 \pm 0.002$, respectively. These values correspond to mole ratios of $\mathrm{Ba}: \mathrm{Y}=1.95 \pm 0.03, \mathrm{Cu}: \mathrm{Y}=$ $2.95 \pm 0.01, \mathrm{Cu}: \mathrm{Ba}=1.51 \pm 0.03$. The absolute accuracy of the technique is $+/-2$ wt. $\%$. This composition is very nearly on the 123 composition but is shifted very slightly toward $\mathrm{Y}_{2} \mathrm{O}_{3}$. This will probably result in the presence of a small level of 211 impurity in the fired material [18].

\section{$\underline{X-r a y}$ Diffraction}

$\mathrm{X}$-ray diffraction of powdered acetate paste yielded no information on phases present in the paste. Figure 10 shows a typical diffraction pattern for an acetate paste batch which was dried, ground to -200 mesh, and analyzed by powder XRD methods. The lack of 


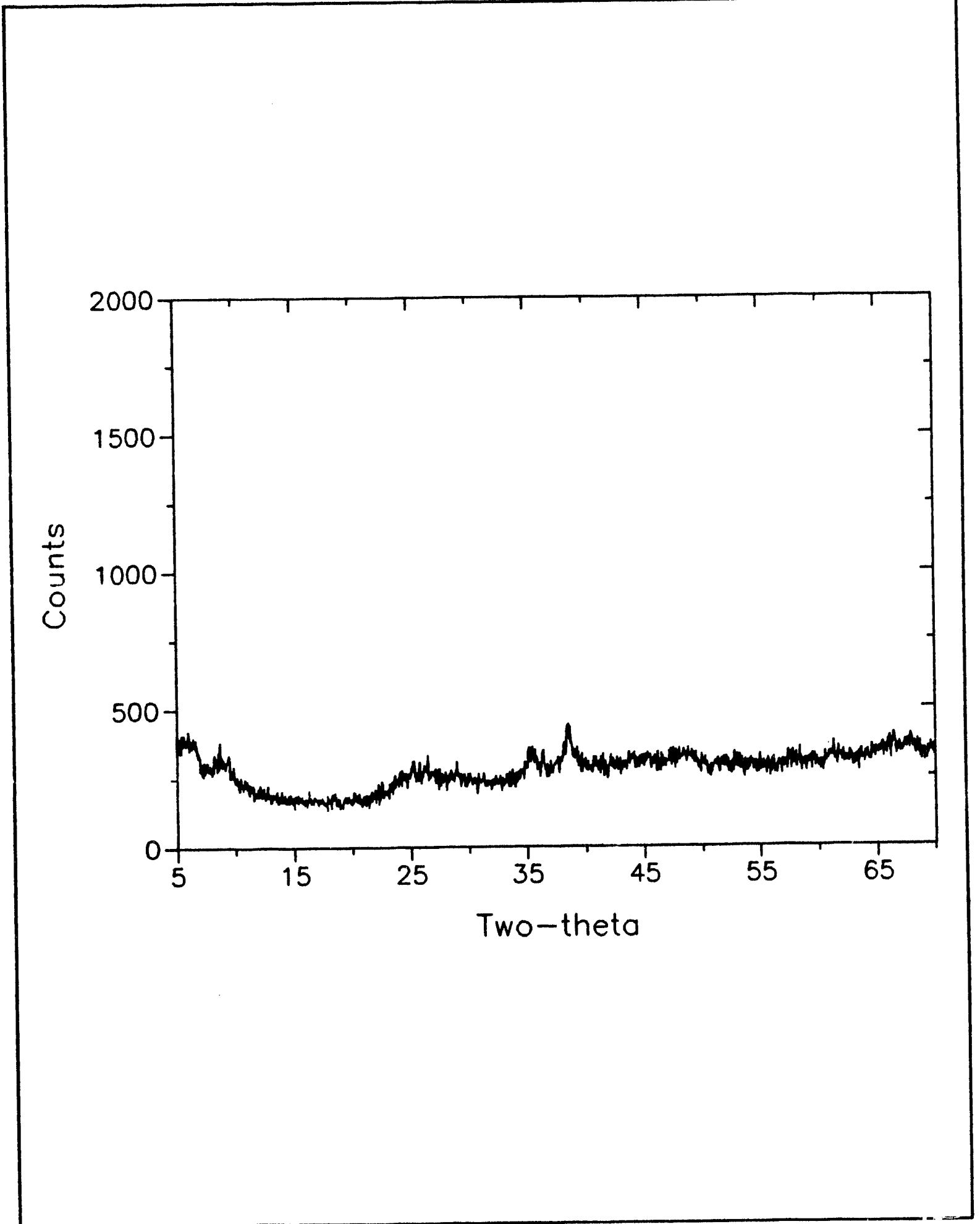

Figure 10. X-ray diffraction pattern of dried, ground acetate precursor 
significant diffraction maxima makes phase identification impossible. There is evidence for fine scale (sub-micron) crystallinity, as evidenced by the broad, low intensity diffraction maxima.

\section{Infrared Spectroscopy}

The infrared absorbance spectrum for an acetate paste prccessed for 60 minutes is shown in Figure 11. Table VIII lists peak locations and assignments observed between 3500 930 venumbers. The phases which we may infer to be present by IR spectroscopy are barium acetate and copper acetate. These phases are not unexpected, as the copper acetate is one of the original reactants, and barium acetate might be expected to form by reaction with the yttrium or copper salt. That the copper acetate apparently exists in the paste as an anhydrate is somewhat startling. In aqueous solution, there is likely to be some hydration water associated with the metal salt.

Indications as to the identity of yttrium-containing phases are scarce. Tackett [19] reports two absorptions for the carboxylate group of yttrium acetate in aqueous solution at 1545 and 1462 wavenumbers. These are assigned, respectively, to the asymmetric and symmetric vibrations from bidentate bonding of yttrium to oxygen supplied by the carboxylate group of the acetate ligand. However, these are not sufficient to identify the yttrium bearing phase.

There are no absorptions which may be correlated to observed values for $\mathrm{Ba}(\mathrm{OH})_{2}$ (hydrated $0,1,3$, or 8 times) [20]. There are a number of peaks which could not be assigned, which probably correlate to unidentified bond motions in the yttrium acetate(?) phase, or other acetate hydrates of barium and copper. 


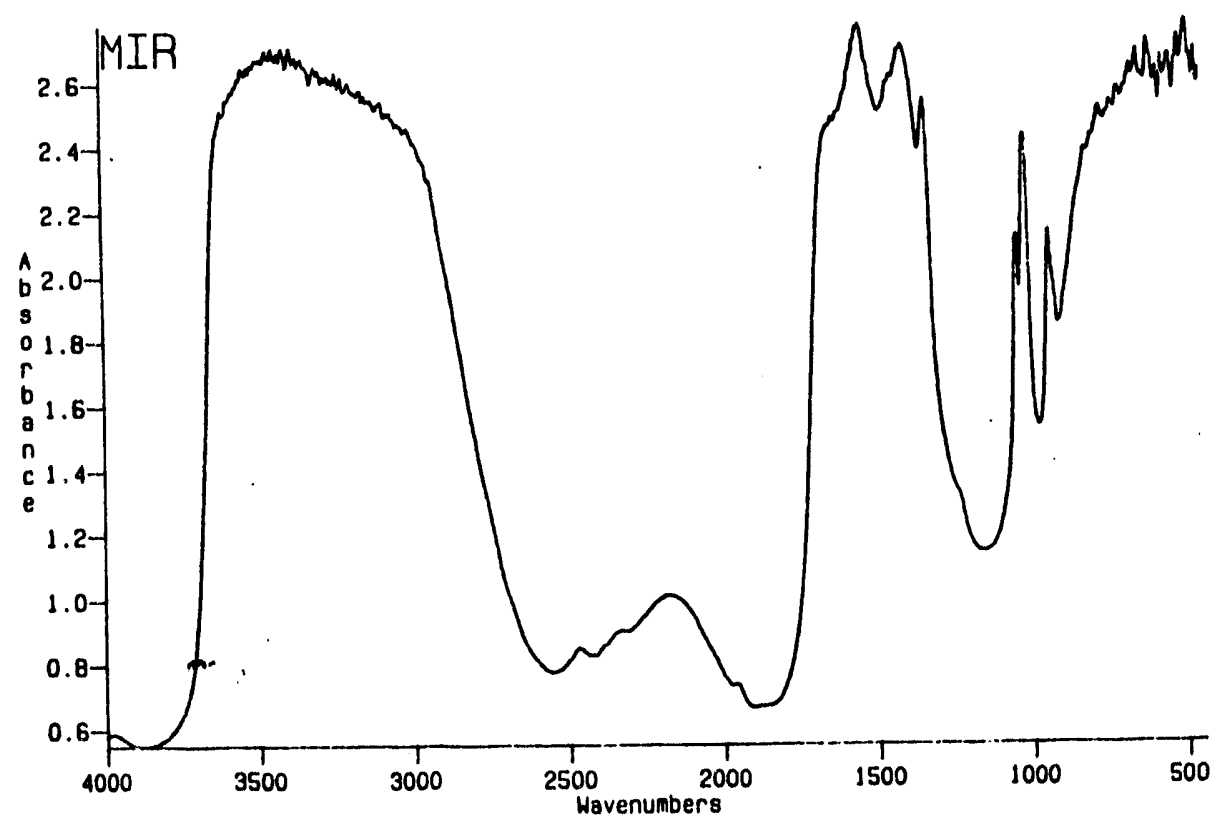

Figure 11. IR absorbance spectrum for acetate paste processed 60 minutes 
Table VII. IR peak assignments for acetate paste processed for 60 minutes. Boxes in 'Standard Peak' column marked "*" could not be assigned to a phase

\begin{tabular}{|c|c|c|c|}
\hline $\begin{array}{l}\text { Observed } \\
\text { Peak }\end{array}$ & $\begin{array}{l}\text { Standard } \\
\text { Peak }\end{array}$ & Phase & Bond motion \\
\hline 3484.8 & & $\mathrm{H}_{2} \mathrm{O}$ & \\
\hline 3004.2 & & $\mathrm{H}_{2} \mathrm{O}$ & \\
\hline $2939.7(\mathrm{sh})$ & $\begin{array}{l}2940 \\
2950\end{array}$ & $\begin{array}{l}\mathrm{Cu}\left(\mathrm{CH}_{3} \mathrm{COO}\right)_{2}[17] \\
\mathrm{Ba}\left(\mathrm{CH}_{3} \mathrm{COO}\right)_{2}[19]\end{array}$ & $\mathrm{CH}_{3}$ sym. stretch \\
\hline 2468.2 & $*$ & & \\
\hline 2362.9 & $*$ & & \\
\hline 2334.1 & * & & \\
\hline 2176.1 & & $\mathrm{H}_{2} \mathrm{O}$ & \\
\hline 1960.5 & $*$ & & \\
\hline 1689.4 & $*$ & & \\
\hline 1650.7 & & $\mathrm{H}_{2} \mathrm{O}$ & \\
\hline 1592.7 & $\begin{array}{l}1595 \\
1590\end{array}$ & $\begin{array}{l}\mathrm{Cu}\left(\mathrm{CH}_{3} \mathrm{COO}\right)_{2}[17] \\
\mathrm{Ba}\left(\mathrm{CH}_{3} \mathrm{COO}\right)_{2}[19]\end{array}$ & C-O asym. stretch \\
\hline 1575.9 & 1572.7 & $\mathrm{Ba}\left(\mathrm{CH}_{3} \mathrm{COO}\right)_{2}[19]$ & C-O asym. stretch (?) \\
\hline 1559.2 & $1560(\mathrm{sh})$ & $\mathrm{Cu}\left(\mathrm{CH}_{3} \mathrm{COO}\right)_{2}[17]$ & C-O asym. stretch \\
\hline 1548.4 & 158 & $\mathrm{Y}\left(\mathrm{CH}_{3} \mathrm{COO}\right):[18]$ & C.O. $\cap$ asys: stretch \\
\hline 1462.8 & $\begin{array}{l}1465 \\
1460\end{array}$ & $\begin{array}{l}\mathrm{Cu}\left(\mathrm{CH}_{3} \mathrm{COO}\right)_{2}[17] \\
\mathrm{Y}\left(\mathrm{CH}_{3} \mathrm{COO}\right)_{3}[18]\end{array}$ & $\begin{array}{l}\mathrm{CH}_{3} \text { asym. bend } \\
\mathrm{C}-\mathrm{O}-\mathrm{O} \text { sym. stretch }\end{array}$ \\
\hline obscured? & $\begin{array}{l}1440 \\
1423\end{array}$ & $\begin{array}{l}\mathrm{Cu}\left(\mathrm{CH}_{3} \mathrm{COO}\right)_{2}[17] \\
\mathrm{Ba}\left(\mathrm{CH}_{3} \mathrm{COO}\right)_{2}[19] \\
\end{array}$ & $\mathrm{CH}_{3}$ asym. ben $\mathrm{J}$ \\
\hline 1412.3 & 1413 & $\mathrm{Cu}\left(\mathrm{CH}_{3} \mathrm{COO}\right)_{2}[17]$ & C-O sym stretch \\
\hline 1354.2 & $\begin{array}{l}1355(\mathrm{sh}) \\
1353 \\
1349\end{array}$ & $\begin{array}{l}\mathrm{Cu}\left(\mathrm{CH}_{3} \mathrm{COO}\right)_{2}[17] \\
\mathrm{Ba}\left(\mathrm{CH}_{3} \mathrm{COO}\right)_{2}[19]\end{array}$ & $\mathrm{CH}_{3}$ sym. bend \\
\hline
\end{tabular}


Table VIII. (continued)

\begin{tabular}{||l|l|l|l||}
\hline $\begin{array}{c}\text { Observed } \\
\text { Peak }\end{array}$ & $\begin{array}{c}\text { Standard } \\
\text { Peak }\end{array}$ & \multicolumn{1}{|c|}{ Phase } & \multicolumn{1}{|c|}{ Bond Motion } \\
\hline 1050.6 & 1050 & $\mathrm{Cu}\left(\mathrm{CH}_{3} \mathrm{COO}\right)_{2}[17]$ & $\mathrm{CH}_{3}$ rocking \\
\hline 1021.1 & 1019 & $\mathrm{Ba}\left(\mathrm{CH}_{3} \mathrm{COO}\right)_{2}[18]$ & $\mathrm{CH}_{3}$ rocking (?) \\
\hline 934.3 & 930 & $\mathrm{Ba}\left(\mathrm{CH}_{3} \mathrm{COO}\right)_{2}[18]$ & $?$ \\
\hline
\end{tabular}

\section{Firing and Sintering}

Densification of the acetate paste proved to be difficult. TG/DTA in oxygen and argon resulted in ignition losses of $42.8 \%$ and $44.1 \%$ respectively. Theoretical weight loss for the system is $56 \%$. DTA of the acetate paste in oxygen showed the presence of a massive exotherm at $450^{\circ} \mathrm{C}$. This exothermic event was still present when the test was performed in argon, but had only $30 \%$ of the heat evolution.

Densification of the acetate powder pellets in oxygen yielded low bulk densities. Typical values range from $37-40 \%$ theoretical relative to $\rho_{123}=6.35 \mathrm{~g} / \mathrm{cm}^{3}$. Prefiring in argon, followed by sintering in oxygen yielded slightly better results, with bulk densities averaging $54 \%$ theoretical.

\section{Fiber Production}

Paste processed for 75 minutes ( 70 grams, 0.59 volume fraction solids) proved to be the best consistency for constant load piston extrusion. Plastic fibers up to 3 meters in length, with fairly uniform diameter could be reproducibly extruded (Figure 12a). The extruded 


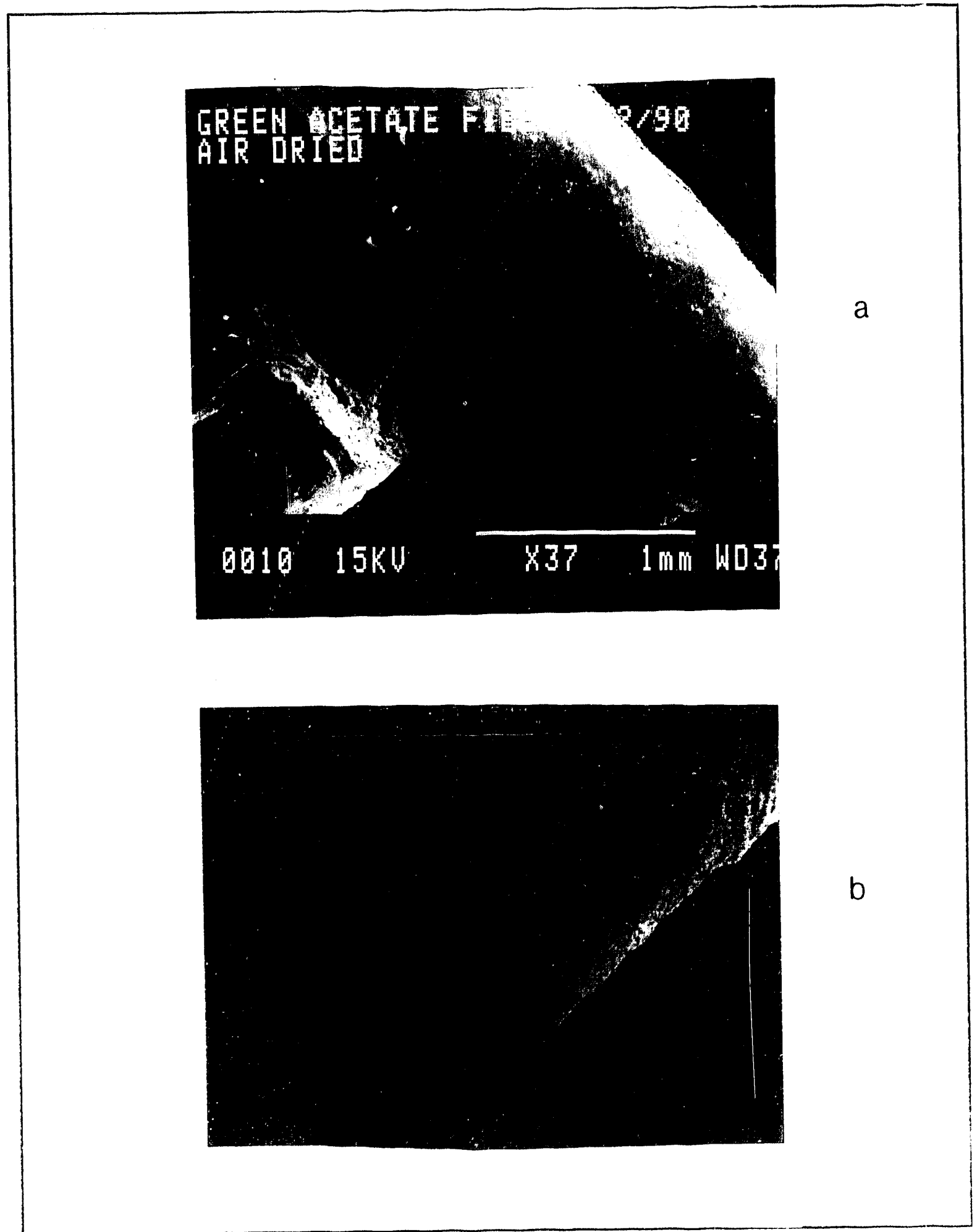

Figure 12. SEM micrographs of acetate fibers. (a) as extruded, (b) sintered 
fibers remained plastic for $1-2$ hours in a normal laboratory environment. Beyond that the fiber surfaces started to form a skin, and surface spalling occurred if the fiber was bent. The fibers were self-supporting; when laid onto a PTFE sheet, no noticeable flattening occurred. Examination of the green fibers shows that the fibers have a smooth, mostly continuous surface, and seem to be made of very fine particles.

Sintering of the acetate fibers by the firing schedule specified above yielded a brittle, porous fiber (Figure 12b). Firing shrinkage (diameter) ranged from $15-20 \%$. Examination of the powder $x$-ray diffraction pattern of the sintered body si'ggests the material is single phase $\mathrm{YBa}_{2} \mathrm{Cu}_{3} \mathrm{O}_{7-\mathrm{x}}$ (Figure 13). However, as noted above, phase pure 123 is hard to manufacture.

Examination of sintered pellets by reflected light microscopy shows the presence of the 211 phase. Estimates of areal distribution of the 211 phase is about $1-2$ percent. There appear to be another $1-2$ percent of other, unidentifiable phases in the sintered compact as well.

\section{Superconducting Properties}

Magnetometry of sintered fibers shows the fibers to consist of superconducting particles. The transition temperature at $10 \%$ of the 50 Oe field cooled saturation level is at 89K. The transition is very broad, about $40 \mathrm{~K}$ between 10 and $90 \%$ of the 50 Oe field cooled saturation value. The results suggest a material in which the individual particles are superconducting, but with low intergranular connectivity (Figure 14). 


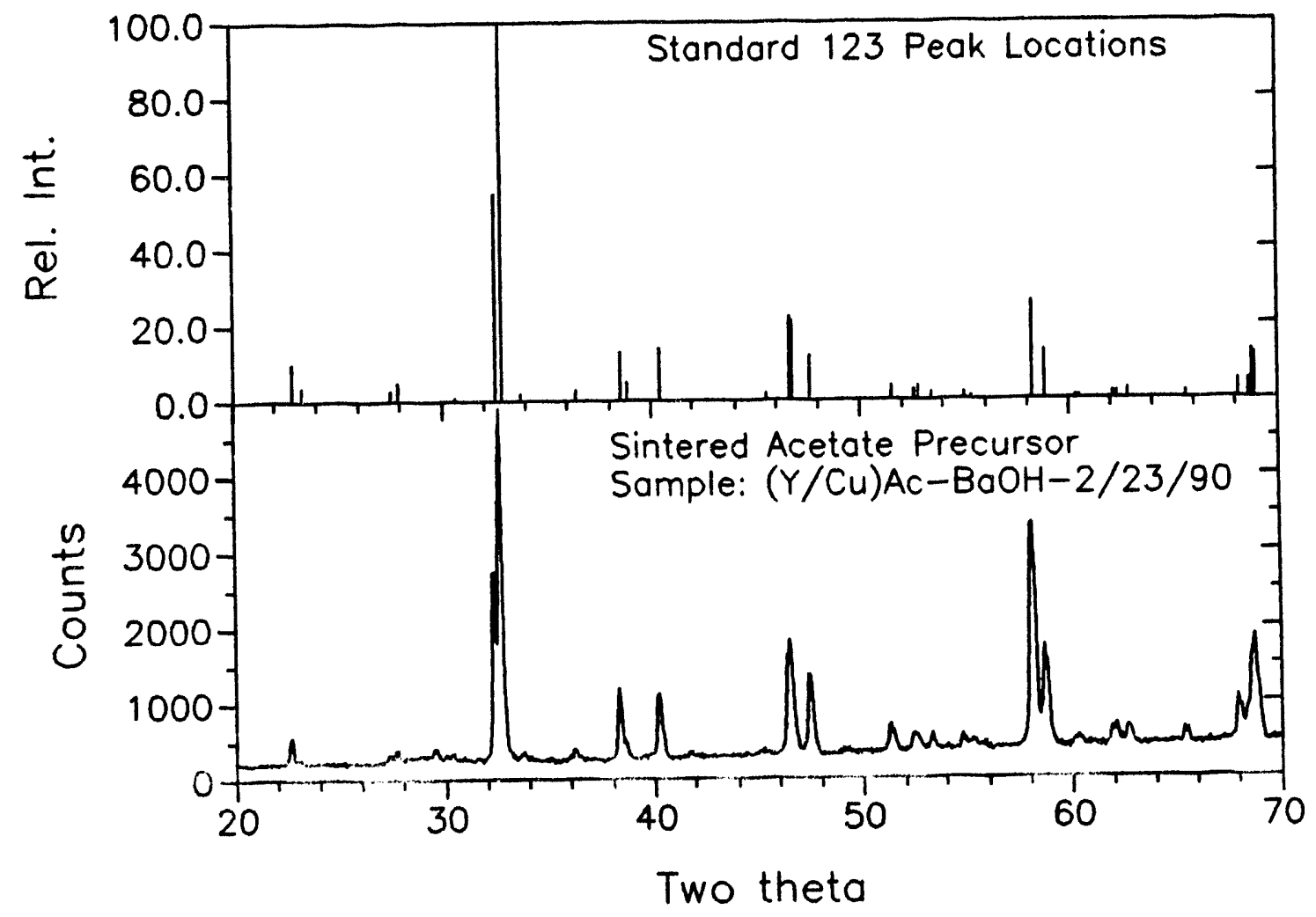

Figure 13. X-ray diffraction pattern for acetate precursor sintered in oxygen 


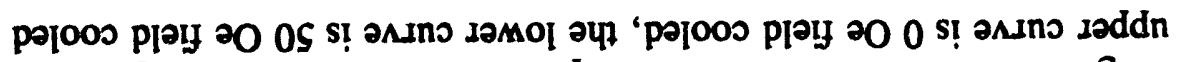

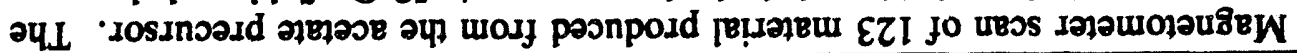
๑I อมก8!t

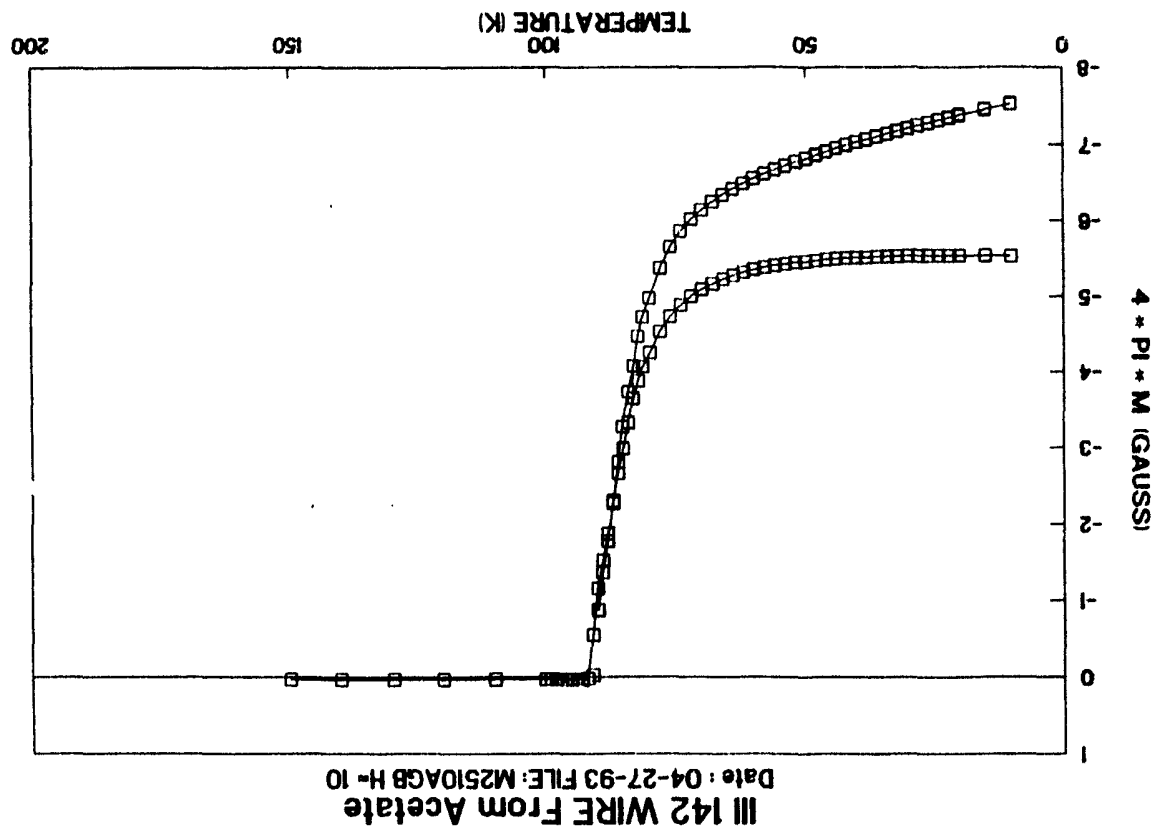




\section{DISCUSSION}

Paste Rheology

The acetate paste is a dense, heterogenous system consisting of micron-sized particles immersed in an aqueous liquid. Such systems commonly exhibit a yield stress, and shear thinning with increasing strain rate $[14,22]$. In a broad sense, flow of the acetate paste follows initial expectations, that is, it fits a Hershel-Bulkley model. However, many factors affect the flow properties. One of the major factors influencing paste rheology in this study is volume fraction of solids. Others such as median particle size and particle size distribution also affect theology. The rheology of the solvent fraction in pastes has been shown to affect flow behavior [23], as has particle texture [22], but these fach will not be considered here.

\section{Concentric Cylinder Rheometry}

The data presented above clearly show the dependence of paste yield stress and viscosity on volume fraction of solids. Concentric cylinder theology (here termed simply rheometry for convenience) of acetate pastes of varying weights demonstrates this dependence by both controlled stress and controlled strain rate methods. from modeling of the pastes as Hershel-Bulkley materials (Table I), it appears the yield stress is unchanged at high paste weights. In these pastes, there is sufficient fluid in the system to lubricate and support flow of particles past one another. As the paste weight decreases past some critical value, particleparticle interactions become more pronounced, and yield stress begins to increase. Finally, at some critical volume fraction solids, the fluid content of the paste is just sufficient to fill the void spaces between the solid particles. Removal of solution beyond this point causes the material to behave as a solid rather than plastic material [14, 23]. Onoda et al. [24] suggest 
that this is because there is dilation which occurs in granular media during shear. They suggest that in liquid deficient granular media, shear causes a dilation pressure, which can cause the material to lose plasticity.

The numerical values of yield stress as statistically determined and the ones directly measured vary by a factor of $2-4$. We expect the value obtained by controlled torque measurements to be more representative of the real yield stress value than that from the statistical fit to a model. There are several reasons for this. First, the Hershel-Bulkley model, as well as other common rheological models such as power law, Bingham Plastic, or Casson, all are based on flow in homogeneous fluid systems in which laminar shear occurs $[14,25]$. As such, they can not be expected to account for deviations from ideal fluid flow seen in particulate slurries or pastes. Second, the regression process may give undue weight to regions of the data which cause deviation of the calculated value relative to the 'true' yield stress. Third, choice of a model for statistical fitting is a somewhat arbitrary process. While parameters such as the coefficient of determination give some idea of how well the model fits the data, the fact remains that in choosing a model we are applying our view of how the material should respond onto the real, complex behavior of the paste.

The increase in plastic viscosity of the acetate paste with increased volume fraction solids is also apparent from Table I. We once again observe a region of low volume fraction solids (high paste weight) over which the viscosity is essentially constant. As paste weight decreases (liquid content decreases), the number of interparticle collisions increases, lubrication at the surface of particles decreases, and thus the plastic viscosity increases.

The shear thinning behavior seen in this study has been widely reported in other work on particulate loaded systems $[22,23,26]$. Shear thinning behavior in such slurries or 
suspensions is due to either 1) shear thinning behavior of the liquid component, or 2) due to changes in the internal structure of the particles in the dispersed (solid) phase [23].

From the rheometer results, we infer that the acetate paste possesses some level of structure as flocculation. At low strain rates, we observe discontinuity in the shear stress. As strain rate is increased, the discontinuities disappear. If the system is sheared at a high strain rate, and the rate is allowed to decay, the shear stress discontinuity is not observed. We attribute this behavior to disruption of the paste microstructure. Further support for this assumption is that the shear stress discontinuity is not present if the paste is re-sheared immediately. The discontinuity reappears if the paste is allowed to rest for 30 minutes.

Rheologically, the shear thinning behavior observed in the pastes may be explained by destruction of large agglomerates. Flocs and agglomerates in a paste will enclose some amount of fluid. This fluid is not excluded from the volume fraction of liquid in the system, and thus effectively raises the volume fraction of solids. If the agglomerate enclosing the liquid is disrupted, the effective volume fraction of solids will decrease, and viscosity will drop [23]. For a monosized particle system, this relationship is expressed by the KriegerDougherty enustion [22?

$$
\eta=\eta_{s}\left(1-\phi / \phi_{m}\right)^{-[\eta] \phi_{m}}
$$

where $\eta=$ the paste viscosity, $\eta_{s}=$ the viscosity of the liquid phase, $\phi=$ the effective volume fraction of solids, $\phi_{\mathrm{m}}=$ the maximum possible packing density of the solid assemblage, and $-[\eta] \phi_{\mathrm{m}}=\mathrm{a}$ factor dependent on the size and shape of the solid particles. In 
many of the paste systems examined above, there is noticeable drop in viscosity at strain rates below $50 \mathrm{sec}^{-1}$. We propose that this is the result of destruction of the flocs in paste structure.

The fluctuations in shear stress decrease with decreased paste weight (increased volume fraction solids). This decrease may be explained if one considers the different types of interactions between particles in the paste at different volume fractions of solids. At higher liquid contents, the particles may move relatively freely, and as the particles move, local regions of high particle concentration, such as bridges, may form. These bridges will support a higher level of shear stress than the bulk paste. When the bridges break, inertia will reduce the level of applied shear stress needed to maintain a given strain rate. As the volume fraction of solids increases, the paste will behave more as a continuous phase, with flow mediated by the interaction of particles which are always in contact with one another to some extent. The formation of a relative continuous phase appears to occur between paste weights of 76 and 71 grams (Figure 2). These weights correspond to volume fraction solids levels of roughly 0.48 and 0.56 , if a median value between the calculated and measured values on Figure 8 is used. Onoda et al. [24] note that Monte Carlo simulations show a order-disorder transition occurs at around $0.50-0.55$ volume fraction solids for uniform spheres. Below this transition point, the particles are disordered as a liquid, above this level, the spheres are ordered as a solid. Effectively, there is glass-solid transition. They note that the onset of dilatancy occurs in hard spheres occurs at $\mathbf{0 . 5 5}$ solids, which is near the order-disorder transition. The reduction in shear stress deviation with increasing volume fraction solids, then, probably relates to onset of dilatancy, i.e. the onset of more uniform, solid-like behavior. Finally, the presence of microscopic structuring is supported by the SEM analysis of the retained fraction in the sieve size analysis (Figure 9), in which we see aggregates of 
large particles, as well as agglomerates of very fine particles. Due to the multiphase nature of the solids in the acetate paste, and also the high solids concentration in the pastes, no attempts were made to determine isoelectric point for the system.

\section{Piston Extrusion}

Yield stress values obtained by piston extrusion, following the method of Benbow et al. [15 - 17] show a drastic increase with decreasing paste weight. Once again this reflects the increase in volume fraction of solids in the paste. For a paste weight of 70 grams, and interpolating from Figure 8, we get an approximate volume fraction solids of 0.59 . For a paste weight of 67 grams, the volume fraction of solids is roughly 0.65 . While these volume fraction solids values seem high, particle size analysis shows that the particles in the acetate paste are not monosized, so we may expect packing fractions in excess of the $0.63-0.64$ range corresponding to optimum packing in monosized assemblages. If we examine the yield stress of paste in the extruder barrel $\sigma_{y}$, we see an increase of $82 \mathrm{kPa}$ for this 0.05 volume fraction increase.

This increase in yield stress may unce ayain be attributed to the same factors rivoked in rheometry. As the liquid content decreases, it becomes more difficult for particles to move past one another as shear deformation occurs in the extruder barrel. These factors fail to explain the order of magnitude differences in yield stress values between the concentric cylinder method and piston extrusion (Table VII). They also fail to explain the difference in the magnitude of the increase in yield stress for the two solids loading levels. For the yield stress data from the rheometer study, we see a two-fold increase in yield stress as volume 
fraction solids increases from 0.65 to $\mathbf{0 . 7 0}$. The same increase in volume fraction solids produces a five-fold yield stress increase as measured by piston extrusion.

Yield stress results obtained for pastes of the same weight by piston extrusion differ markedly from those obtained by use of a concentric cylinder rheometer. Comparison of yield stress values obtained by regression from controlled strain rate methods, measured values by controlled torque methods, and those obtained by piston extrusion demonstrates that the basic principles between techniques are critically different. Table VII shows a comparison

Table IX. Comparison of yield stress values obtained by the various methods used in this study

\begin{tabular}{|c|c|c|c|}
\hline YIELD STRESS & Hershel-Bulkley & Controlled Torque & Piston Extrusion \\
\hline $\begin{array}{c}70 \text { grams } \\
(59 \% \text { solids })\end{array}$ & $1.5 \mathrm{kPa}$ & $3.7 \mathrm{kPa}$ & $22.4 \mathrm{kPa}$ \\
\hline $\begin{array}{c}67 \text { grams } \\
(65 \% \text { solids })\end{array}$ & $2.9 \mathrm{kPa}$ & $5.2 \mathrm{kPa}$ & $104 \mathrm{kPa}$ \\
\hline
\end{tabular}

of yreld values obtained by the aburn :nethods. The values ubtained by use of the curacnus cylinder are clearly less than those obtained by piston extrusion.

When a rheometer is used, there is a system in which the majority of forces act around the annulus between the cup and bob. The system is unconstrained, that is, the paste may change volume (dilate) without hinderance. Thus, when the paste is sheared, i.e. when dilation occurs, the paste may expand freely, and the 'only' forces acting on the paste are rotationally induced. 
In the piston extruder, forces are applied axially, and shear is in response to deformation of the paste along flow laminae. The extruder is essentially a closed system, in that changes in paste volume due to dilation are resisted by the extruder barrel, die, and piston. Exprusion has been compared to undrained soil consolidation tests by several authors [27 - 29]. Undrained shaping of ceramics involves forming processes which maintain constant volume, including extrusion, injection molding, jiggering and ram pressing. This is in contrast to drained forming processes which involve consolidation and liquid removal, such as slip casting or pressure filtration [29]. Implicit in these categories is the ability of the material to dilate freely; thus, we could consider rheometry a drained process.

If we consider the values obtained from rheometry to be a lower limiting case for yield stress of pastes in shear, we still must explain the apparent excess in yield stress exhilited by pastes tested by piston extrusion. The principle of effective stress

$$
\sigma_{T}=\sigma^{\prime}+u
$$

where $o_{\mathrm{T}}=$ die total stress, $\sigma^{\prime}=$ the effective stress, and $u=$ the pore pressure has been used to describe the response of undrained materials to applied stress. The external load applied to a material $\left(o_{\mathrm{T}}\right)$ is supported by both the particulate framework (or percolation network [24]) and by the fluid in the pores of the solid framework. The component of the total stress carried by the pore fluid is the pore pressure, $u$ [28]. The fluid fraction will not support shear, but will resist application of normal stresses. 
In order to initiate flow in an extruder, then, a critical stress level must be reached. In general, the plasticity envelope of a liquid saturated granular material may be described by the Mohr-Coulomb relation

$$
\tau=\sigma^{\prime} \tan \phi+C
$$

where $\tau=$ the shear stress, $\phi$ is the angle of internal friction and $C$ is the cohesive stress. We may combine Equations 6 and 7

$$
\tau=\left(\sigma_{T}-u\right) \tan \theta+C
$$

So, if pore pressure rises, the effective stress decreases, and the shear stress needed to initiate flow drops. Janney demonstrated that in extrusion it is necessary for flow will not start until the effective stress has reached a maximum, and both pore pressure and total stress had reached steady state [28].

Application of this model to extrusion of acetate paste leads to the following arguments. As the piston is loaded, the paste is initially compressed. With further loading, an increasing fraction of the load is supported by the liquid fraction. As the material begins to flow, it dilates, increasing the pore volume, thus reducing the pore pressure. I his results in an increase in the effective stress, and necessitates higher shear components to maintain flow. The amount of dilation is constrained by the extruder body and the pore pressure will once again rise, until a steady state condition is reached. The result is an increased level of shear stress in the system, and a concomitant increase in yield stress seen in piston extrusion.

The implication of the above argument is that at some volume fraction solids the paste will solidify, and plastic deformation will become impossible. Knowledge of the solidification point is useful in production of ceramic bodies, because in practice it is necessary to minimize 
the liquid phase, to reduce induced stress during drying, while maintaining sufficient plasticity to avoid extrusion defects. Benbow et al. [15] suggest that the critical liquid content of a paste may be determined by examining the effect of changing liquid content on reciprocal yield stress. The intercept of the line $d \phi / d \tau_{y}$ with the $y$-axis defines the point at which yield stress approaches infinity as a limit, that is, the point at which the material becomes nonplastic. Performing such an analysis for the rheometry measured yield stress, the inferred yield stress from fitting the Hershel-Bulkley model, and piston extrusion data yields values of $24.84,18.12$ and $28.6 \%$ liquid content, respectively. Extrusion testing of the paste shows that paste weighing less than 64 grams will not extrude at pressures below $50 \mathrm{kN}$ (the limit of our test capabilities). The rheometer ceases to rotate at a similar paste weight.

Extrapolation of the data using Figure 8 gives a solids fraction of roughly $74 \%$ for paste weight $=64$ grams. Reading the graph for a liquid content of $28.6 \%$ (from piston extrusion) gives a paste weight of roughly 63 grams. Similarly, for the regressed rheometer data, a liquid fraction of around 24.7 gives an interpolated paste weight of about 62 grams. The measured yield stress data, however, underestimate the liquid fraction severely. This suggests that the yieid stress-paste weigit relationship is not strictly linear, and yieid siress increases more rapidly as the solidification point is neared. To summarize, the predicted value for the solidification point is quite close to the observed value for the acetate paste as tested by piston extrusion, and yields a low approximation for values obtained by rheometry. 


\section{Paste Chemistry}

The chemistry of the paste remains unknown, for the most part. The only phases which could be identified with any certainty were barium acetate and copper acetate. Both of these phases seem to be reasonable, given the constituents of the system.

Initial mixing of the yttrium acetate and barium hydroxide suggests an anion exchange reaction, forming barium acetate, barium hydroxide, and yttrium hydroxide. Yttrium hydroxide commonly occurs in precipitation reactions in an amorphous form, and is undetectable by XRD. IR may be a viable means of supporting the hypothesized presence of yttrium hydroxide, but in the mid-IR range, the only strong absorption generated from this material would be due to $\mathrm{OH}$ stretching which is obscured by other $\mathrm{OH}$ bearing species including water. $\mathrm{Y}$ - $\mathrm{O}$ stretching will occur in the far IR region. This region was not examined in this study.

IR spectroscopy does not show the presence of a barium hydroxide phase. System stoichiometry limits us to one more hydroxide for substitution. Thus, copper hydroxide or copper acetate hydrate are possible phases. Again, standards for these phases could not be located for the IR work, so identification of reaction products remains uncertain.

\section{Densification and Fiber Forming}

The acetate paste shows a tendency to resist densification when fired in an oxygen rich atmosphere. The fact that the system phases are some combination of acetate and hydroxides suggests that there will be significant outgassing as the paste is heated through its decompositions. Further, the presence of the immense combustion exotherm seen in DTA studies in oxygen suggests that weight loss due to erosion of solids during the degassing is 
quite possible. Thus, it is necessary to perform an initial calcination of the acetate paste before attempting to sinter the compact.

The acetate paste is a good precursor material with regards to forming fibers. Plastic fibers of constant diameter, and of reasonable length may be formed with a small applied load. The extruded fibers have sufficiently high yield stress and viscosity to resist deformation due to gravitationally induced slumping, or by contact with substrate materials.

\section{Superconducting Properties}

The fired material is a superconductor. However, the granular, porous nature of the sintered body results in poor connectivity. The poor connectivity is reflected in the magnetometry results. This suggests that the fired acetate fibers may not be good conductor materials. This is a reasonable assumption, because the porous nature of the compact reduces the cross-sectional area for current transfer, and the grain boundaries, which granular compacts have by nature, provide loci for insulating contaminants such as 211 to form. Further work is in progress to determine whether the low intergranular connectivity is due to

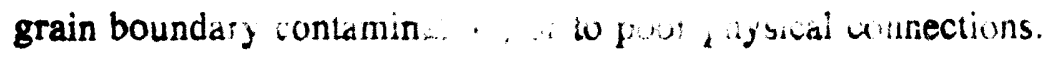

Another problem exists with the acetate paste. The acetate paste was developed to have the ability to directly form conductors which could be fired to 123 . The precalcination step yields very porous fibers. This porosity tends to weaken the fiber. The porosity is difficult to eliminate by solid state sintering. As such, the acetate system discussed here may not be the optimum choice as an extrusion precursor. Still, the precursor does convert to 123 on firing. 


\section{CONCLUSION}

An acetate precursor to $\mathrm{YBa}_{2} \mathrm{Cu}_{3} \mathrm{O}_{7 \cdot \mathrm{x}}$ has been developed. The paste consists of a mixed phase assemblage of acetate and hydroxide salts of yttrium, barium, and copper. The precursor has rheology which is easily controlled by altering the solids fraction in the paste. By decreasing the liquid content in the paste system, the yield stress and viscosity of the paste may be increased to a level needed for a particular forming operation. The paste has a yield stress, and is shear thinning. These are desirable characteristics for material which are to be formed by common ceramic forming techniques. While this study focussed on extrusion, the precursor could be used for other techniques such as tape casting, spraying, or paste forming.

Infrared spectroscopy indicates the presence of barium acetate and copper acetate in the paste, but other phases could not be identified.

The paste forms $\mathrm{YBa}_{2} \mathrm{Cu}_{3} \mathrm{O}_{7-\mathrm{x}}$ when sintered. Impurity phases estimated at $1-2$ volume percent are detectable by reflected light microscopy, although the sintered material is single phase by $x$-ray diffraction.

The acetate precursor densifies with difficulty. As such, it may not be of great use in the $\mathrm{Y}-\mathrm{Ba}-\mathrm{Cu}-\mathrm{O}$ supeicunductor system. However, the acetate methou may be more applicable in congruently melting systems such as $\mathrm{Bi}-\mathrm{Sr}-\mathrm{Ca}-\mathrm{Cu}-\mathrm{O}$, where liquid-assisted sintering methods may be more readily applied. 


\section{REFERENCES}

1. Timothy M. Green and Mufit Akinc, "Shape Forming of Ceramic Superconductors", Bull. Am. Cer. Soc., 70[7] 1162-1166 (1991).

2. R. S. Roth, K. L. Davis, and J. R. Dennis, "Phase Equilibria and Crystal Chemistry in the System Ba $-\mathrm{Y}-\mathrm{Cu}-\mathrm{O}^{n}$, Adv. Cer. Mat, 2[3b], 303-312 (1987).

3. S. Jin and J. E. Graebner, "Processing and Fabrication Techniques for Bulk High-Tc Superconductors: A Critical Review", Mat. Sci. and Eng, B7, 243-260 (1991).

4. D. W. Johnson, E. M. Gyorgy, W. W. Rhodes, R. J. Cava, L. C. Feldman, and R. B. van Dover, "Fabrication of Ceramic Articles from High-Tc Superconducting Oxides", Adv. Cer, Mat. 2[3b], 364-371 (1987).

5. T. Leventouri, "Observations on the Processing of the $\mathrm{Y}-\mathrm{Ba}-\mathrm{Cu}-\mathrm{O}$ Superconductors", Mod. Phys. Lett. B 2[10] 1155-1158 (1988).

6. F. Kloucek, W. E. Rhine, and H. K. Bowen, "Thick Films of $\mathrm{YBa}_{2} \mathrm{Cu}_{3} \mathrm{O}_{7}$ Fabricated from Colloidal Solutions", Physica C 153-155, $798-799$ (1988).

7. R. Millis, A. Cellikaya, M. Akinc, and R. W. McCallum, "Preparation of $\mathrm{YBa}_{2} \mathrm{Cu}_{3} \mathrm{O}_{7}$ Powders by Molten Salt Route", IEEE Transactions on Mag. 25[2] 2250-2252 (1989).

8. M. Akinc and A. Cellikaya, U. S. Patent 4906 608, March 6, 1990 (1990).

9. R. P. Millis, M.S. Thesis, Iowa State University, Ames, IA (1990).

10. T. M. Green, R. P. Millis, and M. Akinc, "Shape Forming of $\mathrm{YBa}_{2} \mathrm{Cu}_{3} \mathrm{O}_{7-\mathrm{x}}$ (abstract)". 1990 lalk Summaries, Electronics Division. American Ceramic Society, Westerville, OH (1990).

11. T. M. Green, "A Nitrate Precursor to $\mathrm{YBa}_{2} \mathrm{Cu}_{3} \mathrm{O}_{7-\mathrm{x}}$ Fibers", (to be published) (1993).

12. T. M. Green and M. Akinc, "Rheology of $\mathrm{YBa}_{2} \mathrm{Cu}_{3} \mathrm{O}_{7-\mathrm{x}}$ Precursors", to be published in Flow and Microstructure of Dense Suspensions, 289, Materials Research Society, Pittsburgh, PA (1993).

13. Aldrich Handbook of IR Spectra, Aldrich Chemical Co., (1991).

14. J. Ferguson and Z. Kemblowski, Applied Fluid Rheology, Elsevier Applied Science Publishers, London (1991). 
15. J. J. Benbow, E. W. Oxley, and J. Bridgwater, "The Extrusion Mechanics of Pastes-the Influence of Paste Formulation on Extrusion Parameters", Chem. Eng. Sci., 42[9] $2151-2162$ (1987).

16. A. Ovenston and J. J. Benbow, "Effects of Die Geometry on the Extrusion of Claylike Material", Trans. Br. Cer. Soc. 67 543-567 (1968).

17. J. J. Benbow, T. A. Lawson, E. W. Oxley, and J. Bridgwater, "Prediction of Paste Extrusion Pressure", Ceramic Bulletin 68[10] 1821-1824 (1989).

18. T. Asalage and K.Keefer, "Liquidus Relations in $\mathrm{Y}-\mathrm{Ba}-\mathrm{Cu}$ Oxides", J. Mat. Res., 3[6] 1279-1291 (1988).

19. J. E. Tackett, "FT-IR Characterization of Metal Acetates in Aqueous Solution", Applied Spectroscopy 43[2] 483-489 (1989).

20. A. M. Heyns, "The Low-Temperature Infrared Spectra of the Copper(II) Acetates", $\underline{\text { J. }}$ Molecular Struct. 11, 93-103 (1972).

21. H. D. Lutz, W. Eckers, G. Schneider and H. Haeuseler, "Raman and Infrared Spectra of Barium and Strontium Hydroxides and Hydroxide Hydrates", Spectrochim. Acta 37A[7], 561-567 (1981).

22. H. A. Barnes, J. F. Hutton, and K. Walters, An Introduction to Rheology, Elsevier Applied Science Publishers, London (1989).

23. R. J. Hunter, Foundations of Colloid Science, Oxford Science Publications, Oxford (1989).

24. G Y. Onoda $F$ I inger, and M A. Jannev, "Dilatancy and Plasticity in Ceramic Particulate Bodies", Ceramic Powder Science 1 B , American Ceramic Society, Westerville, OH (1988).

25. M. Reiner, Deformation, Strain and Flow, H. L. Lewis, London (1969).

26. W. B. Russel, D. A. Saville, and W. R. Schowalter, Colloidal Dispersions, Cambridge University Press, Cambridge (1989).

27. C. H. Schilling, W. -H. Shih, and I. A. Aksay, "Advances in the Drained Shaping of Ceramics", Ceramic Transactions, Vol, 22, American Ceramic Society, Westerville, $\mathrm{OH}(1991)$.

28. M. A. Janney, Ph.D Dissertation, University of Florida (1982).

29. C. H. Schilling, Ph.D Dissertation, University of Washington (1992). 


\section{GENERAL CONCLUSION}

Numerous variables are involved in development of precursor systems to permit production of formed $\mathrm{YBa}_{2} \mathrm{Cu}_{3} \mathrm{O}_{7-\mathrm{x}}$ bodies. We have examined two chemical systems which may be used to produce pastes of controllable theology. The nitrate system yields a blue, viscous paste, which may be fit to either the Bingham Plastic or Hershel-Bulkley model. The paste is granular, with a bimodal size distribution. There is some elemental segregation, with the larger grains being enriched in $\mathrm{Ba}$, while the micron sized matrix is $\mathrm{Y}$ and $\mathrm{Cu}$ rich. Extrusion of fibers using the nitrate paste was hindered by the tendency for the paste to cause extruder locking. The nitrate system yields $\mathrm{YBa}_{2} \mathrm{Cu}_{3} \mathrm{O}_{7 . x}$ on sintering in an oxygen atmosphere.

Using the same molten salt technology, an acetate precursor was also developed. The acetate paste has a nearly monosized particle assemblage, and, like the nitrate system, has a rheology which is controllable by removal of water from the system. The acetate paste is easily extrudable, and fiber of $1 \mathrm{~mm}$ diameter may be produced to virtually any length.

Sintering of the acetate paste results in a porous compact, which is about $65-70 \%$ dense. The porosity is due to the large amounts of volatiles released by the acetate paste when it is fired. The acetate paste also yields $\mathrm{YBa}_{2} \mathrm{Cu}_{3} \mathrm{O}_{7-x}$ when fired in oxygen. The acetate paste was studied by concentric cylinder and piston extrusion rheometry. The study demonstrated that fundamental differences exist between the two test methods.

Concentric cylinder rheometry, a widely used technique, underestimates the stresses needed to initiate and maintain flow through a piston extruder. This error is due to the difference in configuration between the two test systems. The concentric cylinder is an open system, and may be considered what is called a drained system in soil mechanics. The piston extruder is a 
closed system, and is termed an undrained system. The effect of confining pressure on the paste causes order of magnitude differences in the yield stresses measured for the same material by the two methods.

In summary, this project showed that both the nitrate and acetate precursors are viable routes to production of fibers of $\mathrm{YBa}_{2} \mathrm{Cu}_{3} \mathrm{O}_{7-\mathrm{x}}$. However, the inherent nature of each system presents a unique set of difficulties which must be overcome. As a result of these difficulties, neither system has a great potential for commercial utilization at this time. It is possible that the general technique may be applicable to other superconducting systems, however. Perhaps of greater importance is the work on the rheology of non-clay dense pastes. This field is relatively new, and the work performed here may be a valuable addition to the body of knowledge. 


\section{REFERENCES}

1. J. G. Bednorz, and K. A. Muller, "Possible High Tc Superconductivity in the Ba - La - Cu - O System," Z. Phys. B, B64, 189-193 (1986).

2. M. K. Wu, J. R. Ashburn, C. J. Torng, P.H. Hor, R. L. Meng, L. Gao, Z. J. Huang, Q. Wang, and C. W. Chu, "Superconductivity at $93 \mathrm{~K}$ in a New Mixed Phase $\mathrm{Y}-\mathrm{Ba}-\mathrm{Cu}-\mathrm{O}$ Compound System at Ambient Pressure," Phys. Rev.Let. 58[9], 908910 (1987).

3. C. Michel, M. Herview, A. Grandin, F. Deslandes, J. Provost, B. Raveau, "Superconductivity in the $\mathrm{Bi}-\mathrm{Sr}-\mathrm{Cu}-\mathrm{O}$ System," Z. Phys. B. Cond. Matter 68, 421 (1987).

4. C. W. Chu, J. Bechtold, L. Gao, P. H. Hor, Z. J. Huang, R. L. Meng, Y. Y. Sun, Y. Q. Wang, and Y. Y. Hue, "Superconductivity $\mathrm{Up}$ to $114 \mathrm{~K}$ in the $\mathrm{Bi}-\mathrm{Al}-\mathrm{Ca}-\mathrm{Sr}$ $\mathrm{Cu}$ - O Compound System Without Rare-Earth Elements, " Phys. Rev Lett. 60 [10], 941 (1988).

5. 7. Z. Sheng and A. M. Herman, "Superconductivity in the Rare-Earth Free T1 - Ba $\mathrm{Cu}$ - O System Above Liquid-Nitrogen Temperature," Nature 322, 55 (1988).

6. R. M. Hazen, L. W. Finger, R. J. Angel, C. T. Prewitt, N. L. Ross, C. G. Hadidiacos, P. J. Heaney, D. R. Veblen, Z. Z. Sheng, A. El Ali, and A. Herman, "100K Superconducting Phases in the $\mathrm{Tl}-\mathrm{Ca}-\mathrm{Ba}-\mathrm{Cu}-\mathrm{O}$ System," Phys. Rev. Lett. 60 [16], 1657-1660 (1988).

7. K. G. Fraze and D. R. Clarke, "Phase Compatibilities in the System $\mathrm{Y}_{2} \mathrm{O}_{3}-\mathrm{BaO}$ CuO," Adv. Cer. Mat. 2 [3b], 295-302 (1987).

8. R. S. Roth, K. L. Davis and J. R. Dennis, "Phase Equilibria and Crystal Chemistry in the System Ba - Y - Cu - O," Adv. Cer. Mat. 2 [3b], 303-312 (1987).

9. J. D. Whitler and R. S. Roth (editors), Phase Diagrams for High Tc Superconductors, the American Ceramic Society, Westerville, OH, (1991).

10. W. Wong-Ng, R. S. Roth, L. J. Swartzendruber, L. H. Bennett, C. K. Chiang, F. Beech, and C. R. Hubbard, "X-ray Powder Characterization of $\mathrm{Ba}_{2} \mathrm{YCu}_{3} \mathrm{O}_{7-\mathrm{x}}$," $\mathrm{Adv}$. Cer. Mat. 2 [3b], 565-576 (1987).

11. R. M. Hazen, L. W. Finger, R. J. Angel, C. T. Prewitt, N. L. Ross, H. K. Mao, C. G. Hadidiacos, P. H. Hor, R. L. Meng and C. W. Chu, "Crystallographic Description of Phases in the $\mathrm{Y}-\mathrm{Ba}-\mathrm{Cu}$ - O Superconductor, " Phys. Rev. B 25, 7238-7241 (1987). 
12. S. X. Dou, A. J. Bourdillon, C. C. Sorrell, H. K. Liu, J. P. Zhou, X. Y. Sun, H. J. Logren, E. M. Lindh and K. E. Easterling, "Impurity Effects on the Properties of Superconducting $\mathrm{YBa}_{2} \mathrm{Cu}_{3} \mathrm{O}_{7-\mathrm{x}}$," in Ceramic Superconductors II, Man F. Yan, editor, American Ceramic Society, Westerville, OH, 263-271, (1988).

13. C. T. Cheung and E. Ruckenstein, "Superconductor-Substrate Interactions of the Y $\mathrm{Ba}-\mathrm{Cu}$ Oxide, " I. Mat. Research, 4 [1], 1-15 (1989).

14. E. Trolier, S. D. Atkinson, P. A. Fuerier, J. H. Adair, and R. E. Newnham, "Dissolution of $\mathrm{YBa}_{2} \mathrm{Cu}_{3} \mathrm{O}_{7-\mathrm{x}}$ in Various Solvents," Am. Cer. Soc. Bull. 67 [4], 759 762 (1988).

15. D. K. Pham, Z. Ru-Peng, P. E. Fielding, S. Myhra, and P. S. Turner, "The Degradation of $\mathrm{YBa}_{2} \mathrm{Cu}_{3} \mathrm{O}_{7}$ Resulting From Exposure to Wet and Dry Steam," J. Materials Research 6 [6], 1148-1155 (1991).

16. G. C. S. Chang, S. J. Burns, A. Goyal, and P. D. Funkenbusch, "Young's Modulus Measurement of Polycrystalline $\mathrm{YBa}_{2} \mathrm{Cu}_{3} \mathrm{O}_{7 \cdot x}$ Superconductor," in Ceramic

Superconductors II, Man F. Yan, editor, American Ceramic Society, Westerville, OH p. 580-589 (1988).

17. B. N. Lucas, W. C. Oliver, R. K. Williams, J. Byrnestad and M. E. O'Hern, "The Hardness and Bulk Young's Modulus of Bulk $\mathrm{YBa}_{2} \mathrm{Cu}_{3} \mathrm{O}_{7-\mathrm{x}}(1: 2: 3)$ and $\mathrm{YBa}_{2} \mathrm{Cu}_{4} \mathrm{O}_{8}$ (1:2:4) as Determined by Ultra Low Load Indentation," J. Materials Research 6 [12], 2519-2522 (1991).

18. Timothy M. Green and Mufit Akinc, "Shape Forming of Superconducting Ceramics," Am. Cer. Soc. Bull. 70 [7], 1162-1166 (1991).

19. S. H Kim. $\Gamma \mathrm{H}$. Cho $\mathrm{K} \&$ No and J. S Chun, "Denncition Characteristics and Microstructures of the High Ic Superconducting $\mathrm{YBa}_{2} \mathrm{Cu}_{3} \mathrm{U}_{7-x}$ Thun Films Prepared by MOCVD," J. Materials Research 6 [4], 704-711 (1991).

20. M. Ece, R. W. Vook and J. P. Allen, Microstructural Characterization of YBaCuO Thin Films Deposited by RF Magnetron Sputtering as a Function of Annealing Conditions, " J. Materials Research 6 [2], 252-263 (1991).

21. M. -S. Oh, Q. F. Liu, W. Misiolek, A. Rodrigues, B. Avitzur and M. R. Notis, "Fabrication and Microstructure of Composite Metal-Clad Ceramic Superconducting Wires," J. Am. Cer. Soc. 72 [11], 2142-2147 (1989).

22. Rolf E. Hummel, Electronic Properties of Materials, Springer-Verlag, New York, (1985). 
23. Michael Tinkham, Introduction to Superconductivity, Robert E. Krieger Publishing Co., Malabar, FL, (1975).

24. E. A. Lynton, Superconductivity, Methuen \& Co., Ltd., London (1969).

25. F. Donald Bloss, Crystallography and Crystal Chemistry: An Introduction, Holt, Rinehart and Winston, Inc., New York (1971).

26. D. M. Smythe, "Structural Patterns in High Tc Superconductors, " Ceramic Superconductors II, Man F. Yan, editor, American Ceramic Society, Westerville, OH, (1988).

27. S. N. Ruddlesden and P. Popper, "The Compound $\mathrm{Sr}_{3} \mathrm{Ti}_{2} \mathrm{O}$, and Its Structure," Acta Cryst. 11, 54-55 (1958).

28. M. A. Subramanian, C. C. Torardi, J. C. Calabrese, J. Gapalakrishnan, K. J. Morrissey, T. R. Askew, R. B. Flippen, U. Choudhry, and A. W. Sleight, "A New iiigi Tuspuiaiure Superconductor: $\mathrm{Bi}_{2} \mathrm{Sr}_{3-x} \mathrm{Ca}_{x} \mathrm{Cu}_{2} \mathrm{O}_{8+y}$, "Science 239, 1015-1017 (1988).

29. P. K. Gallagher, "Characterization of $\mathrm{Ba}_{2} \mathrm{YCu}_{3} \mathrm{O}_{7-x}$ as a Function of Oxygen Partial Pressure Part I: Thermoanalytical Measurements," Adv. Cer. Mat. 2 [3b], 632-639 (1987).

30. H. M. O'Bryan and P. K. Gallagher, "Characterization of $\mathrm{Ba}_{2} \mathrm{YCu}_{3} \mathrm{O}_{7 . \mathrm{x}}$ as a Function of Oxygen Partial Pressure Part II: Dependence of the O-T Transition on Oxygen Content," Adv. Cer. Mat. 2 [3b], 640-648 (1987).

31. T. Ass!afe and $\mathrm{K}$. Keefer, "Liquidus Relations in Y - Ba - Cu Oxides, " $\mathrm{L}$ Mat. Res. $3 ! 6, \quad 270 \quad 129 ; \quad$ i988).

32. K. G. Fraze and D. R. Clarke, "Phase Compatibilities in the System $\mathrm{Y}_{2} \mathrm{O}_{3}-\mathrm{BaO}$ CuO," Adv. Cer. Mat. 2[3b], 295-302 (1987).

33. B. Bender, L. Toth, J. R. Spann, S. Lawrence, J. Wallace, D. Lewis, M. Osofsky, W. Fuller, E. Skelton, S. Wolf, S. Qadri, and D. Gubser, "Processing and Properties of the High Tc Superconducting Oxide $\mathrm{YBa}_{2} \mathrm{Cu}_{3} \mathrm{O}_{x}$, Adv. Cer. Mat. 2 [3b], 480491(1987).

34. D. W. Johnson, E. M. Gyorgy, W. W. Rhodes, R. J. Cava, L. C. Feldman, And R. B. van Dover, "Fabrication of Ceramic Articles from High Tc Superconducting Oxides," Adv. Cer. Mat. 2 [3b], 364-371 (1987).

35. R. H. Moore, M. O. Eatough, T. J. Gardner, W. F. Hammetter, S. J. Lockwood, R. E. Loehman, R. G. Tissot and E. L. Venturini, "The Relation of $\mathrm{YBa}_{2} \mathrm{Cu}_{3} \mathrm{O}_{7-1}$ 
Properties to Densification Techniques," Ceramic Superconductors II, Man F. Yan, editor, American Ceramic Society, Westerville, $\mathrm{OH}, 216-231$ (1988).

36. J. E. Ullman, R. W. McCallum and J. D. Verhoeven, "Effect of Atmosphere and Rare Earth on Liquidus Relations in RE - Ba - Cu Oxides, " L.Mat. Res., 4 [4], 752 754 (1989).

37. Laura C. Stearns, Mark D. Vaudin, Claudia P. Ostertag, John E. Blendell, and Edwin R. Fuller, "Texture Development in $\mathrm{Ba}_{2} \mathrm{YCu}_{3} \mathrm{O}_{6+x}$ Through Sinter Forging, " Ceramic Superconductors II, Man F. Yan, editor, American Ceramic Society, Westerville, $\mathrm{OH}$, 315-322 (1988).

38. J. W. Ekin, "Transport Critical Current in Bulk Sintered $\mathrm{YBa}_{2} \mathrm{Cu}_{3} \mathrm{O}_{2}$ and Possibilities for its Enhancement," Adv. Cer. Mat., 2 [3b], 586-592 (1987).

39. C. P. Ostertag, R. D. Shull, M. D. Vaudin, J. E. Blendell, L. C. Stearns, and E. R. Fuller, Jr., "Alignment of Superconducting Grains by Magnetic Casting," Ceramic Superconductors II, Man F. Yan, editor, American Ceramic Society, Westerville, OH, $332-342$ (1988).

40. D. P. Dimos, P. Chaudhari, J. Mannhart and F. K. Le Goues, "Orientation Dependence of Grain-Boundary Critical Currents in $\mathrm{YBa}_{2} \mathrm{Cu}_{3} \mathrm{O}_{7 \cdot \mathrm{x}}$ Bicrystals, " Phys. Rev. Letters, 61 [2], 219-223 (1988).

41. D. R. Clarke, T. M. Shaw, and D. Dimos, "Issues in the Processing of Cuprate Ceramic Superconductors," L. Am. Cer. Soc., 72 [7], 1103-1113 (1989).

42. S. Nakahara, G. J. Fisanick, M. F. Yan, R. B. van Dover, T. Boone, and R. Moore, "On the Defect Structure of Grain Boundaries in $\mathrm{Ba}_{2} \mathrm{YCu}_{3} \mathrm{O}_{7-x}$," J. Cryst. Growth, 85. 639-643 (1987).

43. D. W. Johnson, "Innovations in Ceramic Powder Processing," Advances in Ceramics, Vol. 21: Ceramic Powder Science, American Ceramic Society, Westerville, $\mathrm{OH}$, (1987).

44. B. I. Lee, V. Modi, M. D. Sherrill, "YBCO Superconductors via Nitrates." Ceramic Superconductors II, Man F. Yan, editor, American Ceramic Society, Westerville, $\mathrm{OH}$, 148-155 (1989).

45. R. P. Millis, M. S. Thesis, Iowa State University, Ames, IA, (1990).

46. X. Z. Wang, M. Henry, J. Livage, I. Rosenman, "The Oxalate Route to Superconducting $\mathrm{YBa}_{2} \mathrm{Cu}_{3} \mathrm{O}_{7-x}$," Solid State Comm., 64[6], 881-883 (1987).

47. T. Leventouri, "Observations on the Processing of the $\mathrm{Y}-\mathrm{Ba}-\mathrm{Cu}-\mathrm{O}$ Superconductors," Mod. Phys. Lett. B, 2[10], 1155-1158 (1988). 
48. F. Kloucek, W. E. Rhine, H. K. Bowen, "Thick Films of $\mathrm{YBa}_{2} \mathrm{Cu}_{3} \mathrm{O}$, Fabricated from Colloidal Solutions, " Physica C, 153-155, 798-799 (1988).

49. T. M. Green, R. P. Millis, and M. Akinc, "Shape Forming of $\mathrm{YBa}_{2} \mathrm{Cu}_{3} \mathrm{O}_{7-x}$ (abstract)," 1990 Talk Summaries, Electronics Division, American Ceramic Society, Westerville, $\mathrm{OH},(1990)$.

50. O. Sbaizero and $\mathrm{S}$. Maschio, "Production of $\mathrm{YBa}_{2} \mathrm{Cu}_{3} \mathrm{O}_{7-\mathrm{x}}$ Fibers from Acetate Solution," Materials Chemistry and Physics, 21, 85-91 (1989).

51. Tomoko Goto and Iwao Horiba, "A Method for Producing High- $\mathrm{T}_{\mathrm{c}} \mathrm{Y}-\mathrm{Ba}-\mathrm{Cu}-\mathrm{O}$ Superconducting Filaments by Die-Free Spinning," Japanese Joumal of Applied Physics, 26[12], L1970-L1972 (1987).

52. Shingo Katayama and Masahiro Sekine, "Fabrication of Superconducting $\mathrm{YBa}_{2} \mathrm{Cu}_{3} \mathrm{O}_{7-x}$ Fibers by the Sol-Gel Method Using Metal Alkoxides," L. Materials Research 6[8], 1629-1633 (1991).

53. Peter J. Melling, Scott L. Schwartz, Marta Pradavi-Horvath, and E. W. Collings, "Powder Preparation and Thermal Properties of 1-2-3 Y Ba Cu Oxide

Superconductor," Advances in Cryogenic Engineering (Materials), Vol. 34. (1989).

54. A. M. Kini, U. Geiler, I. Huey-Chuen, K. Carlson, H. Wang, M. Monaghan, and J. Williams, "High-Tc Superconductors: Selective Preparation and Characterization of Tetragonal and Orthorhombic (93K Superconductor) Phases of $\mathrm{YBa}_{2} \mathrm{Cu}_{3} \mathrm{O}_{7-x}$," Inorganic Chemistry 26, 1834-1835 (1987).

55. M. Ece, R. W. Vook, and John Allen, "Microstructural Characterization of YBaCuO Thin Films Deposited by RF Magnetron Sputtering as a Function of Annealing Conditions, " J. Materials Research 6「2] 252-263 (1991).

56. Julia M. Philips, M. P. Siegal, R. B. van Dover, T. H. Tiefel, J. H. Marshall, C. D. Brandle, G. Berkstresser, A. J. Strauss, R. E. Fahey, S. Sengupta, A. Cassanho, and H. P. Jenssen, "Comparison of $\mathrm{Ba}_{2} \mathrm{YCu}_{3} \mathrm{O}_{7-\mathrm{x}}$ Thin Films Grown on Various Perovskite Substrates by Coevaporation," I, Materials Research 7[10], 2650-2657 (1992).

57. T. Aida, T. Fukazawa, A. Tsukamoto, S. Takayama, K. Takagi, and K. Miyauchi, "Preparation of $\mathrm{YBa}_{2} \mathrm{Cu}_{3} \mathrm{O}_{7-\mathrm{x}}$ and $\mathrm{ErBa}_{2} \mathrm{Cu}_{3} \mathrm{O}_{7-\mathrm{x}}$ Superconducting Thin Films by RfMagnetron Sputtering, " Ceramic Superconductors II, Man F. Yan, editor, American Ceramic Society, Westerville, OH, 483-490 (1989).

58. S. Jin and J. E. Graebner, "Processing and Fabrication Techniques for Bulk High-Tc Superconductor: A Critical Review, " Materials Science and Engineering, B7, 243-260 (1991). 
59. G. C. Robinson, "Extrusion Defects," Ceramic Processing Before Firing, George Y. Onoda, Jr. and Larry L. Hench, editors, J. Wiley and Sons, New York (1978).

60. Bedrettin Subasilar and Turgay Erturk, "Effects of Deformation Zone Geometry on Particle Alignment in the Extrusion of Clay, "Br. Ceram. Trans. J 85[2], 49-51 (1985).

61. M. A. Janney, M. C. Vance, A. C. Jordan, and M. P. Kertesz, Bibliography of Ceramic Extrusion and Plasticity, Oak Ridge National Laboratory Document 6363, (1987).

62. David J. Williams, Polymer Science and Engineering Prentice-Hall, Inc., New Jersey, (1971).

63. H. A. Barnes, J. F. Hutton, and K. Walters, An Introduction to Rheology: Rheology Series Vol. 3 Elsevier, Amsterdam, (1989).

64. Walter Michaeli, Extrusion Dies, Hanser Publishers, Munich, (1984).

65. Markus Reiner, Deformation, Strain and Flow, 2nd Edition, H. K. Lewis \& Co., London, 347 pp. (1969).

66. Jingmin Zheng, William B. Carlson, and James S. Reed, "Flow Mechanics on Extrusion Through a Square-Entry Die, " L. Am. Cer. Soc. 75[11], $3011-3016$ (1992).

67. John J. Benbow, Toni A. Lawson, Eric W. Oxley, and John Bridgwater, "Prediction of Paste Extrusion Pressure," Bull. Am. Cer. Soc. 68[10], 1821-1824 (1989).

68. G. Capriz, "A Theoretical Analysis of Extrusion Processes, " Br. Ceram. Trans. J 62 , 339-361 (1963).

69. J. J. Benbow, E. W. Oxley, and J. Bridgwater, "The Extrusion Mechanics of Pastes-The Influence of Paste Formulation on Extrusion Parameters," Chem. Eng. Sci. 42[9], 2151-2162 (1987).

70. A. Ovenston and J. J. Benbow, "Effects of Die Geometry on the Extrusion of Claylike Material, " Br. Ceram. Trans. J. 67, 543-567 (1968).

71. H.J. Berghaus, Forch. Geb. Ingeneirwes, 23 135-141 (1957).

72. G. Segre, and A. Silberberg, "Behavior of macroscopic rigid spheres in Poiseuille Flow," J. Fluid Mech, 14, 115-135 (1962). 
73. O. C. Zienkiewicz and P. N. Godbole, "Flow of Plastic and Visco-Plastic Solids with Special Reference to Extrusion and Forming Processes," Int.J. for Num. Methods in Eng, 8, 3-16 (1974).

74. W. B. Carlson, J. Zheng, and J. S. Reed, "Numerical Simulation of the Extrusion of Plastic Bodies," Ceramic Transactions: Formine Science and Technology for Ceramics, 26, 132-140 (1992).

75. M. A. Janney, Plasticity of Ceramic Particulate Systems, Ph.D Dissertation, University of Florida (1982).

76. C. H. Schilling, Plastic Shapine of Colloidal Ceramics, Ph.D Dissertation, University of Washington (1992).

77. C. P. Wroth and G. T. Houlsby, "Applications of Soil Mechanics Theory to Ceramics Processing," Ultrastructure Processine of Ceramics, Glasses, and Composites L. L. Hench and D. R. Ulrich, editors, John Wiley and Sons, New York, (1984).

78. Merlin G. Spangler, and Richard L. Handy, Soil Engineering, Harper and Row, New York (1982).

79. J. Schwedes and D. Schulze, "Measurement of Flow Properties of Bulk Solids," Powder Technology, 61, 59-68 (1990).

80. M. J. Keedwell, Rheology and Soil Mechanics, Elsevier Applied Science Publishers, London, (1984). 


\section{ACKNOWLEDGEMENTS}

I would like to first thank my major professor, Mufit Akinc. He has been reasonable beyond all expectations, and any success I have in this field may be largely attributed to his teaching. Bill McCallum provided financial support for roughly two years. This is quite generous, given that I was not one of his students.

There have been several people with whom I shared office space, or with whom I discussed my research. The feedback from all 14 of the other graduate students in Mufit's group during my tenure was an irreplaceable asset, and many flashes of insight are due to conversations with my peers.

Finally, I thank my wife, Nancy, who has toiled to keep me housed and fed for the last several years, while I did my best to avoid entering the real world.

This work was performed at Ames Laboratory under contract no. W-7405-eng-82 with the U.S. Department of Energy. The United States government has assigned the DOE Report number IS-T 1642 to this thesis. 

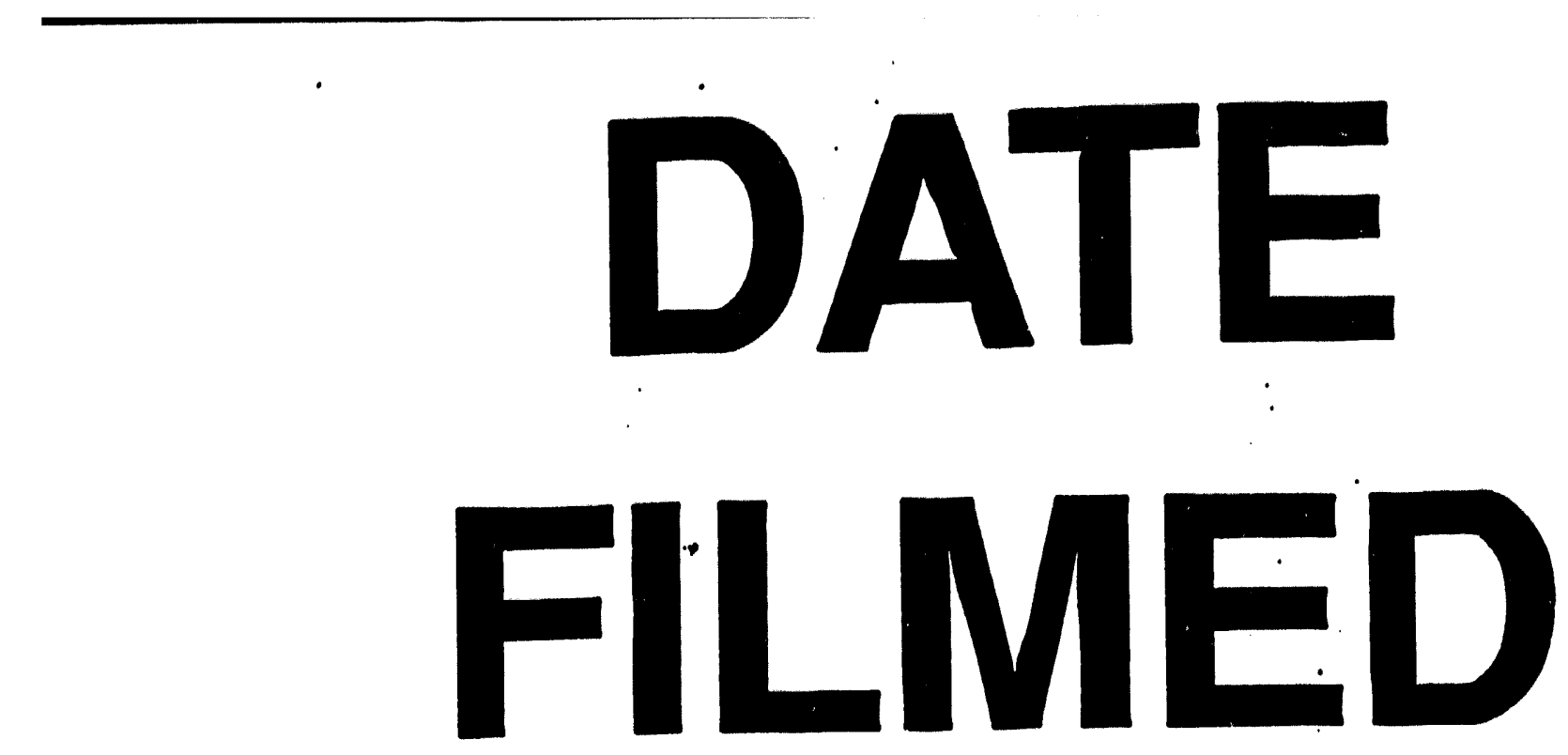

$2 / 4 / 94$
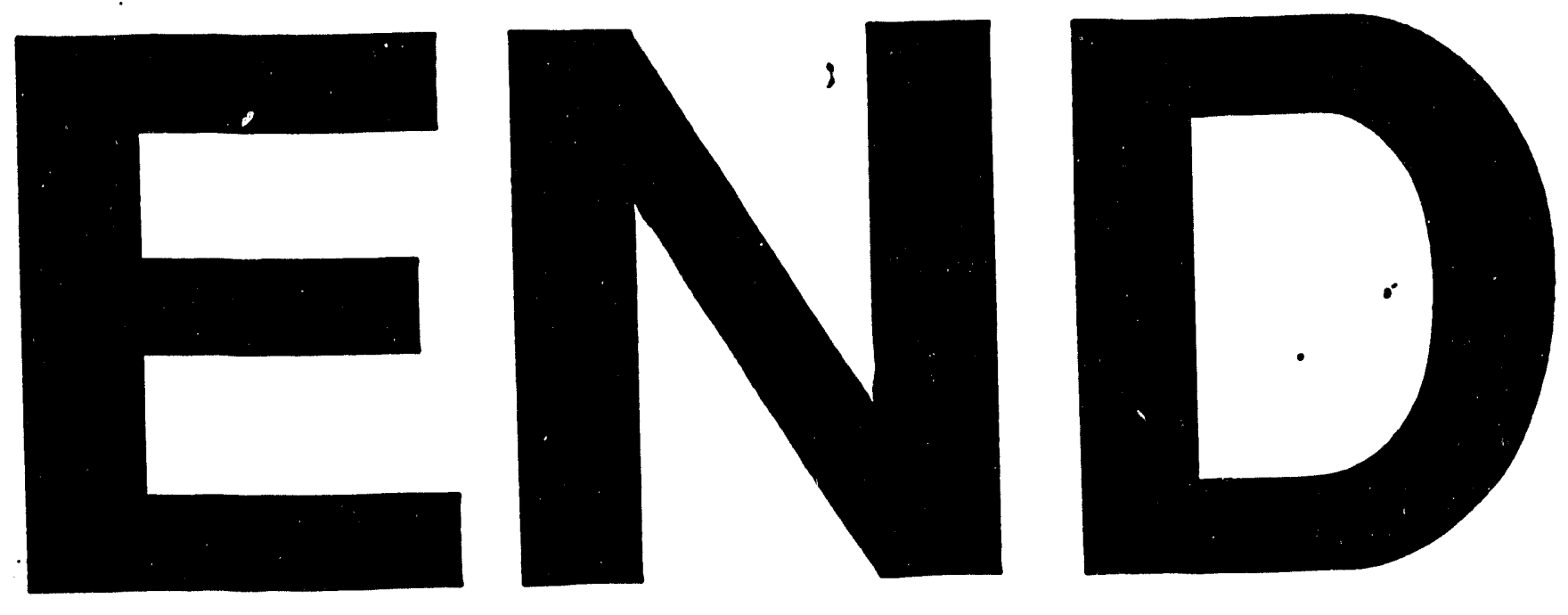


$$
\longrightarrow
$$

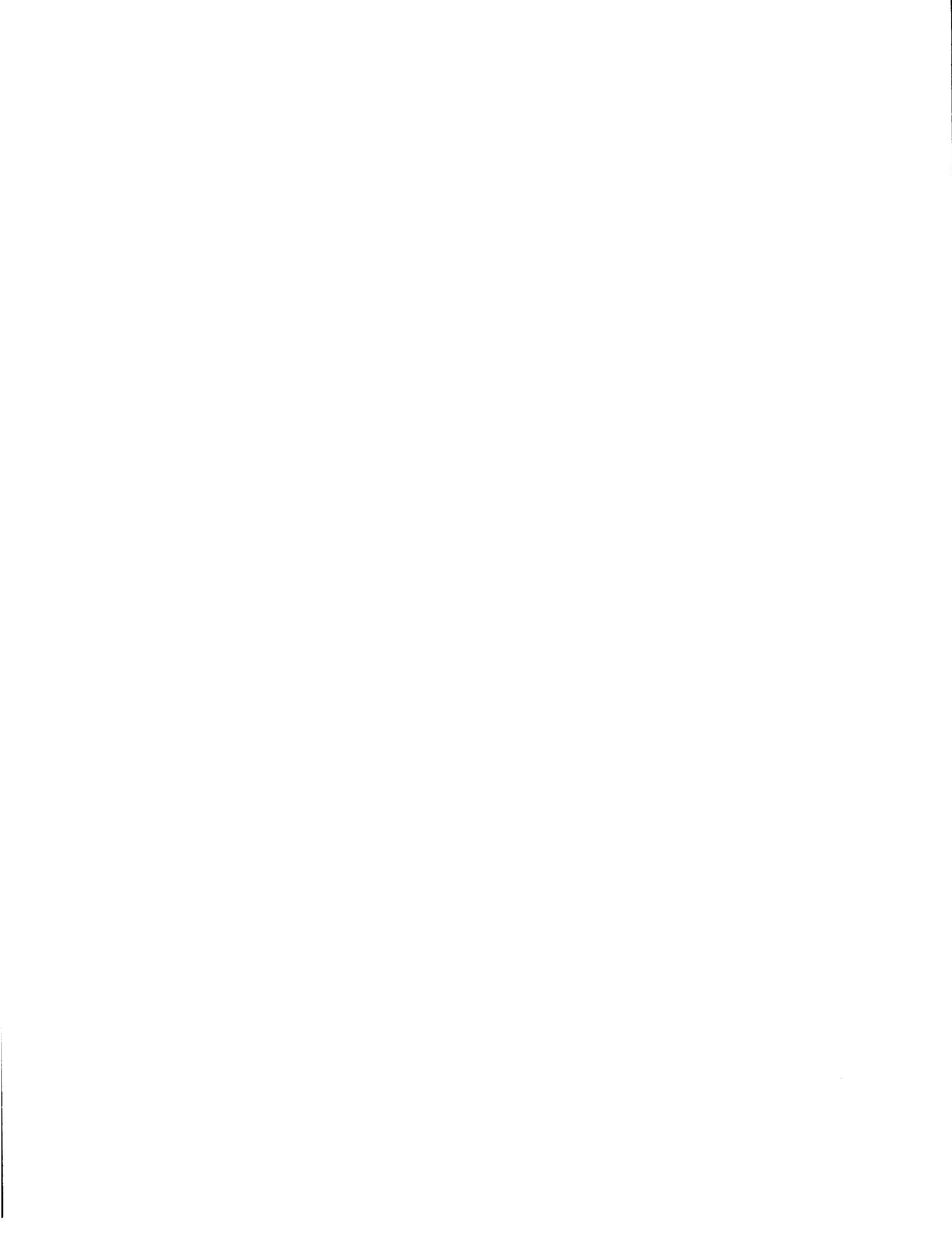

